\title{
Estimulação Vagal Extracardíaca Para Avaliar a Eficácia da Denervação Vagal Pós-Ablação dos Ninhos de Fibrilação Atrial
}

\author{
Enrique Indalécio Pachón Mateo
}

Tese apresentada ao Instituto Dante Pazzanese de Cardiologia Entidade Associada da Universidade de São Paulo, para obtenção do título de Doutor em Ciências

Programa de: Medicina, Tecnologia e Intervenção em Cardiologia

São Paulo 
Dados Internacionais de Catalogação na Publicação (CIP)

Preparada pela Biblioteca do Instituto Dante Pazzanese de Cardiologia

Creprodução autorizada pelo autor

Pachón-M, Enrique Indalécio

Estimulação vagal extracardíaca para avaliar a eficácia da denervação vagal pós-ablação dos ninhos de fibrilação atrial / Enrique Indalécio PachónM. - São Paulo, 2019.

Tese (doutorado)--Instituto Dante Pazzanese de

Cardiologia Universidade de São Paulo

Área de Concentração: Medicina, Tecnologia e Intervenção em

Cardiologia

Orientador: Profa. Dra. Amanda Guerra Moraes Rego Sousa

Descritores: 1. Ablação por Cateter de Radiofrequência. 2. Denervação. 3. Síncope. 4. Sistema Nervoso Autônomo. 5. Fibrilação Atrial. 6. Estimulação Cardíaca Artificial.

USP/IDPC/Biblioteca/100/19 


\section{Dedicatória}

Aos meus pais, Carlos Pachón e Pepita Mateos, pelo seu amor, apoio incondicional, base da minha formação moral e estímulo constante ao meu crescimento profissional e científico.

À minha esposa Denilda, com amor, admiração e gratidão por sua compreensão, carinho, presença e incansável apoio desde que nos conhecemos.

Aos meus filhos José Lucas e Leonardo, atual razão da minha existência, e com os quais compartilho todos os valores da vida.

Ao meu irmão José Carlos, o maior cientista que conheço, fonte inesgotável de inspiração e conhecimento, coautor deste trabalho.

Ao meu sobrinho Carlos Thiene, companheiro inseparável, exímio estimulista e eletrofisiologista, batalhador incansável e exemplo mais profundo de amizade. 
"Se fui capaz de ver mais longe, é porque me apoiei em ombros de gigantes." 


\section{Agradecimentos}

À minha orientadora, Profa. Dra. Amanda Guerra Moraes Rego de Sousa, quem me estimulou a seguir na vida acadêmica e quem dispensou muitas horas corrigindo esta tese e ensinando-me a melhor forma de fazê-la;

Ao meu coorientador e irmão, Prof. Dr. José Carlos Pachón Mateos, criador da Cardioneuroablação, por ter idealizado, concebido e compartilhado comigo o desenvolvimento dos conceitos, das técnicas, dos dispositivos e das patentes que compreendem esta tese;

A todos os médicos e funcionários do Serviço de Arritmias Dr. Pachón - SEMAP, companheiros essenciais e obstinados, com quem obtive apoio constante na solução de tantos desafios durante a realização desta tese;

Aos meus irmãos Dra. Maria Glória e Prof. Dr. Juán Carlos, pelo afeto e ajuda incondicionais que formam o esteio de nossa família;

Ao Dr. Christian Higuti e ao Prof. Ricardo Amarante, nossos ex-residentes e agora colegas de especialidade, pela amizade, companheirismo e colaboração irrestritos em todas as etapas da realização deste trabalho;

À minha cunhada, Dra. Maria Zélia, Diretora-Executiva da SEMAP, pelo apoio, incentivo, profunda amizade e dedicação com a família, gerenciando e solucionando, de forma discreta e anônima, todos os problemas da especialidade, permitindo que fosse aplicada com o máximo de benefício aos pacientes;

Aos pacientes que aceitaram participar deste estudo e que contribuíram de forma altruísta e imprescindível para o desenvolvimento e aperfeiçoamento de técnicas que visam expandir os horizontes da eletrofisiologia. 


\section{Normalização}

Esta tese está de acordo com as seguintes normas, em vigor no momento desta

apresentação:

Universidade de São Paulo. Sistema Integrado de Bibliotecas. Diretrizes para apresentação de Dissertações e Teses da USP - Parte IV (Vancouver); $3^{\text {a }}$ edição - São Paulo: 2016.

Elaborado por Vânia Martins Bueno de Oliveira Funaro, Maria Cláudia Pestana, Maria Cristina Cavarette Dziabas, Eliana Maria Garcia, Maria Fátima dos Santos, Maria Marta Nascimento, Suely Campos Cardoso.

Abreviaturas dos títulos dos periódicos de acordo com List of Journals indexed in Index Medicus. 


\section{ÍNDICE}

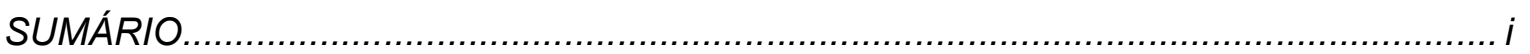

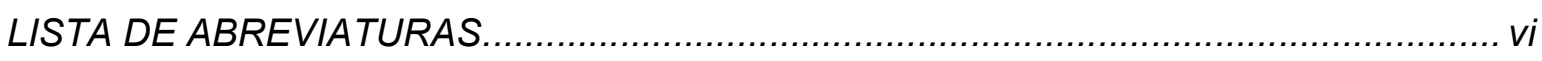

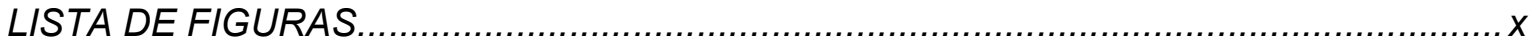

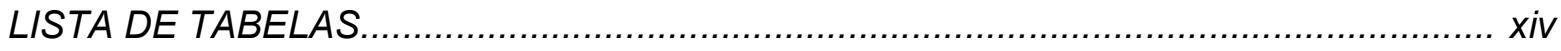

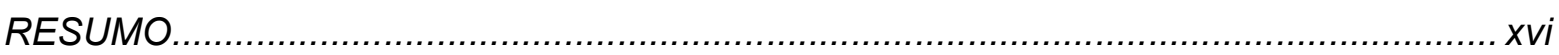

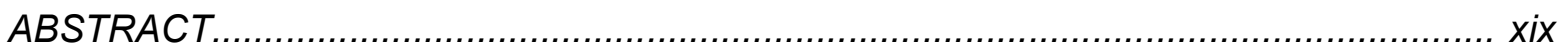

\section{SUMÁRIO}

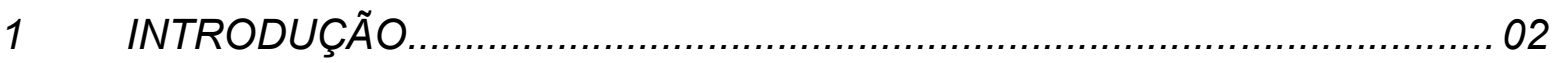

1.1 Frequência Cardíaca Intrínseca.................................................. 03

1.2 Mapeamento da Interface Neuromiocárdica.................................... 04

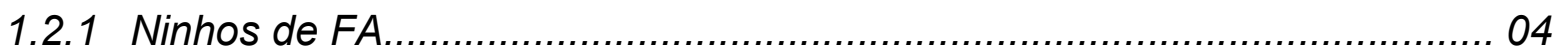

1.2.2 Fundamentos da Análise Espectral................................................ 04

1.2.3 Análise Espectral do Miocárdio Atrial.....................................................

1.2.4 Sistema Nervoso Autônomo..................................................... 09

1.2.5 Fisiologia do Sistema Nervoso no Coração............................................. 10

1.2.6 Inervação Cardíaca e os Ninhos de FA.............................................. 10

1.3 Plexos Ganglionares Paracardíacos................................................ 13

1.4 Identificando a Interface Neuromiocárdica............................................ 16

1.4.1 Efeito da Radiofrequência sobre os NFA....................................... 17

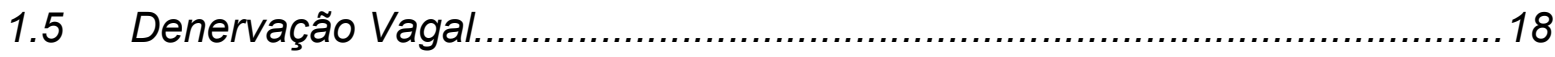

1.6 Validação da Denervação Vagal...................................................... 21

1.6.1 Estimulação Vagal Extracardíaca................................................ 21 
2 JUSTIFICATIVA

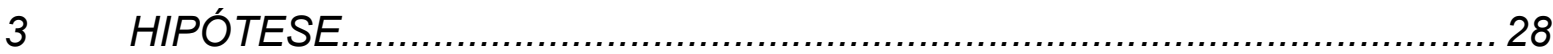

4 OBJETIVOS

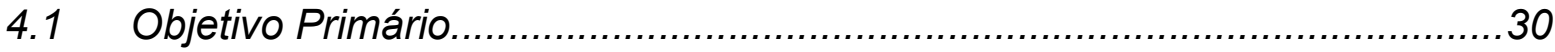

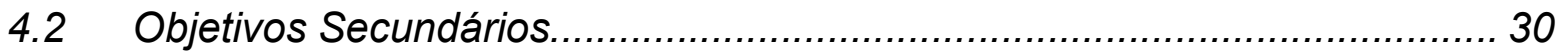

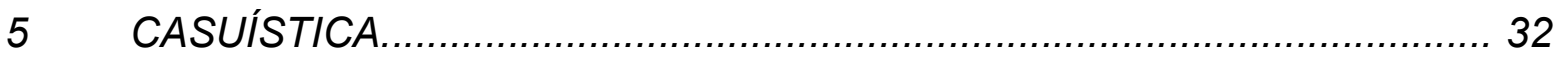

5.1 Sigilo, privacidade e confiabilidade dos dados coletados........................... 32

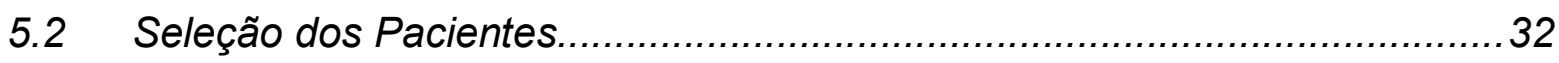

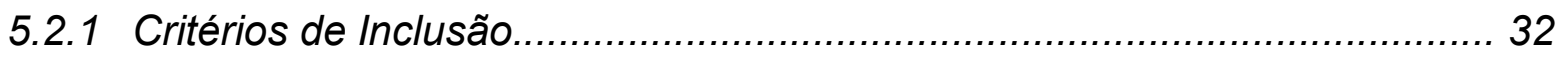

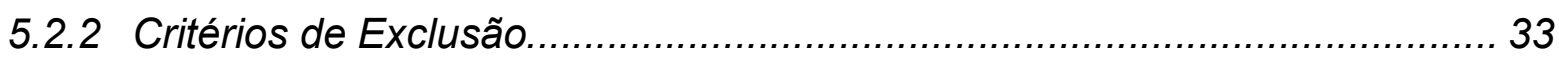

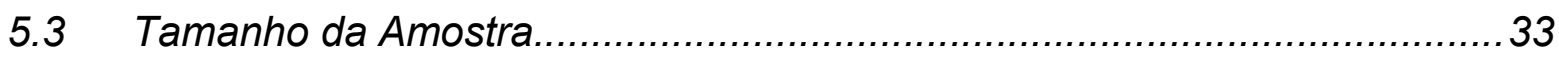

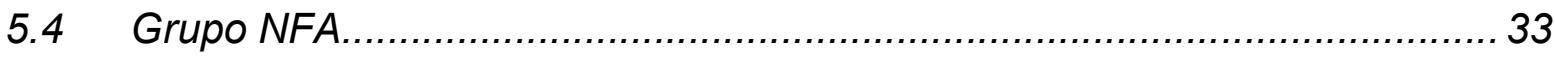

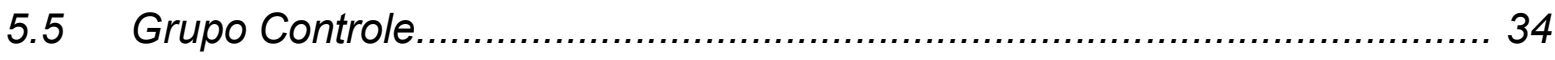

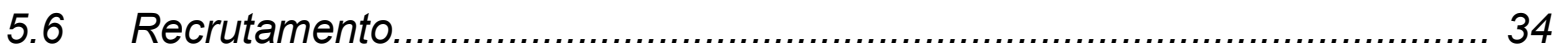

$6 \quad$ MÉTODOS

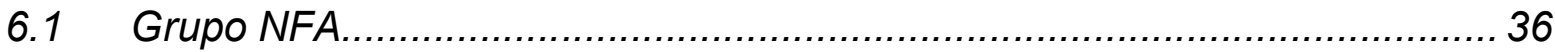

6.1.1 Rotina de Ablação de FA Utilizada Neste Trabalho.....................................37

6.2 Grupo Controle

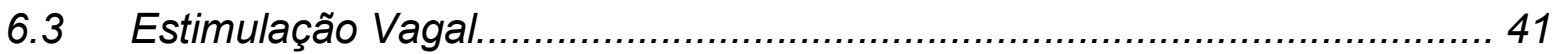

6.4 Medida da Frequência Cardíaca Durante a EVEC..................................... 43

6.5 Materiais Utilizados Neste Estudo....................................................... 44

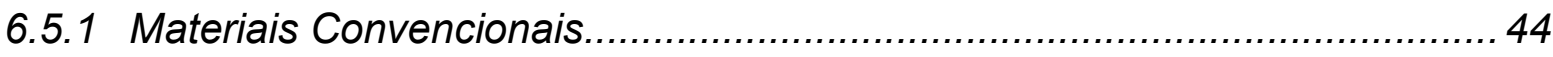

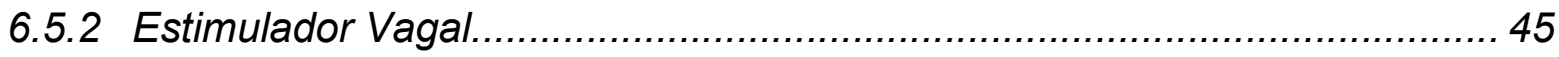

6.6 Acompanhamento dos pacientes após a ablação...................................... 46

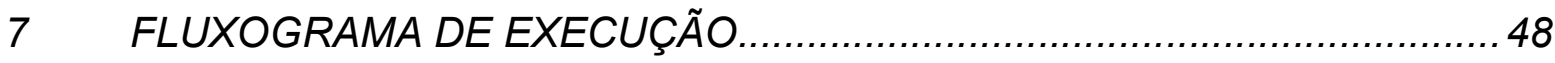

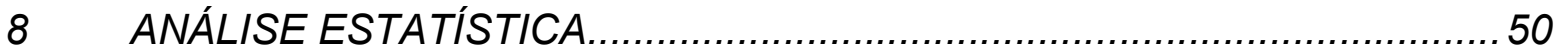

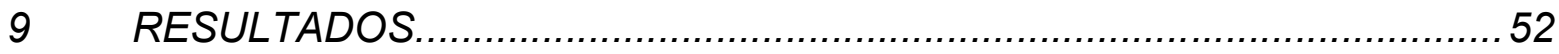


9.1 Pacientes Incluídos no Estudo...................................................... 52

9.2 Arritmias Tratadas no Grupo Controle............................................... 53

9.3 Tipos de Arritmias Tratadas no Grupo NFA........................................... 54

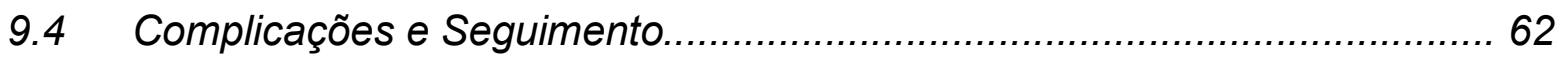

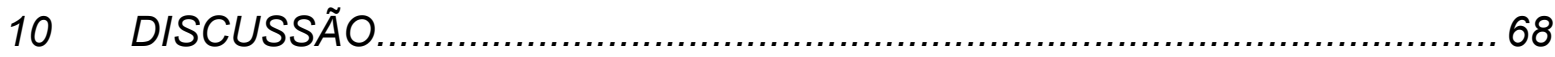

10.1 Denervação Parassimpática..................................................... 68

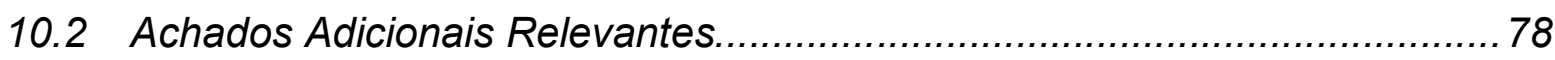

10.2.1 Reversão das Taquicardias Supraventriculares Pela EVEC..................... 78

10.2.2 Denervação Parcial da Junção AV.................................................... 80

10.2.3 Tratamento das Bradiarritmias Funcionais......................................... 80

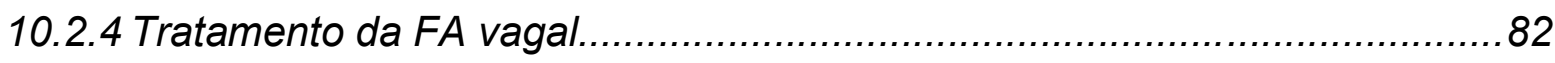

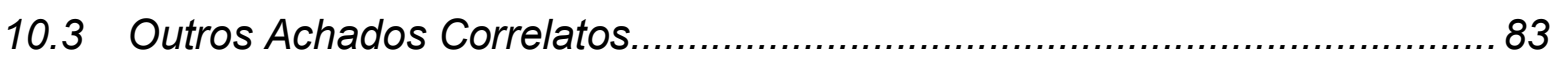

10.4 Teste de Atropina Versus Estimulação Vagal Extracardíaca.......................84

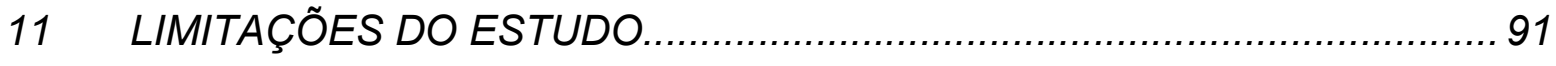

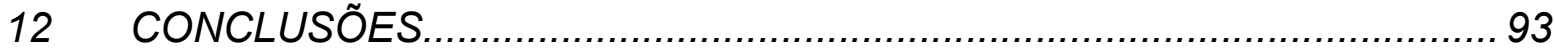

12.1 Conclusão Primária......................................................................... 93

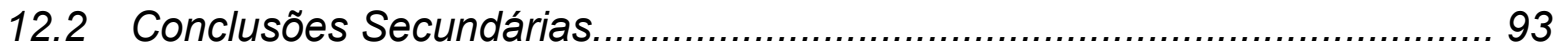

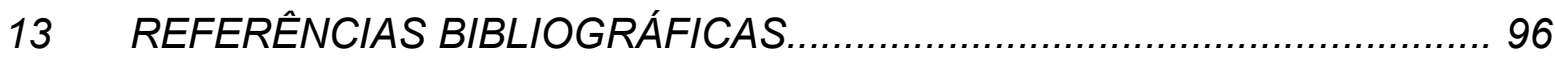

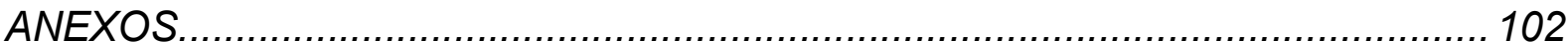

Anexo A - Patentes registradas/pendentes relacionadas a esta tese................... 102

Anexo A.1 Patente nos EUA, referente aos NFA ..................................... 102

Anexo A.2 Patente aplicada na Europa, referente ao Estimulador Neural Extracardíaco..................................................................................... 103

Anexo A.3 Patente aplicada nos EUA, referente ao eletrodo para estimulação vagal por via endovascular.......................................... 104

Anexo A.4 Patente aplicada nos EUA, referente ao desviador mecânico do esôfago................................................................... 105

Anexo B - Demonstração Experimental dos Efeitos da EVEC .......................... 106 
Anexo C - Cronograma de Execução............................................................... 108

Anexo D - Termo de Consentimento Livre e Esclarecido...................................... 109

Anexo E - Palavras de Grafia Imprecisa Utilizadas Nesta Tese............................116 
LISTA DE ABREVIATURAS

\begin{tabular}{ll}
\hline Símbolo & Significado \\
\hline AD & Átrio Direito \\
\hline AE & Átrio Esquerdo \\
\hline AV & Atrioventricular \\
\hline BAVT & Bloqueio Atrioventricular Total \\
\hline BPM & Batimentos por Minuto \\
\hline BIS & Brain Index Spectral \\
\hline 'C & Graus Celsius \\
\hline CNA & Cardioneuroablação \\
\hline DC & Corrente Contínua \\
\hline DVN & Dupla-Via-Nodal \\
\hline ECG & Eletrocardiograma \\
\hline ETE & Ecocardiograma Transesofágico \\
\hline EV & Extrassístole Ventricular \\
\hline EVEC & Estimulação Vagal Extracardíaca \\
\hline FA & Fibrilação Atrial \\
\hline FC & Frequência Cardíaca \\
\hline FE & Fração de Ejeção \\
\hline FFT & Transformada Rápida de Fourier \\
\hline FX & Feixe Anômalo \\
\hline GNFA & Grupo Controle \\
\hline Grupo NFA \\
\hline Gânglio Parassimpático Paracardíaco \\
\hline
\end{tabular}




\begin{tabular}{ll}
\hline h & Hora \\
\hline HCor & Hospital do Coração - Associação Beneficente Síria \\
\hline Hz & Hertz \\
\hline IDPC & Instituto Dante Pazzanese de Cardiologia \\
\hline IV & Intravenosa \\
\hline kg & Quilograma \\
\hline mg & Miligrama \\
\hline min & Minuto \\
\hline mm & Milímetro \\
\hline ms & Milissegundo \\
\hline NFA & Ninhos de Fibrilação Atrial \\
\hline pct(s) & Pacientes(s) \\
\hline pág(s) & Páginas(s) \\
\hline ppm & Pulsos por Minuto \\
\hline PW & Ponto de Wenckebach \\
\hline RAV & Reentrada Atrioventricular \\
\hline RF & Radiofrequência \\
\hline RS & Ritmo Sinusal \\
\hline $\mathbf{S}$ & Segundos \\
\hline SEMAP & Serviço de Eletrofisiologia, Marca-passos e Arritmias Dr. \\
\hline SNC & Pachón \\
\hline TCLE & Síndrome Neurocardiogênica \\
\hline TNV & Termo de Consentimento Livre e Esclarecido \\
\hline
\end{tabular}




\begin{tabular}{ll}
\hline VCI & Veia Cava Inferior \\
\hline VCS & Veia Cava Superior \\
\hline VD & Ventrículo Direito \\
\hline VE & Ventrículo Esquerdo \\
\hline VP & Veia Pulmonar \\
\hline VPSD & Veia Pulmonar Superior Direita \\
\hline VPSE & Veia Pulmonar Superior Esquerda \\
\hline VPID & Veia Pulmonar Inferior Direita \\
\hline VPIE & Veia Pulmonar Inferior Esquerda \\
\hline VSVD & Via de Saída do Ventrículo Direito \\
\hline W & Watt \\
\hline WPW & Síndrome de Wolff-Parkinson-White \\
\hline
\end{tabular}




\section{LISTA DE FIGURAS}




\section{LISTA DE FIGURAS}

Figura 1 - Frequência Cardíaca Intrínseca......................................................... 03

Figura 2 - Esquema mostrando que a somatória de ondas senoidais pode gerar ondas quadradas.

Figura 3 - Espectrômetro construído por Pachón et al.

Figura 4 - Classificação espectral do miocárdio atrial.

Figura 5 - Espectro do músculo atrial compacto e fibrilar. .09

Figura 6 - Inervação vagal do coração

Figura 7 - Microfotografia para visualização de inervação parassimpática .12

Figura 8 - Ninhos de FA vistos por microscopia da parede atrial.

Figura 9 - Representação esquemática da localização anatômica habitual dos quatro principais gânglios parassimpáticos paracardíacos.

Figura 10 - Proximidade dos gânglios paracardíacos com a parede atrial.

Figura 11 - Profundidade da lesão de RF 16

Figura 12 - Mapeamento dos Ninhos de FA

Figura 13 - Espectro do músculo compacto e do músculo fibrilar. 18

Figura 14 - Esquema da ablação autonômica endocárdica baseada nos NFA e plexos ganglionares.

Figura 15 - Avaliação histológica de gânglios neurais cardíacos antes e após a ablação.

Figura 16 - Esquema da estimulação vagal extracardíaca proposta pelos autores.

Figura 17 - Validação da inervação vagal com a EVEC. 
Figura 18 - Comparação da EVEC antes e após infusão de isoprenalina. 24

Figura 19 - Laboratório de eletrofisiologia. 36

Figura 20 - Sequência radiológica durante a ablação de paciente do GNFA 39

Figura 21 - Isolamento das veias pulmonares. 40

Figura 22 - Imagem fluoroscópica durante EVEC .42

Figura 23 - Método para medida da frequência cardíaca durante a EVEC 44

Figura 24 - Fluxograma de execução. 48

Figura 25 - Arritmias tratadas no grupo controle com as respectivas incidências. 54

Figura 26- Distribuição das diferentes arritmias no grupo ninhos de FA 55

Figura 27 - Comparativo entre peso dos pacientes e energia utilizada na EVEC.. 56

Figura 28 - Exemplo do Grupo Controle. 58

Figura 29 - Gráfico comparativo entre as pausas pré e pós-ablação em ambos os grupos.

Figura 30- Gráfico comparativo entre as pausas pré e pós-ablação ocasionadas pela EVEC em ambos os grupos.

Figura 31 - Evolução da frequência sinusal após cada etapa no GNFA 62

Figura 32 - Curvas de Kaplan-Meier mostrando a evolução livre de eventos. 63

Figura 33 - Ilustração de caso do GNFA comparando a EVEC antes e após a ablação dos NFA.

Figura 34 - Exemplo de ablação de NFA escalonada .71

Figura 35 - Modificação do ponto de Wenckebach durante a denervação. .72

Figura 36 - Representação esquemática do "ponto P" e do sulco de Waterston. 74

Figura 37 - Aplicação de RF no "Ponto P" 75 
Figura 38 - Gráfico comparativo entre as pausas pré e pós-ablação pela EVEC no GC

Figura 39 - Exemplo de aplicação adicional da EVEC na reversão de taquicardia supraventricular sustentada...

Figura 40 - Manutenção da denervação no longo prazo.

Figura 41 - Exemplo de surgimento de FA após a EVEC em paciente do GNFA

Figura 42 - Mapa dos locais dos NFA .84

Figura 43 - Exemplo de eliminação completa da resposta induzida pela EVEC após a atropina. 85

Figura 44 - Exemplo dos efeitos da EVEC em paciente do GC com pré-excitação ventricular. .87

Figura 45 - Comparação entre a EVEC e a adenosina em paciente do GC .88

Figura 46 - Preparação experimental de estimulação neural. 106 


\section{LISTA DE TABELAS}




\section{Lista de Tabelas}

Tabela 1 - Dados demográficos e indicações de ablação .53

Tabela 2 - Comparação entre os dados dos pacientes do GNFA (Grupo Ninhos de Fibrilação Atrial) e GC (Grupo Controle). .55

Tabela 3 - Dados comparativos dos valores obtidos no GNFA e no GC, pré e pós-procedimento

Tabela 4 - Dados da média da frequência sinusal do GNFA após cada etapa da ablação dos NFA.

Tabela 5 - Seguimento dos pacientes do GC, após: 60 dias, 6 meses e 1 ano do procedimento, até o momento do levantamento destes dados

Tabela 6 - Seguimento dos pacientes do GNFA, após: 60 dias,

6 meses e 1 ano do procedimento, até o momento do levantamento destes dados.

Tabela 7 - Resumo dos comentários a respeito das tendências dos comportamentos do ritmo sinusal e da junção $A V$ observado no GNFA de acordo com a localização dos NFA ablacionados 76

Tabela 8 - Resumo dos comentários a respeito das tendências dos comportamentos do ritmo sinusal e da junção AV observados no GC, conforme a localização do foco arritmogênico 


\section{RESUMO}

Pachón Mateo El. Estimulação Vagal Extracardíaca para Avaliar a Eficácia da Denervação Vagal Pós-Ablação dos Ninhos de Fibrilação Atrial. São Paulo, 2019 100p, Tese - Instituto de Cardiologia Dante Pazzanese, Afiliado da Universidade de São Paulo.

Introdução: A hiperatividade vagal está diretamente relacionada a várias condições clínicas, como bradiarritmias funcionais, reflexas e fibrilação atrial vagal (FA). A cardioneuroablação promove a denervação vagal terapêutica por meio da ablação por radiofrequência (RF) endocárdica nesses casos. Os principais desafios são: a identificação da interface neuro-miocárdica e o controle e validação da denervação. $A$ observação inicial de que a ablação dos ninhos de FA (NFA) elimina a resposta à atropina e diminui a variabilidade RR sugere que essas estruturas estão relacionadas à inervação vagal.

Objetivo: Verificar se a ablação dos NFA pela RF realmente promove a denervação vagal em comparação com um grupo controle submetido à ablação de arritmias não relacionadas aos NFA, e se esta denervação pode ser comprovada pela estimulação vagal extracardíaca (EVEC).

Método: Estudo prospectivo, controlado, longitudinal, com 62 pacientes (pcts) reunidos em dois grupos: grupo NFA (GNFA - 32 pcts) com bradiarritmias funcionais, reflexas ou FA vagal, tratados com ablação por RF dos NFA, e um grupo controle (GC - 30 pcts) com arritmias distintas (feixes anômalos, extra-sístoles ventriculares, flutter atrial, reentrada nodal e taquicardia atrial), tratados com ablação convencional (nãoNFA). No GNFA, a ablação foi direcionada aos NFA detectados pela fragmentação dos eletrogramas endocárdicos e pela localização eletroanatômica em 3D dos plexos ganglionares. A resposta vagal foi avaliada antes, durante e após a ablação, realizando a estimulação vagal sem contato direto, por $5 \mathrm{~s}$, ao nível do forame jugular, através das veias jugulares internas, e analisando a média da frequência cardíaca por $15 \mathrm{~s}$, o intervalo RR mais longo, as pausas e os bloqueios AV. Todos os pcts apresentavam indicação formal de ablação das arritmias pelas diretrizes atuais. 
Resultados: A EVEC induziu pausas sinusais pré-ablação, assistolia e bloqueio AV transitório em ambos os grupos, indicando resposta vagal intensa sem diferença significativa entre os grupos $(p=0,96)$. Após a ablação, no GNFA, a EVEC mostrou completa eliminação da resposta vagal cardíaca em todos os casos (EVEC pré versus pós-ablação: $p<0,000$ ), demonstrando denervação vagal consistente. Entretanto, no $\mathrm{GC}$, a resposta vagal permaneceu praticamente inalterada após a ablação $(p=0,35)$, mostrando que a ablação não relacionada aos NFA não promove denervação vagal significativa.

Conclusão: A ablação endocárdica dos NFA promove intensa denervação vagal. A ablação não direcionada aos NFA não mostrou alterações significativas na inervação vagal. Esses resultados confirmam que os NFA estão intrinsecamente relacionados à inervação vagal. A EVEC foi fundamental para a validação gradual da denervação vagal durante a ablação endocárdica.

Palavras-chave: 1. Síncope; 2. Fibrilação atrial; 3. Cardioneuroablação; 4. Ninhos de FA; 5. Estimulação vagal; 6. Denervação; 7. Síncope vasovagal; 8. Ablação. 


\section{ABSTRACT}

Pachón Mateo El. Extracardiac Vagal Stimulation to Evaluate the Effectiveness of Vagal Denervation After Ablation of Atrial Fibrillation Nests. São Paulo, 2019 100p, Thesis - Institute Dante Pazzanese of Cardiology, Affiliate of the University of São Paulo.

Background: Vagal hyperactivity is directly related to several clinical conditions such as reflex and functional bradyarrhythmias and vagal atrial fibrillation (AF). Cardioneuroablation has achieved therapeutic vagal denervation through endocardial RF ablation for treatment of these cases. The main challenges are the identification of the neuro-myocardium interface and the denervation control and validation. The seminal observation that the AF-Nest (AFN) ablation cancel the atropine response and decreases the RR variability suggests that these structures are related to the vagal innervation.

Objective: To verify whether AFN ablation really promotes vagal denervation compared to a control group with non-AFN ablation.

Method: Prospective, controlled, longitudinal study enrolling 62 patients (pts) gathered in two groups: AFN group (AFNG-32 pts) with functional or reflex bradyarrhythmias or vagal AF treated with AFN ablation, and a control group (CG-30 pts) with several arrhythmias (anomalous bundles, ventricular extrasystoles, atrial flutter, nodal reentry and atrial tachycardia) treated with conventional ablation (non-AFN ablation). In the AFNG ablation was targeted to the AFN detected by fragmentation of the endocardial electrograms and by 3D anatomical location of the ganglionated plexus. Vagal response was evaluated before, during, and post-ablation by $5 \mathrm{~s}$ of non-contact vagal stimulation at the level of the jugular foramen through the internal jugular veins Extracardiac Vagal Stimulation (ECVS), analyzing 15s mean heart rate, longest RR, pauses, and AV block. All pts had current guidelines arrhythmia ablation indication.

Results: ECVS pre-ablation induced sinus pauses, asystole and transient AV block in both groups, indicating plain and strong vagal response $(p=0.96)$. Post-ablation, in the AFNG, ECVS showed complete abolishment of the cardiac vagal response in all cases (ECVS pre versus post-ablation $=p<0.000$ ), demonstrating robust vagal denervation. However, in the CG, vagal response remained practically unchanged 
post-ablation $(p=0.35)$ showing that non-AFN ablation promotes no significant denervation.

Conclusion: AFN endocardial ablation promotes significant vagal denervation. Ablation not targeting the AFN showed no significant changes in vagal innervation. These results suggest that AFN are intrinsically related to vagal innervation. The ECVS was fundamental to stepwise vagal denervation validation during cardioneuroablation.

Keywords: 1. Syncope; 2. Atrial Fibrillation; 3. Cardioneuroablation; 4. AF Nest; 5. Vagal stimulation; 6. Denervation; 7. Vasovagal syncope; 8. Ablation. 


\section{Introdução}

Devido à liberação de acetilcolina, a estimulação vagal provoca cardioinibição com bradicardia, assistolia e/ou bloqueio AV de alto grau. Na década de noventa, por meio do mapeamento espectral, identificamos e descrevemos o miocárdio fibrilar e os Ninhos de FA (NFA) nas paredes atriais ${ }^{1}$. Logo nos primeiros estudos, verificamos que estas estruturas estavam relacionadas à interface neuromiocárdica, pois sua ablação eliminava a resposta do coração à atropina ${ }^{1}$. Deste modo, propusemos que a ablação dos NFA poderia ser utilizada como opção terapêutica nos distúrbios relacionados ao aumento do tônus vagal, tais como: síncope cardioinibitória, fibrilação atrial vagal e bradiarritmias funcionais, dando origem à "Cardioneuroablação" (CNA) ${ }^{1}$.

Em 2005, foi publicado o primeiro estudo propondo a ablação vagal para o tratamento de síncopes por bradiarritmias funcionais sem implante de marca-passo ${ }^{1}$. O objetivo era obter uma atenuação da inervação parassimpática, fazendo a ablação dos neurônios viscerais vagais nas paredes atriais, por meio da aplicação de radiofrequência, com o propósito de abolir a resposta cardioinibitória e reduzir o tônus vagal em longo prazo. Os resultados, claramente positivos nas primeiras séries de casos, estimularam interesse crescente da Eletrofisiologia nacional e internacional. A denervação cardíaca vagal por radiofrequência (RF) mediante o uso de cateteres, passou a ser um método viável e que deveria ser aperfeiçoado para ampliar as aplicações clínicas.

Neste sentido, dois grandes desafios apresentavam-se:

a) como mapear a interface neuromiocárdica e

b) como validar e confirmar o grau de denervação vagal.

Este estudo procura abordar estas questões, a primeira utilizando o mapeamento dos "Ninhos de FA" (NFA) e a segunda por meio da "Estimulação Vagal Extracardíaca" (EVEC). Finalmente, procura verificar se existe relação dos NFA com a inervação vagal do coração. 


\subsection{Frequência Cardíaca Intrínseca}

Considera-se "Frequência Intrínseca" a frequência que o coração apresenta após completa denervação farmacológica ${ }^{2}$ ou cirúrgica. A primeira pode ser obtida com uso de atropina $(0,04 \mathrm{mg} / \mathrm{kg})$ e propranolol $(0,2$ a $0,5 \mathrm{mg} / \mathrm{kg})$ endovenosos. É inversamente proporcional à idade e pode ser prevista, de forma aproximada, subtraindo-se metade da idade de 118 bpm. Isto significa que o coração denervado tem frequência cardíaca sensivelmente maior que o coração normal ${ }^{3}$, Figura 1. Este fato se deve ao potente e permanente efeito inibitório da ação vagal. Deste modo, quando eliminamos as terminações vagais ocorre significativo aumento da frequência cardíaca, mesmo que o simpático esteja bloqueado. Este fato também é bastante relevante no coração transplantado. Neste princípio baseia-se a CNA, que busca eliminar as terminações vagais, de modo permanente, mediante a ablação por RF.

Figura 1 - Frequência Cardíaca Intrínseca

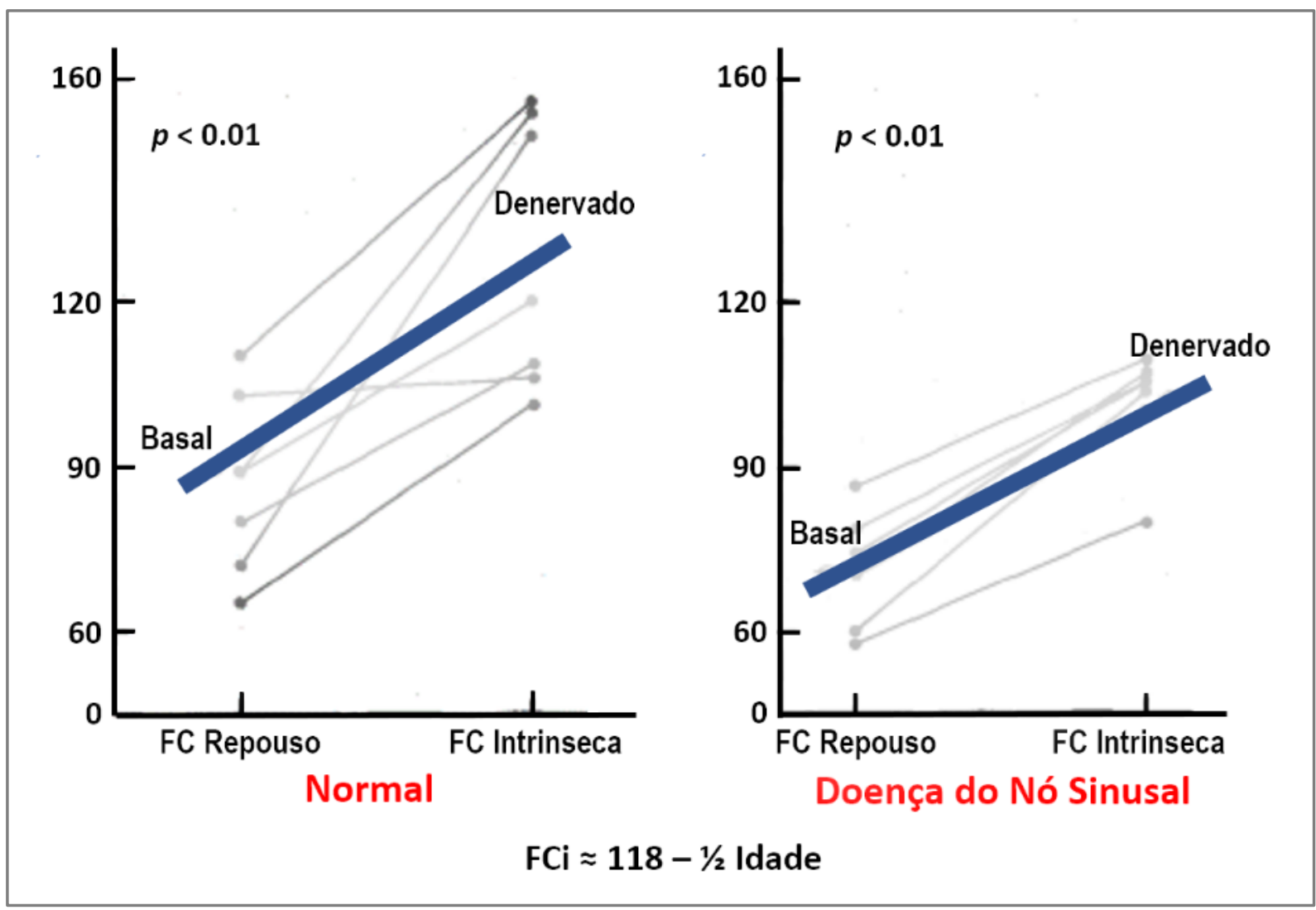

Frequência cardíaca obtida após completo bloqueio farmacológico em pacientes com coração normal e portadores de doença do nó sinusal. É marcante que, sem inervação, o coração tem uma frequência espontânea significativamente superior à frequência normal, Fonte: Marcus B et al, $1990^{3}$. 


\subsection{Mapeamento da Interface Neuromiocárdica}

Após a publicação do trabalho original, vários autores propuseram técnicas adicionais para identificar a interface neuromiocárdica, tais como:
a) mapeamento espectral simplificado dos NFA ${ }^{1,4}$;
b) mapeamento convencional dos NFA por fragmentação $5,6,7$;

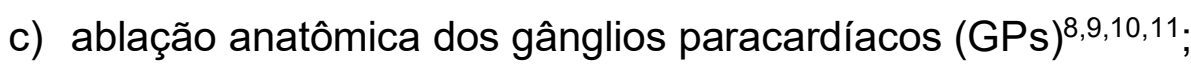
d) estimulação atrial de alta frequência ${ }^{12,13}$;
e) observação direta e excisão dos $\mathrm{GPs}^{14} \mathrm{e}$
f) tomografia computadorizada ${ }^{15}$.

No estudo inicial, a identificação da interface neuromiocárdica foi obtida por meio do mapeamento espectral dos NFA utilizando um espectrômetro, através do método simplificado (utilizando filtros seletivos do próprio polígrafo) e pela localização anatômica dos plexos ganglionares do coração.

\subsubsection{Ninhos de FA}

Os NFA são pontos nas paredes atriais que têm um padrão de condução elétrica heterogênea mesmo em corações normais. Foram descritos na década de 90 , publicados em $2004^{4}$ e patenteados nos EUA em $2005^{16}$ (Anexo A1 - pág 102). Apesar de ser possível identificá-los pelo sinal convencional do polígrafo, os NFA são melhor caracterizados pela análise espectral, e receberam essa denominação pelo fato de estarem diretamente envolvidos na manutenção da fibrilação atrial (FA), através do fenômeno de ressonância elétrica ${ }^{4,16}$.

\subsubsection{Fundamentos da Análise Espectral}

Em 1822, Jean Baptiste Joseph Fourier (1768-1830), estudando a teoria de propagação do calor, concluiu que qualquer sinal ondulatório irregular (assim como são os potenciais endocárdicos), pode ser desmembrado numa infinidade de ondas senoidais regulares de frequências distintas. O gráfico de amplitude versus frequência destas ondas compõe o "Espectro" e a "Análise Espectral". Por sua vez, numa 
operação inversa, se estas ondas forem superpostas novamente e somadas, desde que respeitadas as fases originais, devolvem o sinal inicial, assim como ocorre em qualquer equação matemática, Figura 2 - linha 1.

Figura 2 - Esquema mostrando que a somatória de ondas senoidais pode originar ondas quadradas

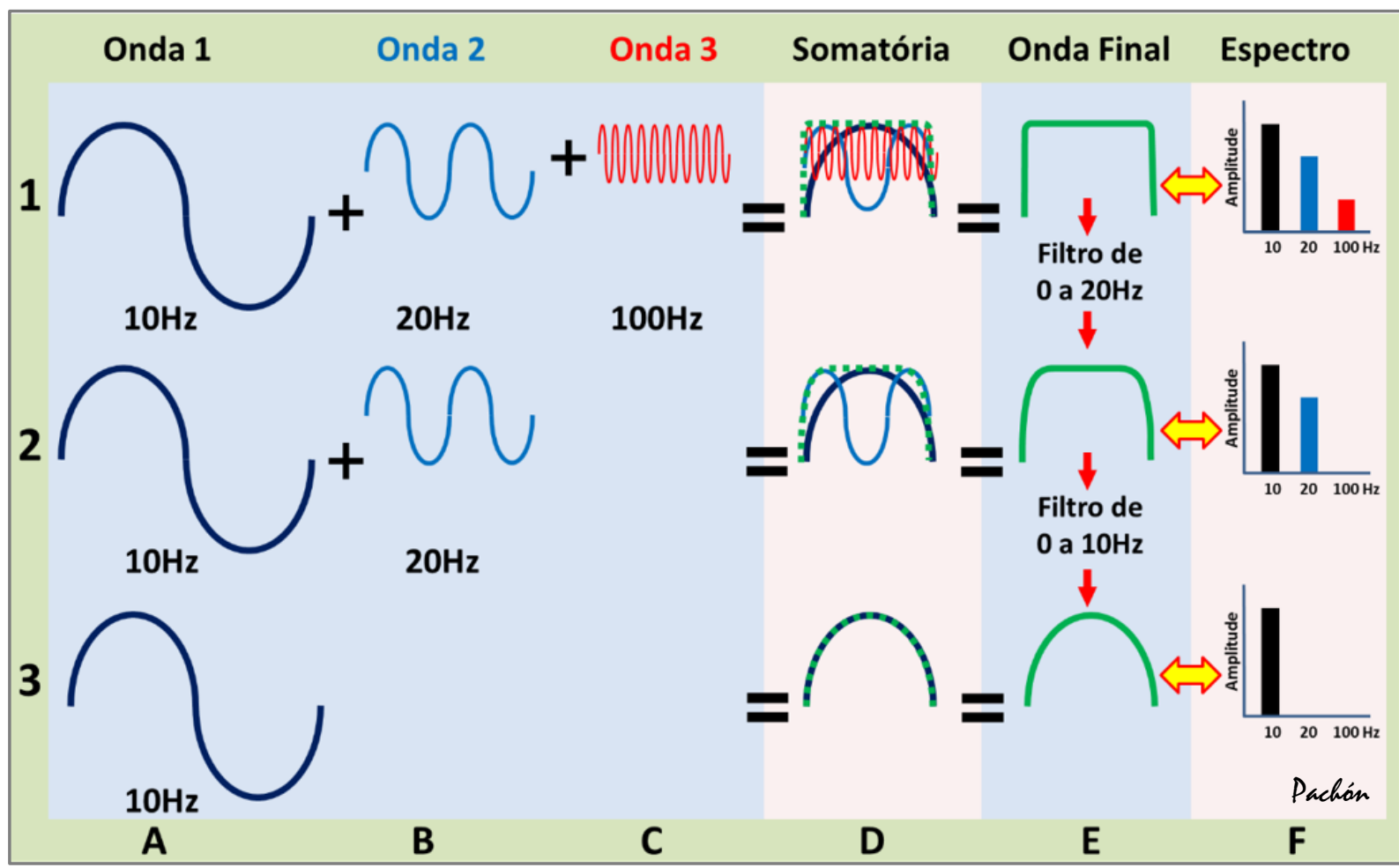

É possível "montar" ou "desmontar" uma onda "quadrada" com/em ondas senoidais "redondas". Algumas ondas são representadas somente por uma fase por questão de facilidade gráfica. Na linha 1, observa-se que a somatória de três ondas senoidais com frequências crescentes origina uma onda quadrada em 1E. A representação gráfica da frequência e amplitude de cada uma dessas ondas é o espectro mostrado em $1 \mathrm{~F}$. Se fizermos a operação inversa, o espectro da onda quadrada nos mostra que a mesma é composta pelo menos pelas três ondas originais, e ainda nos dá a amplitude com que cada uma aparece (na realidade, quanto maior número de ondas senoidais mais "quadrada" será a onda final). Por facilidade, neste exemplo, utilizamos uma onda quadrada, porém qualquer sinal, tal como um QRS, uma onda $\mathrm{P}$ ou um eletrograma endocavitário, pode ser igualmente montado/desmontado numa infinidade de ondas regulares, senoidais. A coluna $E$ também mostra o efeito de filtros, os quais, dependendo de suas características poderão transformar uma onda "quadrada" numa onda "arredondada" na medida que impedem a expressão de ondas de maior frequência (1E, 2E e 3E). Fonte: Pachon Mateos, JC - capítulo 1, pág $25^{17}$.

A representação gráfica destas ondas, relacionando a amplitude na vertical e a frequência na horizontal constitui o espectro, Figura 2 - 1F, o qual é utilizado em inúmeras aplicações do conhecimento humano. Só para citar alguns exemplos, a análise do espectro é utilizada para a compressão das fotografias digitais e para filtrar 
determinados instrumentos em uma música, mas também é utilizada para analisar a composição química das estrelas e planetas, fenômenos meteorológicos ou até mesmo o comportamento da bolsa de valores. Isso nos dá ideia do potencial dessa ferramenta e de seu uso ilimitado dentro da ciência e da Eletrofisiologia. A análise espectral amplia drasticamente as informações contidas num potencial endocárdico.

Em um registro eletrocardiográfico, a análise espectral do sinal mostra, por exemplo, que no QRS predominam componentes com alta frequência e que nas ondas $\mathrm{T}$ e nas ondas $\mathrm{P}$ as frequências predominantes são menores. Isso é muito importante porque permite a construção de filtros para detecção seletiva dos sinais cardíacos. O espectro também é fundamental porque carrega inúmeras informações das propriedades elétricas, físicas e químicas do meio que produz e transporta uma determinada onda.

Por meio do espectrômetro acoplado a um computador, Figura 3-A, utilizando a transformada rápida de Fourier (FFT), é possível obter o espectro de cada despolarização cardíaca, em tempo real, durante a realização de um estudo eletrofisiológico ${ }^{1}$. Deste modo, o polígrafo ou o eletrocardiógrafo mostram o sinal no padrão convencional de amplitude versus tempo (domínio do tempo) e o espectrômetro mostra, simultaneamente, o mesmo sinal, porém relacionando a amplitude versus a frequência intrínseca do sinal (domínio da frequência), Figura 3-B e Figura 4-1C, 1D, 2C, 2D.

Com a rápida evolução dos microprocessadores dos computadores modernos, é possível ver o espectro de cada batimento cardíaco quase instantaneamente, fornecendo uma grande quantidade de informações incluídas no sinal elétrico, relacionadas não somente com a sua formação, mas também com a sua propagação, e que não conseguiríamos visibilizar totalmente utilizando somente o eletrocardiograma convencional. 
Figura 3 - Espectrômetro construído por Pachón et al.

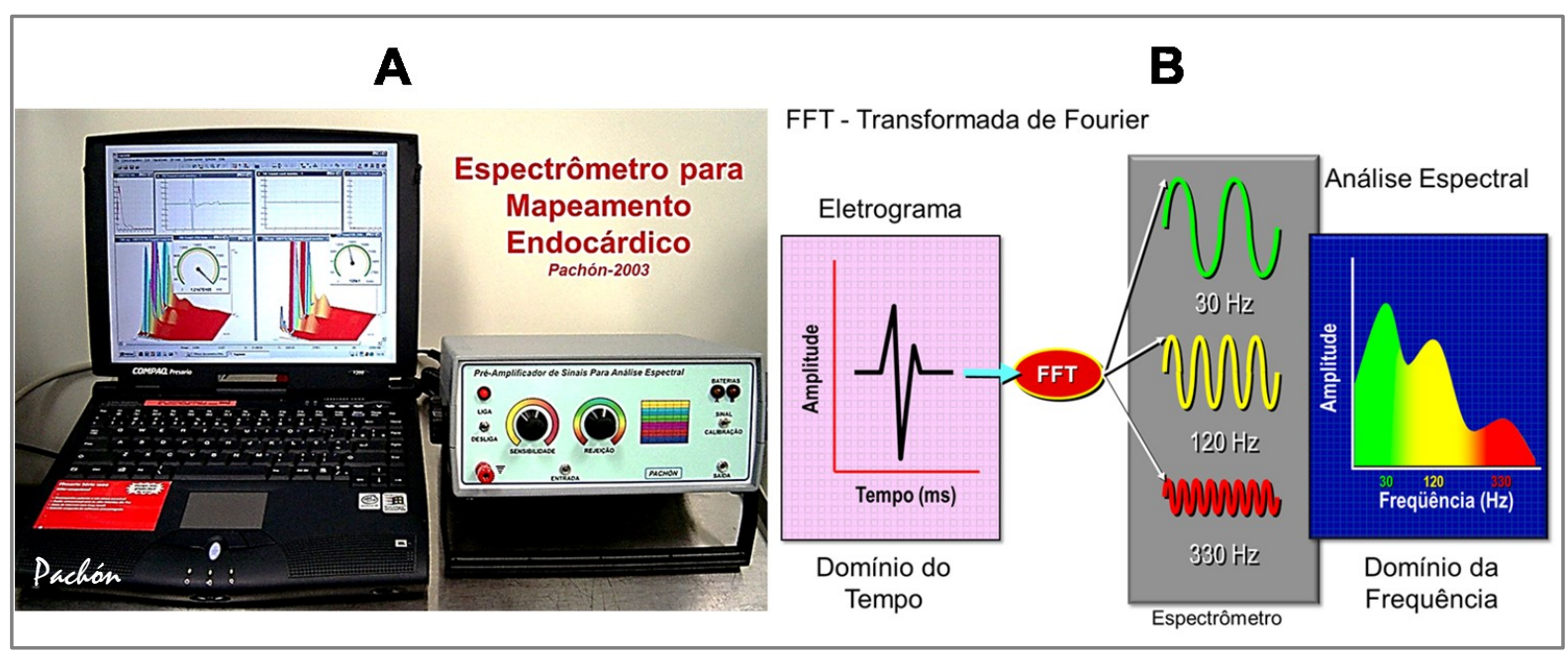

A: Equipamento baseado num amplificador instrumental de alta precisão e num computador IBM-PC com software específico; B: Esquema do funcionamento do sistema, mostrando que um sinal endocárdico é instantaneamente processado, desmontado em inúmeras ondas senoidais (no esquema são representadas somente três) pelas equações da transformada rápida de Fourier (FFT - Fast Fourier Transform), fornecendo o espectro de cada eletrograma em milésimos de segundo durante os estudos eletrofisiológicos. Fonte: Pachón et al, 2005'.

Figura 4 - Classificação espectral do miocárdio atrial.

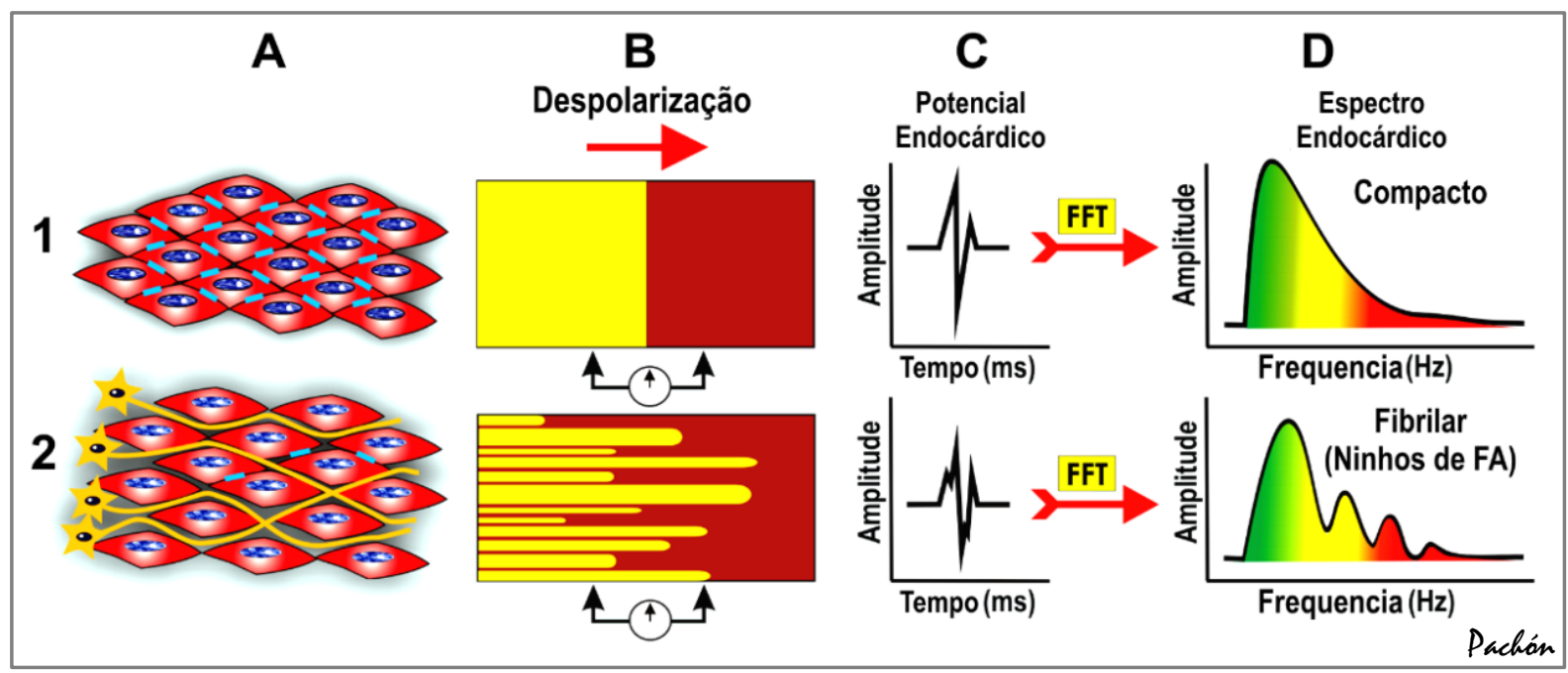

1A: esquema do miocárdio compacto com as respectivas conexinas e padrão sincicial; 2A: Esquema do miocárdio fibrilar (Ninho de FA) com miócitos parcialmente separados pela entrada da inervação representada pelos neurônios viscerais pós-ganglionares parassimpáticos; 1B: Esquema da condução sincicial homogênea do miocárdio compacto; 2B: esquema da condução heterogênea do miocárdio fibrilar; 1C: Potencial elétrico do miocárdio compacto; 2C: Potencial elétrico do miocárdio fibrilar; 1D: Espectro liso do potencial do miocárdio compacto; 2D: Espectro segmentado do potencial do miocárdio fibrilar. Fonte: Pachón et al, $2005^{1}$. 


\subsubsection{Análise Espectral do Miocárdio Atrial}

O estudo espectral dos sinais endocárdicos atriais permitiu verificar que existem pelo menos dois tipos de miocárdio atrial, o compacto e o fibrilar, Figura 4.

A estrutura primordial do miocárdio baseia-se no conceito de sincício, no qual as células normais se unem por meio dos discos intercalares e, graças às conexinas, simulam as propriedades elétricas de uma única célula, Figura 4-1A. A tendência é de todas as células normais terem uma condução elétrica organizada, isotrópica e homogênea, numa única frente de onda, sem os saltos de condução de uma célula à outra, Figura 4-1B. O miocárdio que apresenta este tipo de condução foi denominado "miocárdio compacto"4, Figura 4-A.

As regiões das paredes atriais onde as células estão eletricamente parcialmente desconectadas (por diversas razões), foram chamadas de NFA, Figura 4-2A. Estas regiões apresentam condução elétrica heterogênea, com frentes de ondas múltiplas, como se fossem feixes musculares relativamente independentes, Figura 42B. O miocárdio formado por esses NFA foi denominado "miocárdio fibrilar", Figura 42A. A análise espectral identifica facilmente estes dois tipos de miocárdio, Figura 4-D.

O compacto pode gradativamente transformar-se no fibrilar, pela desconexão progressiva de suas células, o que pode ocorrer por inúmeros fatores patológicos. $\mathrm{O}$ miocárdio fibrilar pode ter seu comportamento modificado pela aplicação de RF, eliminando os componentes responsáveis pelas frequências mais elevadas do espectro, assemelhando-se novamente ao comportamento do músculo compacto.

Seis anos após a publicação original, exatamente os mesmos achados de Pachón et al. foram reproduzidos com os mesmos métodos por Oh et al. e publicados em $2010^{18}$. O registro espectral dos miocárdios compacto e fibrilar também foram obtidos de forma reprodutível em experimento com cães e estão demonstrados na Figura 5. 
Figura 5 - Espectro do músculo atrial compacto e fibrilar.

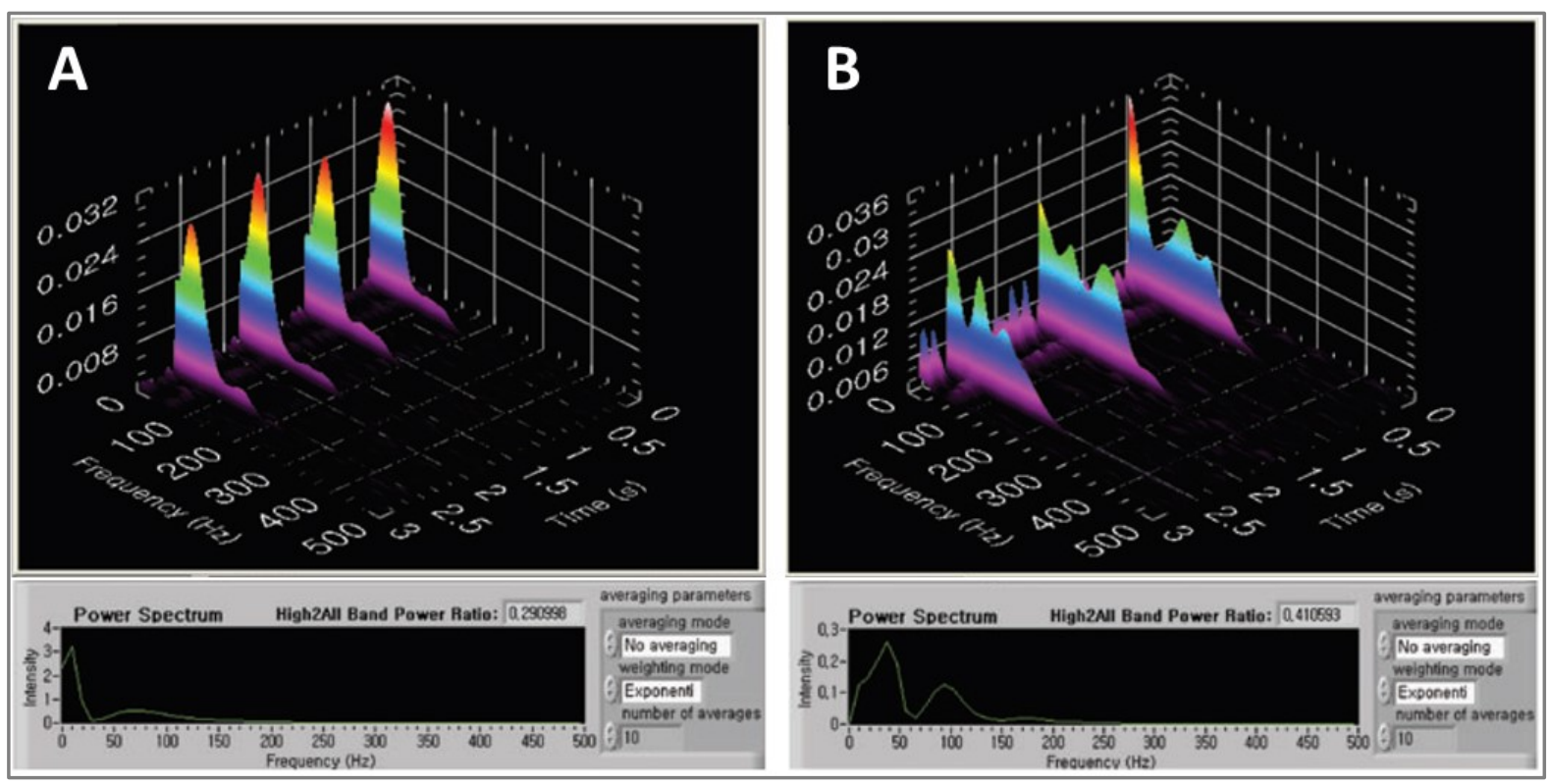

Registro do espectro do músculo atrial compacto $(A)$ e fibrilar $(B)$ conforme experimento realizado por Oh et al. ${ }^{17}$ em cães, em 2010 , reproduzindo os mesmos achados descritos por Pachón et al. ${ }^{1}$ Fonte: Oh et al, $2010^{18}$.

\subsubsection{Sistema Nervoso Autônomo}

O sistema nervoso autônomo do coração consiste em três divisões principais, uma aferente - o sistema nervoso sensorial - e duas partições eferentes, a parassimpática e a simpática. A medula oblonga é o principal centro de integração da inervação cardíaca, cuja atividade é modulada pelo hipotálamo e por centros mais superiores. As fibras sensoriais são neurônios bipolares, cujos corpos celulares estão na medula oblonga. As fibras eferentes compreendem essencialmente dois neurônios principais, o pré e o pós-ganglionar. A fibra pós-ganglionar parassimpática é muito curta, porque o corpo do neurônio está localizado no coração, principalmente na parede atrial e nos plexos ganglionares ${ }^{19,20}$ (coxins adiposos paracardíacos). $O$ corpo celular do neurônio pré-ganglionar parassimpático está na medula oblonga, mais especificamente nos núcleos ambíguo e motor dorsal dos vagos ${ }^{21}$. Seu axônio é conduzido ao coração pelos nervos vagos. Em contraste, o neurônio pós-ganglionar simpático é longo, porque seu corpo celular está situado na cadeia simpática paravertebral, distante do músculo cardíaco. O resultado dessa distribuição é que 
apenas o corpo do neurônio pós-ganglionar parassimpático está localizado no coração e somente este é propenso a ser eliminado pela ablação endocárdica por RF.

\subsubsection{Fisiologia do Sistema Nervoso no Coração}

Apesar do coração ser um músculo estriado, sua atividade não depende da inervação. Ao contrário do músculo esquelético, que se atrofia quando denervado, o coração retém seu metabolismo, estrutura e atividade normais, independentemente da inervação. Esse fato é facilmente observado em pacientes transplantados cardíacos. No entanto, o sistema nervoso autônomo atua permanentemente, modulando todas as propriedades cardíacas, através de um intenso tônus inibitório (parassimpático) e excitatório (simpático). Esse antagonismo funcional cria um equilíbrio mediado pelo tronco cerebral, que determina a frequência cardíaca instantânea. Esse equilíbrio é constantemente restaurado pelo sistema nervoso autônomo, ajustando a fisiologia cardíaca a cada momento. Assim, no caso de denervação vagal, observa-se progressivamente uma redução proporcional do tônus simpático, determinada pelo balanço reflexo do sistema nervoso autônomo, trazendo a frequência cardíaca de volta para o valor basal.

\subsubsection{Inervação Cardíaca e Ninhos de FA}

Já no estudo inicial foi observado que os NFA (miocárdio fibrilar) do coração normal, estão relacionados com a entrada da inervação e, desta forma seu mapeamento pode ser usado para guiar as técnicas de denervação ${ }^{2,18,22,23}$, Figura 4B. Na interface neuromiocárdica, devido à ausência de placa motora, a entrada da inervação ocorre pela interpolação das fibras neurais com os cardiomiócitos. Isto provoca uma certa separação entre as células, alterando a velocidade e o padrão de condução do estímulo nestas regiões, sendo um dos fatores na formação dos NFA. Além do mais, somam-se nestes pontos as frequências de trabalho dos cardiomiócitos com as frequências de trabalho mais elevadas das terminações neurais, Figura 4-B e Figura 6. Adicionalmente, independente da inervação, na junção venoatrial (veias pulmonares, veias cavas e seio coronário) ocorre uma "rarefação" muscular na transição dos tecidos e desconexão das células miocárdicas, com a formação de 
grande número de NFA ${ }^{24,25}$. Nesses locais também existe a entrada de inervação que acompanha os vasos, de forma que estes NFA indicam adicionalmente elementos da junção neuromiocárdica. Estes dados explicam, de forma coerente, o bom resultado da ablação da fibrilação atrial paroxística com a aplicação de RF nestas regiões.

Figura 6 - Inervação vagal do coração.

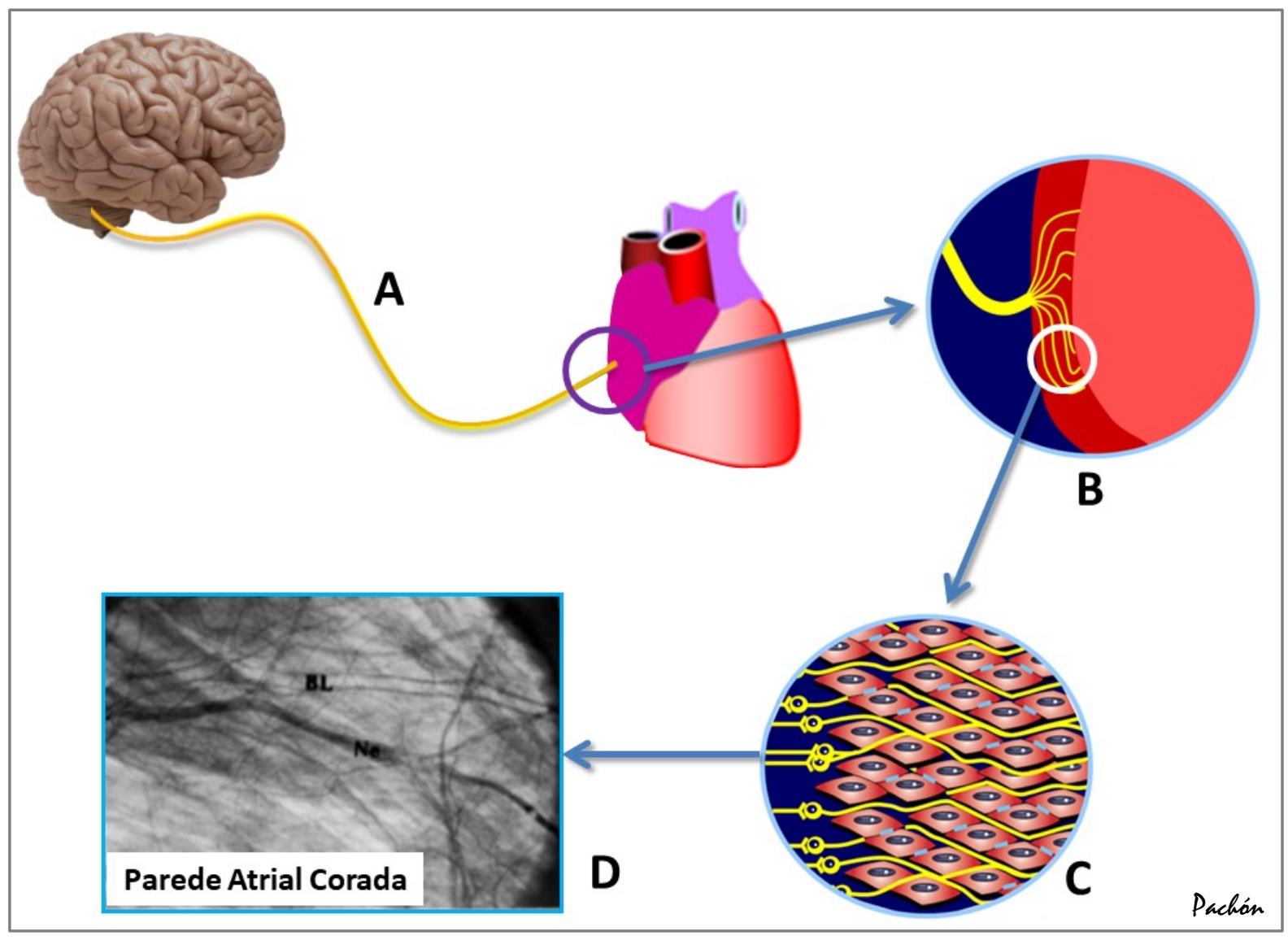

Esquema demonstrando como a penetração da inervação vagal ( $\mathrm{A}$ e B) através dos neurônios pósganglionares parassimpáticos $(\mathrm{C})$, pode contribuir para a desconexão dos miócitos atriais, criando o miocárdio fibrilar. Essa densa malha neural pode ser observada em microscopia, após adequada coloração da acetilcolinesterase por meio de imuno-histoquímica (D). Fonte: Trabalho de Pauza et al. ${ }^{26}$ e Modificado de Pachón et al., 2015²7. 
Vários achados demonstraram uma estreita relação entre o miocárdio fibrilar, NFA e a interface neuromiocárdica, quais sejam:

a) a aplicação de RF no miocárdio fibrilar, tipicamente causa reações autonômicas imediatas, como um aumento significativo da frequência cardíaca e aumento do ponto de Wenckebach ${ }^{6,28,29}$;

b) estudos baseados em coloração neural com marcadores imuno-histoquímicos, mostraram um número elevado de neurônios e gânglios parassimpáticos nas áreas do miocárdio fibrilar ${ }^{26,30}$, Figura 7 e Figura 8;

c) uma grande quantidade de miocárdio fibrilar é encontrada nas regiões anatômicas dos plexos ganglionares cardíacos ${ }^{4,22}$;

d) observações iniciais mostraram que a ablação dos NFA abolia a resposta cardíaca à atropina ${ }^{1,28,29}$.

Figura 7 - Microfotografia para visualização de inervação parassimpática.

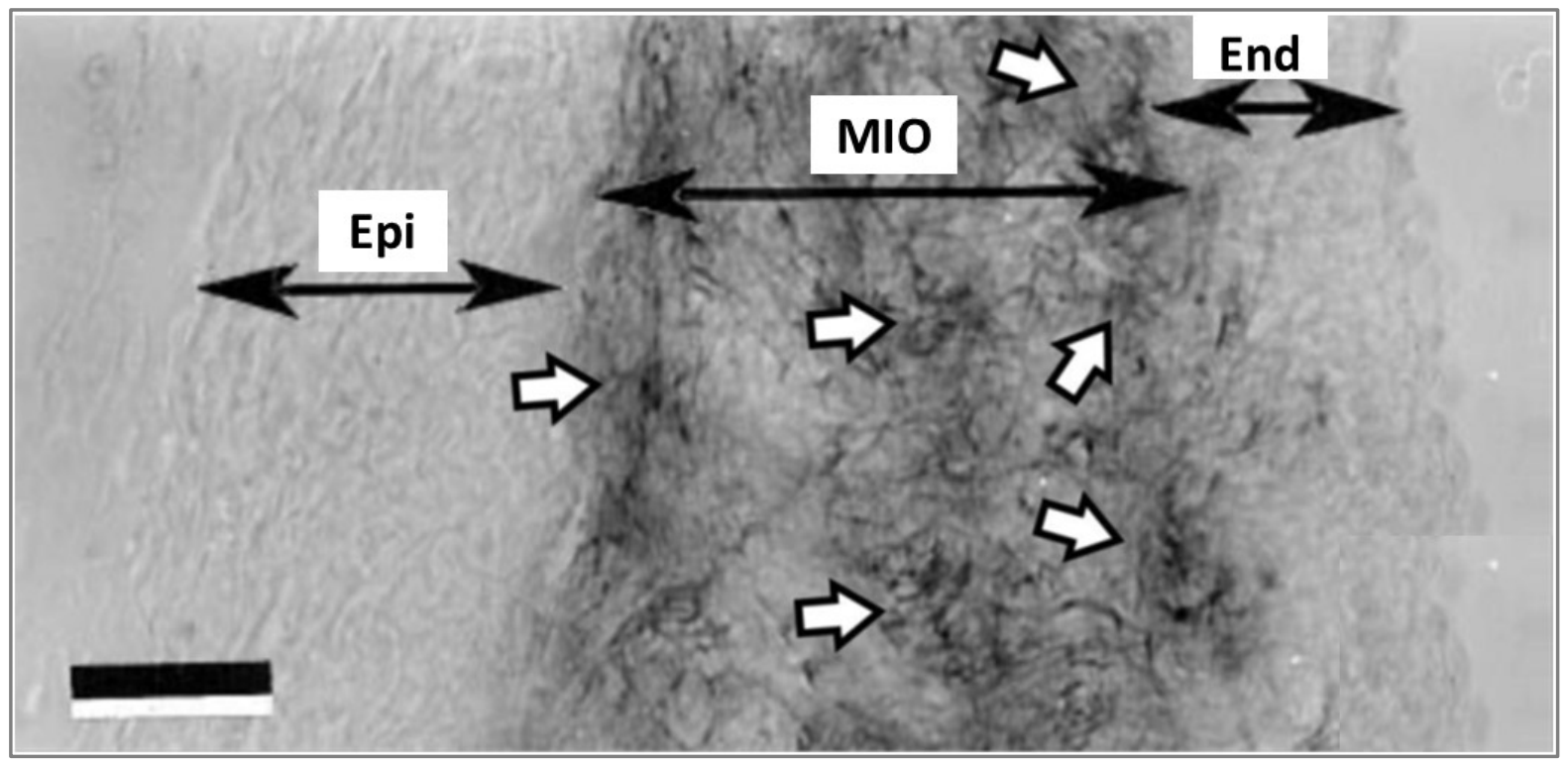

Microfotografias de cortes transversais de parede atrial direita canina adulta. Epi: epicárdio; Mio: miocárdio; End: endocárdio. As zonas escuras na fotografia representam neurônios corados por método histoquímico para a acetilcolinesterase. As setas brancas indicam fibras neurais e aglomerados

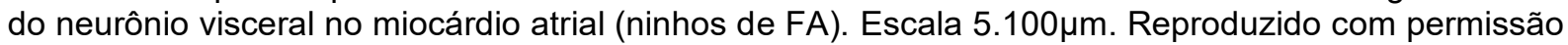
de Pauza et al. ${ }^{30}$. 
Figura 8 - Ninhos de FA vistos por microscopia da parede atrial.

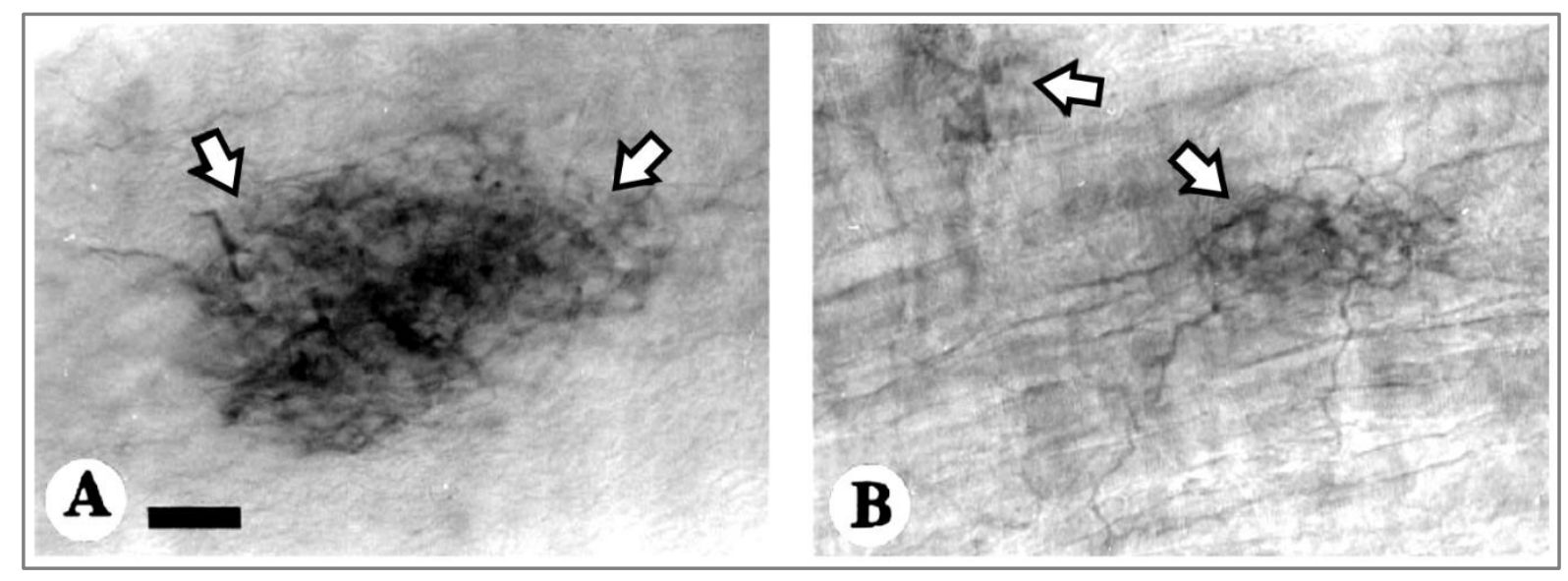

Exemplos de aglomerados do neurônio na parede atrial (ninhos de FA - setas brancas), no endocárdio atrial direito canino (A) e miocárdio (B), que foram corados por imuno-histoquímica da acetilcolinesterase (aqui demonstrados em tons de cinza). Escala $550 \mu \mathrm{m}$ para A, B. Reproduzido com permissão de Pauza et al. ${ }^{31}$.

\subsection{Plexos Ganglionares Paracardíacos}

Diferentemente dos neurônios simpáticos e sensoriais, os neurônios parassimpáticos pós-ganglionares estão localizados no coração. Além da localização intramural nas paredes atriais, Figura 7 , muitos neurônios parassimpáticos pósganglionares reúnem-se em gânglios paracardíacos, que podem variar em número de três a sete, sendo quatro os mais importantes $32,33,34,35,36$, Figura 9:

a) gânglio 1, localizado entre a veia cava superior e a raiz aórtica, logo acima da veia pulmonar superior direita;

b) gânglio 2, localizado entre a veia pulmonar superior direita e o átrio direito;

c) gânglio 3, localizado entre a veia cava inferior e o átrio direito / esquerdo e

d) gânglio 4, localizado na base da veia pulmonar superior esquerda. 
Figura 9 - Representação esquemática da localização anatômica habitual dos quatro principais gânglios parassimpáticos paracardíacos.

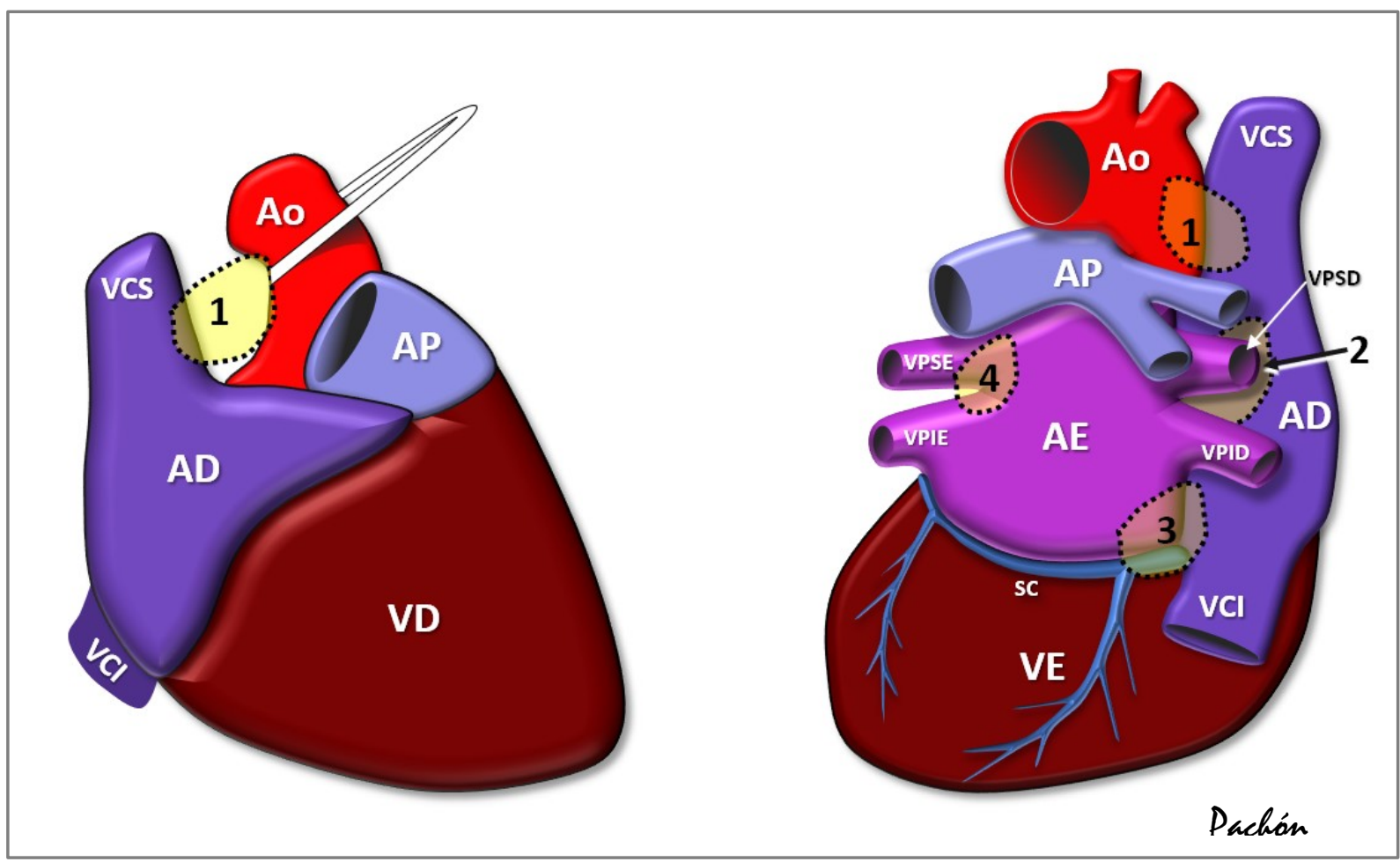

AD: Átrio Direito, VPSD: Veia Pulmonar Superior Direita; VPSE: Veia Pulmonar Superior Esquerda; VPID: Veia Pulmonar Inferior Direita; VPIE: Veia Pulmonar Inferior Esquerda; VCS: Veia Cava Superior; VCl: Veia Cava Inferior; Ao: Aorta; AP: Artéria Pulmonar; VD: Ventrículo Direito; VE: Ventrículo Esquerdo; AE: Átrio Esquerdo, AD Átrio Direito; SC: Seio Coronário. Fonte: Arquivo SEMAP.

As regiões das paredes atriais superpostas a estes gânglios, tipicamente apresentam maior número de NFA. Nestes pontos, a RF aplicada no endocárdio pode chegar a estes gânglios, devido à íntima relação dos mesmos com as paredes atriais, as quais têm pequena espessura, principalmente quando utilizados cateteres irrigados que atingem maior profundidade ${ }^{37}$.

Já no estudo inicial foi descrito que na CNA, além da ablação dos NFA, também deve ser aplicada RF nas regiões correspondentes dos principais GPs, orientada anatomicamente. Estas aplicações devem ser mais prolongadas, aproximadamente de um minuto, com objetivo de atingir maior profundidade, chegando até o epicárdio ${ }^{9}$, Figura 10. 
Figura 10 - Proximidade dos gânglios paracardíacos com a parede atrial

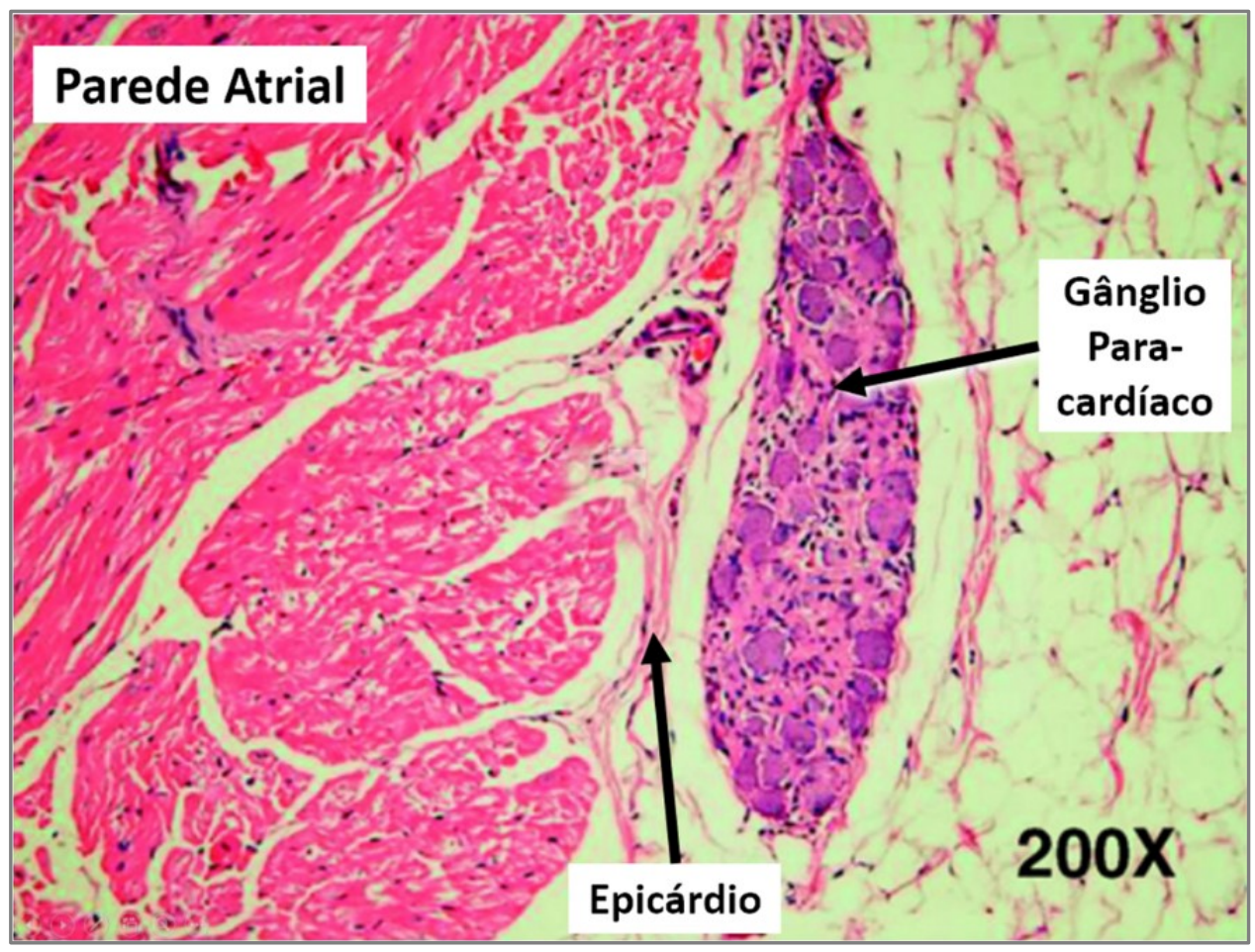

Corte histológico experimental em coração de cão. Verifica-se que o plexo ganglionar está justaposto diretamente ao epicárdio, podendo ser atingido pela energia térmica da RF aplicada no endocárdio. Fonte: Cui B, et al., $2011^{9}$.

Deste modo, é fundamental o uso de eletrodos de RF com grande superfície ou, preferivelmente, eletrodos com irrigação, cujas lesões podem atingir maior profundidade (10 a $15 \mathrm{~mm}$ ), suficiente para transpor a parede atrial e atingir os $\mathrm{GPs}^{37}$, Figura 11-A. Mesmo que não haja lesão completa, a transmissão do calor até a superfície epicárdica pode ocasionar redução dos neurônios ganglionares, contribuindo para a atenuação vagal que é o objetivo maior da CNA. Uma prova contundente de que a energia de RF endocárdica atravessa as paredes atriais, e pode lesar estruturas epicárdicas e torácicas, foi descrita por outros autores como a ocorrência de lesão da parede do esôfago nas aplicações de RF na parede posterior do $A E$ ou nas veias pulmonares superpostas a esta víscera ${ }^{38}$. Infelizmente esta lesão pode ocorrer durante ablações convencionais quando a RF é aplicada sem medidas de proteção do esôfago podendo levar à temida complicação da fístula atrioesofágica, Figura 11-B. A prevenção desta complicação levou ao desenvolvimento de métodos de segurança com o desvio do esôfago durante a ablação de FA e de feixes anômalos posteriores $^{39}$. 
Figura 11 - Profundidade da lesão de RF.

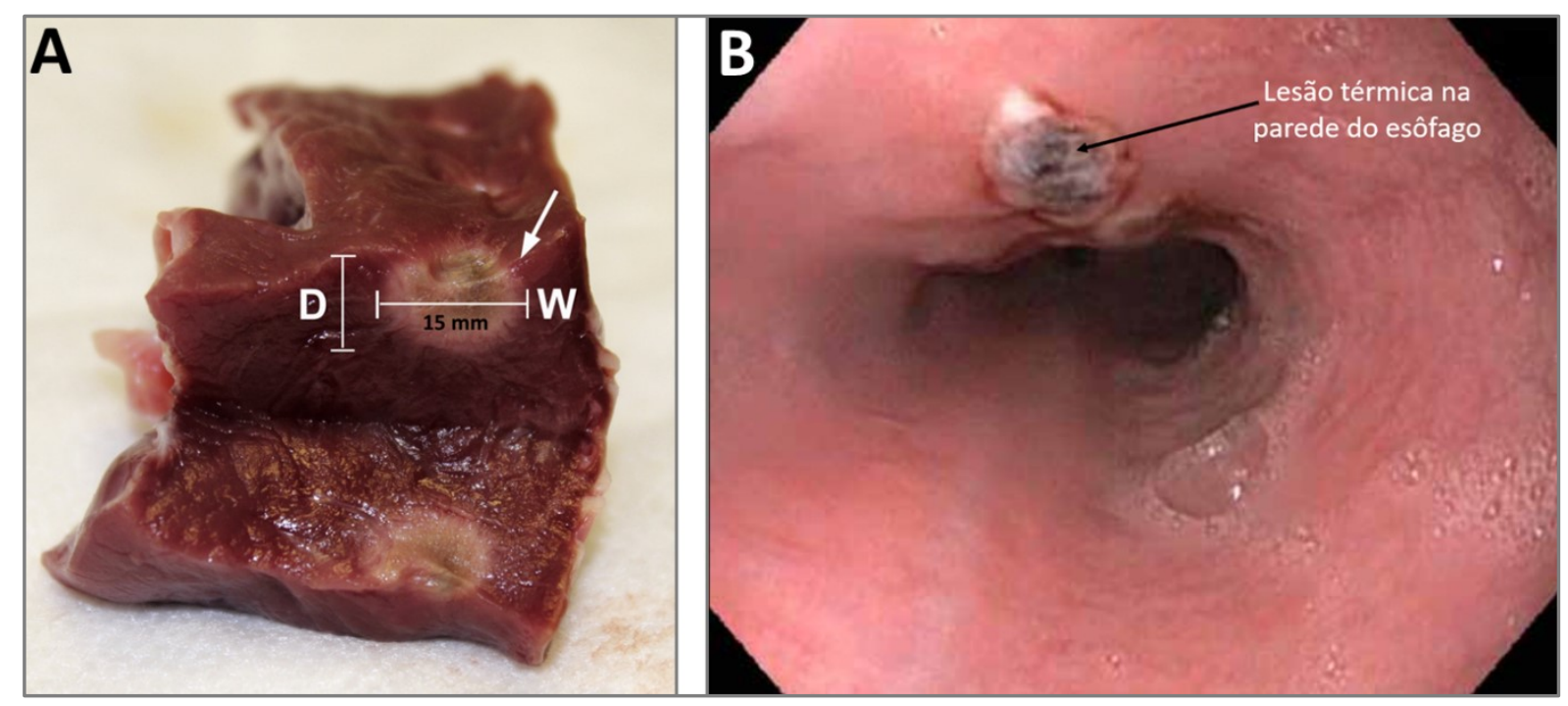

A: Com os modernos cateteres irrigados é possível obter lesões com 10 a $15 \mathrm{~mm}$ de profundidade, extensão suficiente para transpor a parede atrial e atingir os plexos ganglionares. Neste estudo experimental, utilizando coração de porco, observa-se que a lesão pode atingir profundidade de 10 a $15 \mathrm{~mm}^{37}$. B: Caso da literatura mostrando uma lesão térmica da parede anterior do esôfago vista por endoscopia, a partir do lúmen da víscera, num paciente de 69 anos, queixando-se de disfagia um dia após ablação das veias pulmonares ${ }^{38}$. Fonte: A: Calzolari V, et al., 2017³; B: Chavez P, et al., $2015^{38}$.

\subsection{Identificando a Interface Neuromiocárdica}

Além do mapeamento espectral, recentemente têm sido descritas técnicas adicionais de mapeamento da interface neuromiocárdica, tais como: estimulação neural endocárdica com alta frequência, cintilografia com Medicina Nuclear ou Tomografia Computadorizada, etc. Entretanto, do ponto de vista prático, o mapeamento dos NFA e a abordagem anatômica dos plexos ganglionares, descritos no estudo original ${ }^{4}$, parecem ser bastante satisfatórios e de grande praticidade, tendo sido reproduzidos por outros autores ${ }^{6,10,18,24}$. Os NFA podem ser identificados pelo polígrafo convencional, Figura 12, entretanto a falta de disponibilidade de bandas de frequência nos filtros e a reduzida taxa de amostragem da maioria dos polígrafos existentes em nosso meio dificultam a identificação pormenorizada destes sinais. Por outro lado, a análise espectral independente não sofre este tipo de interferência, sendo mais acurada e específica. 
Figura 12 - Mapeamento dos Ninhos de FA.

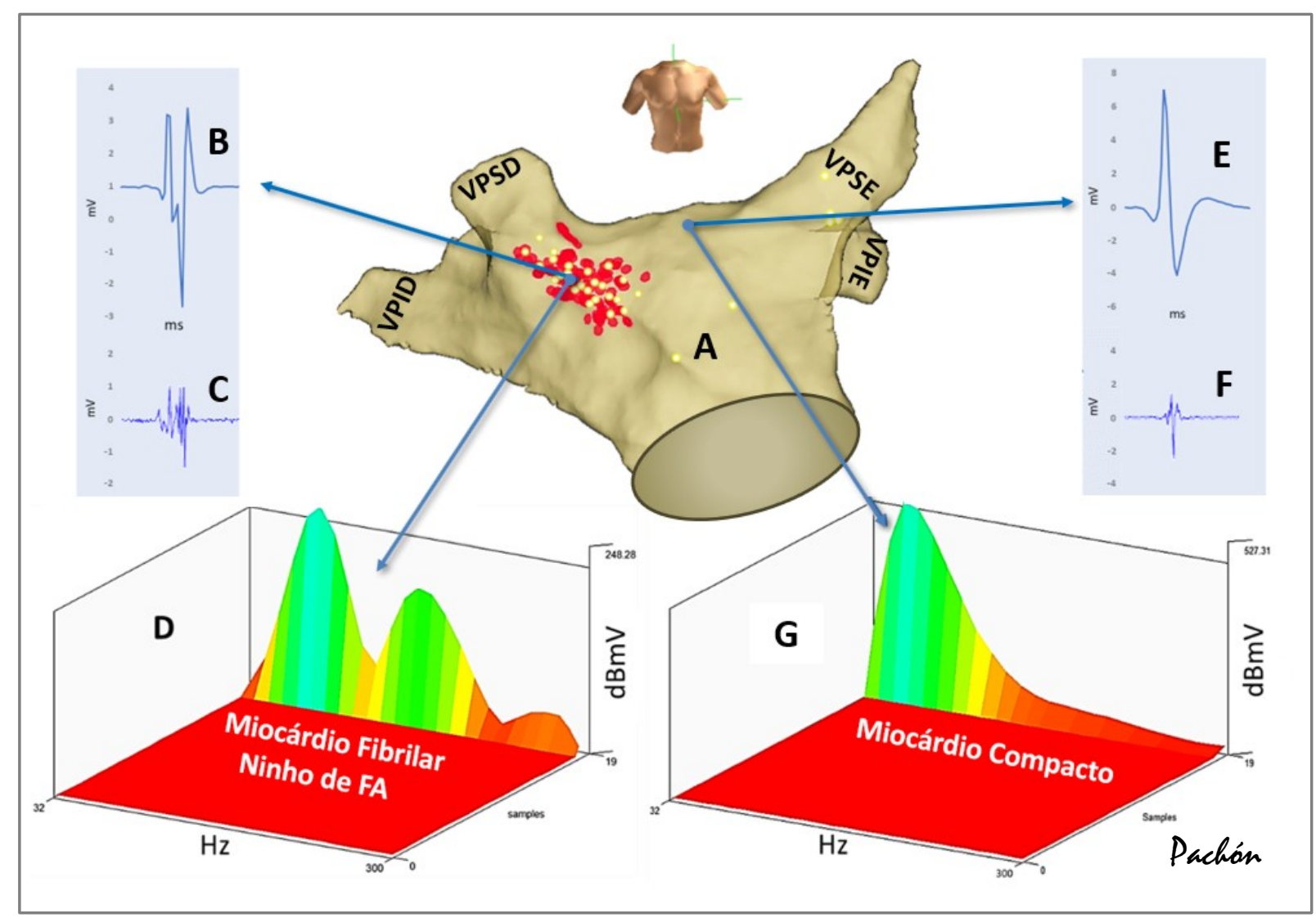

A: Modelo eletroanatômico do átrio esquerdo em OAE. Os pontos vermelhos são locais tratados com $\mathrm{RF}$; B: Registro do polígrafo com filtro convencional em área próxima à VPSD; C: Mesmo sinal anterior com filtro entre 300 e $500 \mathrm{~Hz}$; D: Espectro desse mesmo sinal típico de NFA; E: Registro do polígrafo com filtro convencional em região septal alta; F: Mesmo sinal anterior com filtro entre 300 e $500 \mathrm{~Hz}$; G: Espectro desse mesmo sinal típico de músculo compacto. Observar que usando o filtro passa-banda entre 300 e $500 \mathrm{~Hz}$ é possível identificar os NFA pelo sinal do polígrafo, mesmo sem utilizar o espectrômetro. Fonte: Arquivo SEMAP.

\subsubsection{Efeito da Radiofrequência sobre os NFA}

A aplicação de RF sobre os NFA promove alterações significativas sobre o potencial intracardíaco e consequentemente sobre o espectro desse sinal observado pelo espectrômetro. Na Figura 13, podemos observar os espectros do miocárdio compacto $(A)$ e do miocárdio fibrilar (B - NFA). Pode-se notar que as frequências altas neste último, acima de $80 \mathrm{~Hz}$, apresentam grande segmentação, ao contrário do músculo compacto cujo espectro é mais homogêneo, com decaimento progressivo da potência sem interrupções significativas. A aplicação de RF sobre os NFA promove uma atenuação de todo o espectro, com desaparecimento preferencialmente das altas frequências, acima de $80 \mathrm{~Hz}$. Este efeito é altamente desejável já que promove a 
eliminação das células desconectadas eletricamente e preserva as que têm comportamento sincicial, reduzindo a ressonância elétrica presente nos NFA. No caso dos NFA relacionados à penetração da inervação, a aplicação de RF elimina os cardiomiócitos desconectados, assim como os microneurônios parietais e as terminações neurais, promovendo a denervação que é o objetivo do procedimento nos casos selecionados.

Figura 13 - Espectro do músculo compacto e do músculo fibrilar.

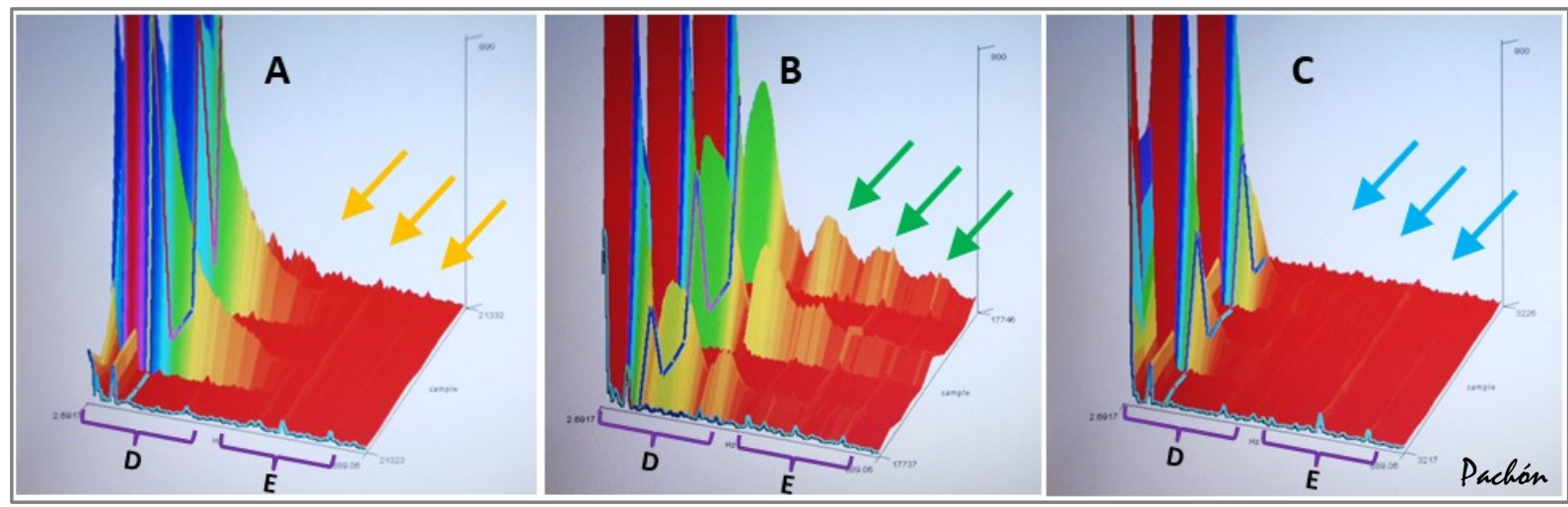

Imagens do espectro do músculo compacto (A) e do músculo fibrilar [NFA] (B). O músculo compacto tem espectro contínuo ao contrário do fibrilar que apresenta espectro segmentado principalmente acima de $80 \mathrm{~Hz}$ (setas amarelas $\mathrm{x}$ setas verdes). Em C, podemos observar o resultado do NFA mostrado em $B$, após a aplicação de radiofrequência. As altas frequências são eliminadas (setas azuis), tornando o espectro do NFA semelhante ao do músculo compacto. D sinaliza a área do espectro com baixas frequências e $E$ com as frequências maiores. Fonte: Arquivo SEMAP.

\subsection{Denervação Vagal}

A denervação vagal proposta pela CNA é realizada por via endocárdica, por meio da ablação por cateter, utilizando radiofrequência nos NFA e nas regiões anatômicas que correspondem aos GPs. Uma outra opção é a retirada cirúrgica dos GPs, entretanto esta técnica, além de ser muito invasiva, não elimina os neurônios pósganglionares intramurais não sendo suficiente para este propósito ${ }^{11}$.

A aplicação endocárdica de RF pode atingir 5 a $15 \mathrm{~mm}$ de profundidade ${ }^{40}$ de modo a eliminar boa parte dos neurônios pós-ganglionares parietais e ganglionares epicárdicos. Além dos neurônios pós-ganglionares parassimpáticos, são também 
eliminadas fibras simpáticas e sensoriais, porém estas últimas recuperam-se já que o corpo neural está longe do efeito da RF, Figura 14.

Figura 14 - Esquema da ablação autonômica endocárdica baseada nos NFA e plexos ganglionares.

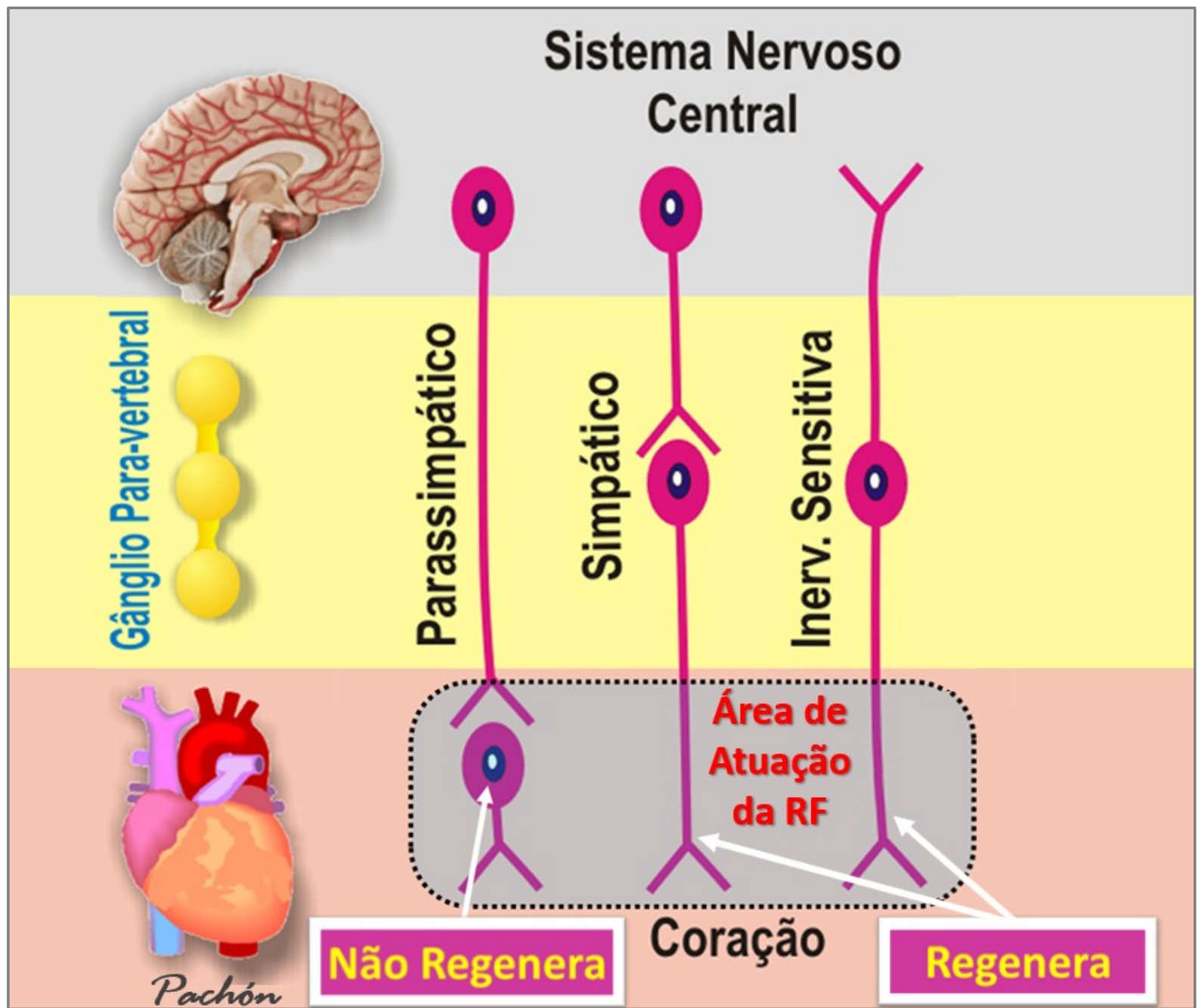

Os corpos neurais simpático e sensorial estão localizados longe do coração, na cadeia simpática paravertebral, e no sistema nervoso central. A aplicação de RF no endocárdio atrial elimina o corpo neural parassimpático pós-ganglionar e fibras simpáticas e sensoriais. Considerando que, ao contrário dos corpos neurais, estas últimas recuperam-se em semanas ou meses, o resultado predominante é essencialmente uma denervação parassimpática seletiva. Neste fato baseia-se a denervação terapêutica (CNA). Devido à eliminação do corpo neural parassimpático, a reinervação parassimpática é bastante atenuada. Fonte: Pachón et al., $2005^{1}$.

A profundidade da lesão da RF depende: da quantidade de energia aplicada, das características do cateter, da pressão que este exerce sobre o endocárdio, da superfície de contato e da presença de irrigação. 
Na Figura 15, pode-se observar em cortes histológicos corados por duas técnicas diferentes, como a aplicação de RF na parede atrial é capaz de produzir lesões significativas sobre os gânglios neurais parietais, os quais se tornam praticamente inexistentes ${ }^{22}$.

Figura 15 - Avaliação histológica de gânglios neurais cardíacos antes e após a ablação.

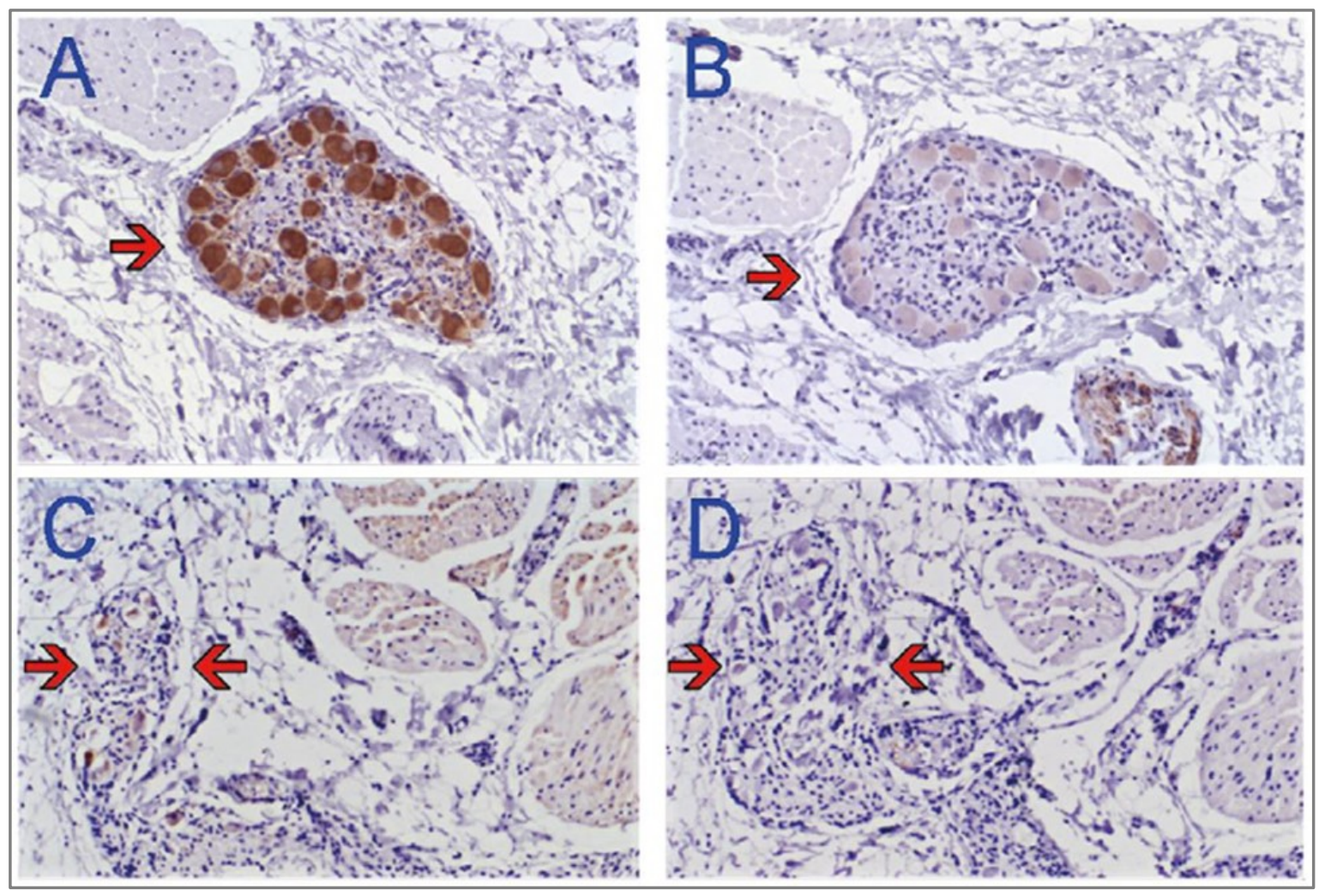

Exemplos de estudos histológicos corados com colina-acetiltransferase (A) e tirosina-hidroxilase (B), retirados de coração de cães-controle, mostrando gânglios neurais normais. $C$ e $D$ são fragmentos corados com a mesma técnica, após a ablação por RF dos gânglios, demonstrando significativa lesão sobre os mesmos. Fonte: Chang, $\mathrm{HY}$ et al. ${ }^{22}$

Com o propósito de atingir os corpos celulares mais distantes do endocárdio, rotineiramente, o cateter irrigado é utilizado para a ablação. Este cateter apresenta uma via de irrigação que impede a formação de trombos/coágulos na sua ponta, ao mesmo tempo que refrigera o entorno da ponta do cateter, por meio da infusão de solução salina. Como a RF aplicada diminui com o aumento da temperatura do tecido, que é detectada pelo termômetro localizado no eletrodo distal do cateter, o 
resfriamento da ponta permite aplicar maior quantidade de energia para atingir a temperatura desejada, aprofundando mais a lesão.

\subsection{Validação da Denervação Vagal}

\subsubsection{Estimulação Vagal Extracardíaca}

Qualquer técnica de denervação vagal deve ser acompanhada de validação e confirmação rigorosas. Diversas tentativas têm sido feitas com estimulações localizadas endocárdicas, porém com limitações bem conhecidas, pois a inervação vagal é muito extensa e variável nas paredes atriais. Além do mais, na tentativa de estimular a inervação na parede atrial, facilmente pode-se induzir fibrilação atrial, após a qual, somente a condução AV pode ser avaliada, já que a função sinusal torna-se encoberta pela fibrilação. Estimulações feitas diretamente sobre o nervo vago dependem de dissecção cirúrgica desta estrutura, sendo viáveis apenas em aplicações experimentais. Por conta disto, a estimulação vagal extracardíaca (EVEC) foi desenvolvida para suprir essa necessidade, sendo realizada no tronco neural dos vagos direito e esquerdo, a partir do interior das veias jugulares internas, sem contato direto com os nervos ${ }^{27}$, Figura 16.

A EVEC:

a) é facilmente obtida;

b) é altamente eficaz;

c) é transitória;

d) não apresenta efeitos residuais;

e) pode ser repetida em procedimentos escalonados;

f) é amplamente reprodutível (ver vídeo: Indução de FA pela EVEC-01 [https://youtu.be/dOOrMT33BIA], vídeo: Indução de FA pela EVEC-02 [https://youtu.be/rrl6oUPmzWs] e vídeo: Reprodutibilidade da EVEC [https://youtu.be/vFZ4kkylLOc] na plataforma digital) e

g) permite estudo detalhado das inervações do nó sinusal e do nó AV, com estimulações dos nervos vagos direito e esquerdo respectivamente (vídeo: 
Estimulação do Vago Esquerdo gerando BAV [https://youtu.be/9e76grn Tpg8]).

Figura 16 - Esquema da estimulação vagal extracardíaca proposta pelos autores.

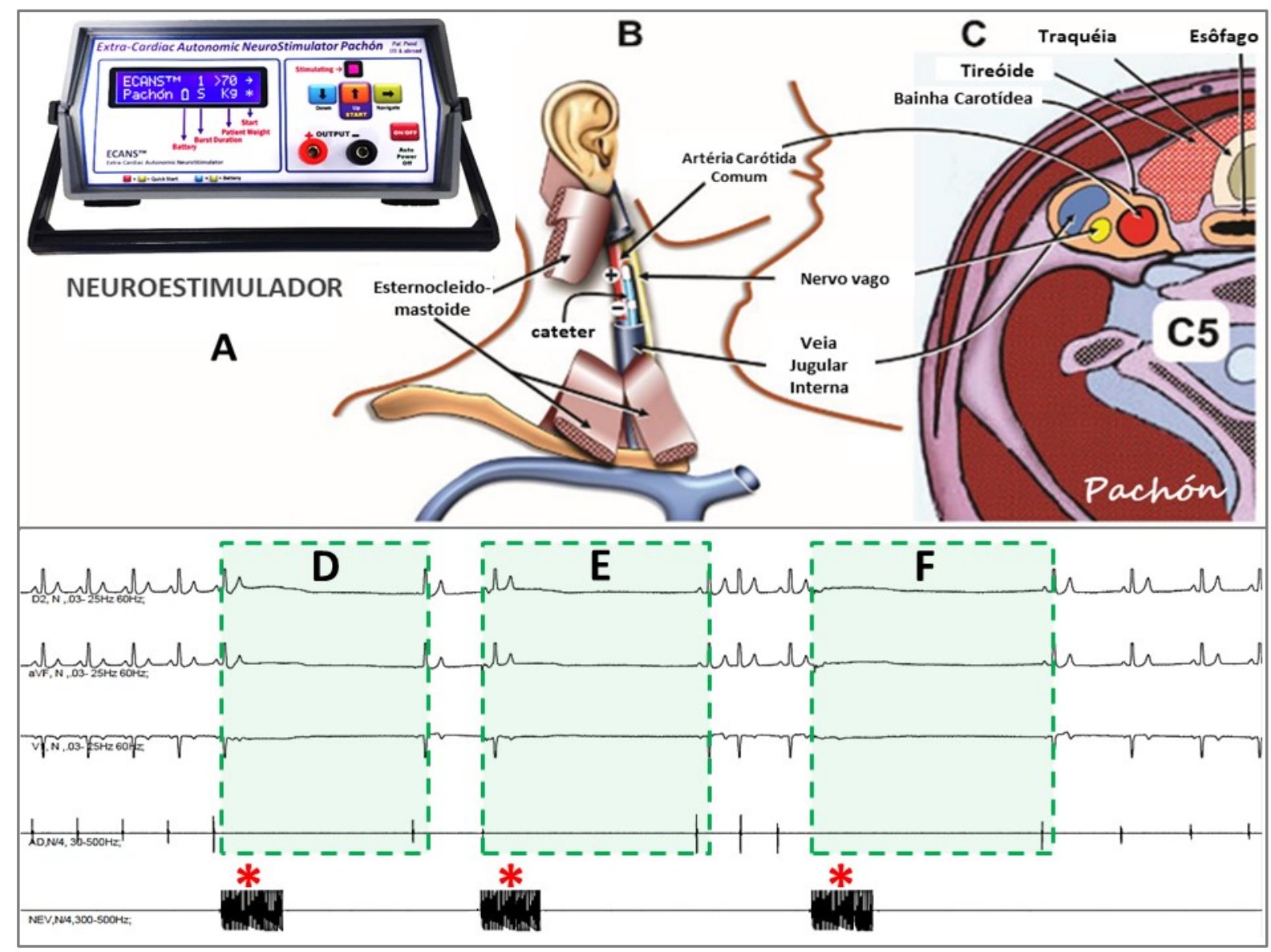

Acima: Esquema da estimulação vagal extracardíaca (EVEC), usada para detectar a integridade da inervação vagal pré-ablação e a denervação pós-ablação. A: Neuroestimulador; B: Posicionamento do cateter de estimulação no interior da veia jugular interna; C: secção transversa do pescoço mostrando a grande proximidade do nervo vago com a jugular interna e com a artéria carótida. Abaixo: Traçado mostrando a resposta cardíaca (assistolia D, E, F) e sua reprodutibilidade a cada estimulação neural de apenas $1 \mathrm{~s}(*)$. Fonte: Modificado de Pachón et al, 201527.

O fato de que as pausas ocorrem mediadas pelo vago pode ser comprovado pela ausência de pausas após a atropinização plena do paciente $(0,04 \mathrm{mg} / \mathrm{kg}$ até o máximo de 2,0mg), com total desaparecimento da resposta vagal, Figura 17.

Tendo-se em conta estes conceitos fundamentais, que visam ao mapeamento da inervação vagal através dos NFA e o controle da denervação pela EVEC, 
buscamos também confirmar a observação do estudo inicial sobre a relação entre os NFA e a inervação vagal, comparando os resultados com ablações fora dos NFA em um grupo controle.

Figura 17 - Validação da inervação vagal com a EVEC.

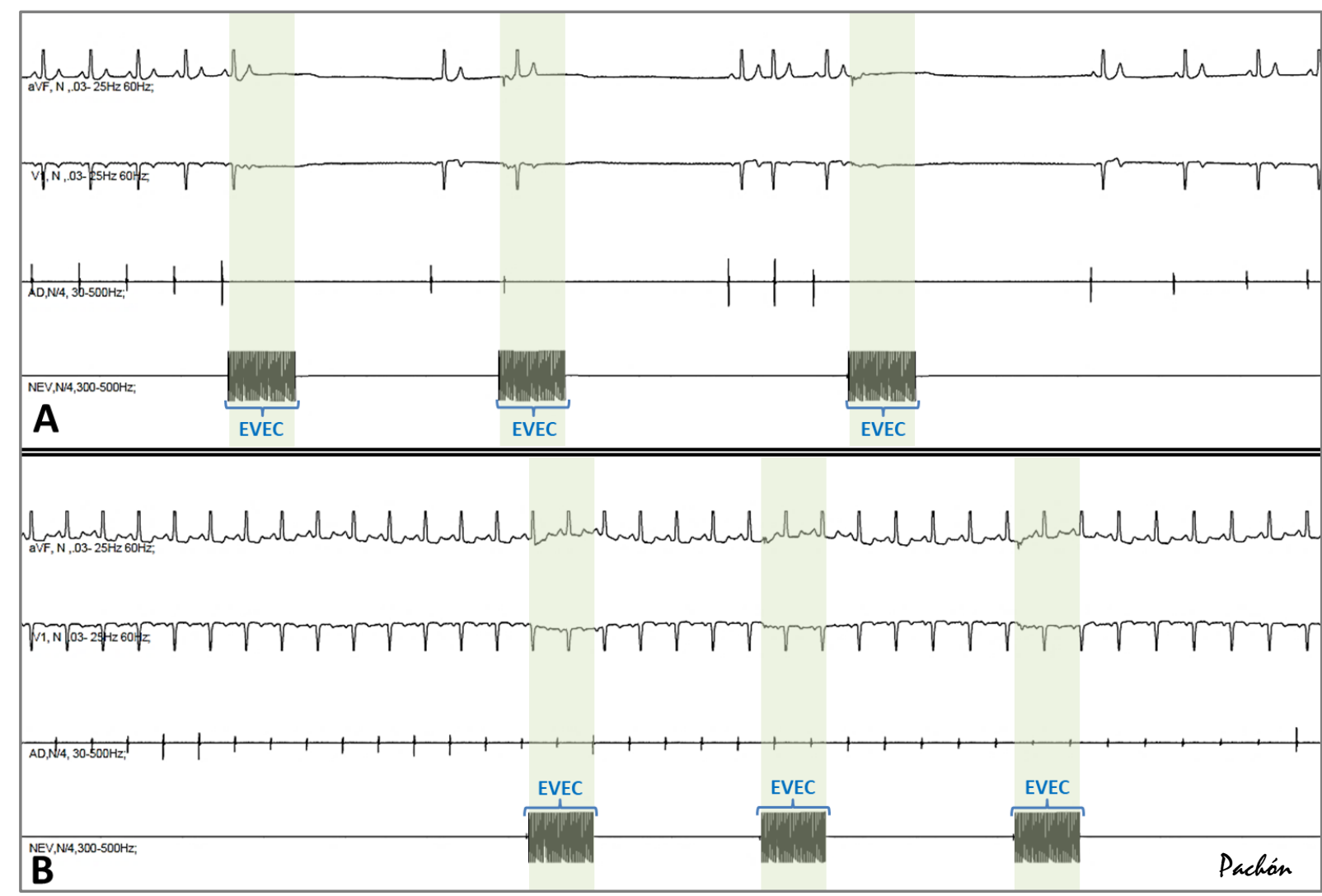

Exemplos de EVEC no mesmo paciente para validação da inervação vagal. Em $A$, são realizadas diversas estimulações vagais consecutivas de apenas $1 \mathrm{~s}$, para demonstrar a reprodutibilidade do método, com o aparecimento das pausas por parada sinusal. Em B, estimulação vagal idêntica foi realizada após atropinização plena do paciente $(2,0 \mathrm{mg} \mathrm{EV})$, não sendo mais possível reproduzir as pausas. Fonte: Arquivo SEMAP.

O desaparecimento da resposta vagal, após a atropinização plena, vem comprovar que as pausas ou bradicardia observadas com a EVEC são mesmo mediadas pelo vago, haja vista que a atropina é uma droga muito seletiva e potente para o bloqueio dos receptores muscarínicos do sistema parassimpático ${ }^{41}$. Uma das grandes vantagens da EVEC, além da sua seletividade, é o efeito transitório que perdura apenas por alguns segundos, permitindo que as estimulações sejam repetidas em alguns segundos, para controle escalonado da denervação. Esse efeito 
transitório decorre da alta velocidade de ação da acetilcolinesterase em degradar a acetilcolina, que é o neurotransmissor vagal em nível cardíaco ${ }^{42}$. Além disso, a ação vagal é predominante sobre a ação simpática, de tal forma que mesmo após a infusão de adrenalina ou isoprenalina a EVEC continua promovendo resposta vagal intensa sobre o coração, Figura 18.

Figura 18 - Comparação da EVEC antes e após a infusão de isoprenalina.

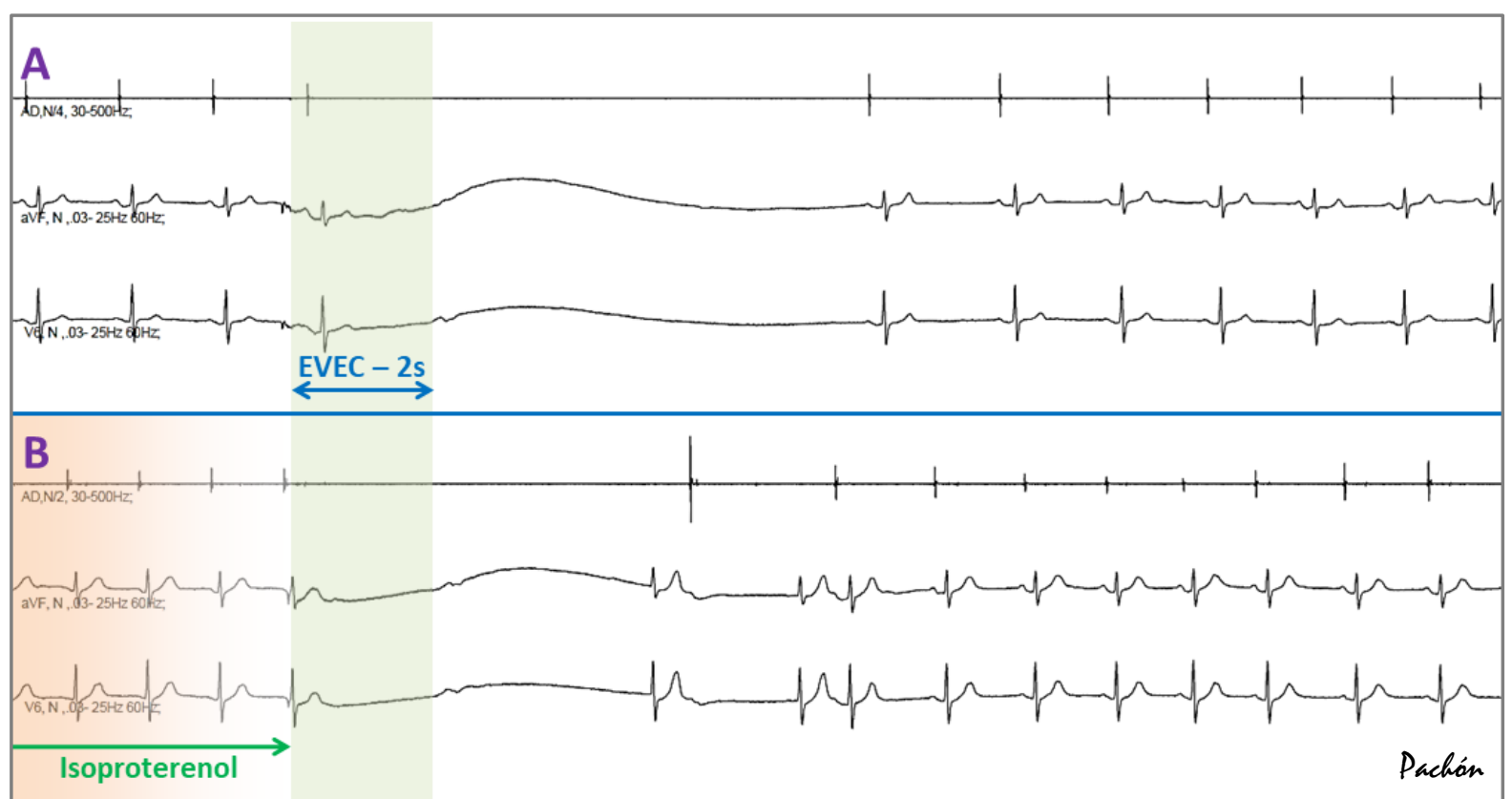

Traçados de polígrafo de paciente do GC, mostrando em A a resposta do ritmo cardíaco a uma EVEC de apenas $2 \mathrm{~s}$ (área sombreada verde). Ocorre uma parada sinusal total de $8 \mathrm{~s}$. Em B, a mesma EVEC foi aplicada após a infusão de isoprenalina $(0,3 \mu \mathrm{g} / \mathrm{kg})$. Nota-se intensa inibição sinusal pela ação vagal, apesar do estímulo beta, ocorrendo escape juncional e em seguida sinusal. Fonte: Arquivo SEMAP. 


\section{Justificativa}

Na década de noventa, foi criada a primeira técnica propondo a denervação vagal do coração como alternativa terapêutica para as bradiarritmias reflexas e funcionais ${ }^{1,4}$. O mapeamento da interface neuromiocárdica nas paredes atriais é primordial para o sucesso deste procedimento. O estudo inicial, que descreveu os $\mathrm{NFA}^{4}$, chama a atenção para diversas evidências que mostram a íntima relação destas estruturas com a inervação vagal. Desta forma, o mapeamento dos NFA poderia auxiliar no mapeamento da inervação vagal e, consequentemente, poderia ajudar a guiar a ablação da interface neuromiocárdica, contribuindo para obter a denervação vagal.

Entretanto, ainda não havia uma comprovação funcional específica da relação dos NFA com a inervação. O surgimento da EVEC, pelo fato de mostrar a ação vagal de forma imediata e objetiva, poderia contribuir demonstrando diretamente, mesmo durante o procedimento, o efeito da ablação dos NFA na ação vagal. Deste modo, caso os NFA sejam realmente relacionados à inervação vagal, espera-se que haja eliminação da ação vagal com a ablação dos mesmos. 
3 HIPÓTESE 


\section{Hipótese}

Os NFA estão relacionados com a inervação vagal do coração, assim sendo, a aplicação de radiofrequência sobre estes pontos produz denervação vagal, que pode ser avaliada e confirmada por meio da estimulação vagal extracardíaca durante o procedimento. 


\section{Objetivos}

\subsection{Objetivo Primário}

Avaliar a resposta vagal do coração por meio da estimulação vagal extracardíaca, antes e após a ablação dos NFA, identificados durante o mapeamento eletrofisiológico convencional, comparando os graus de denervação resultantes.

\subsection{Objetivos Secundários}

a) Avaliar se a estimulação vagal extracardíaca é reprodutível, confiável, específica e se pode ser utilizada como uma ferramenta adicional na Eletrofisiologia, e se apresenta algum efeito indesejável durante o período de acompanhamento dos pacientes.

b) Avaliar os locais onde a aplicação de radiofrequência resulta na modificação da inervação vagal do coração, permitindo criar um "mapa da cardioneuroablação", observando a reprodutibilidade destes locais nos diversos pacientes.

c) Avaliar a evolução clínica desses pacientes com este tipo de ablação dos NFA, controlada pela EVEC.

d) Verificar se as aplicações de RF em locais diferentes dos NFA produzem alteração da resposta vagal do coração identificada pela EVEC. 


\section{Casuística}

O estudo é prospectivo controlado, constituído por dois grupos: o "Grupo NFA" (GNFA) composto por pcts que foram submetidos à ablação para tratamento de fibrilação atrial vagal ou bradiarritmias funcionais, pela eliminação dos NFA e um "Grupo Controle" (GC) composto por pcts que foram submetidos a ablações convencionais por outras arritmias, que não envolvem o mapeamento e não são direcionadas à eliminação dos NFA. A identificação dos NFA, por não ser tema deste trabalho, foi pormenorizada no item 1.2.1 até 1.2.6 (págs 4 a 13). Todos os pacientes assinaram o termo de consentimento livre e esclarecido que está transcrito no Anexo D, (pág 109).

\subsection{Sigilo, Privacidade e Confidencialidade dos Dados Coletados}

Os dados coletados de cada pct durante o estudo são sigilosos e confidenciais, e permanecerão arquivados pelo autor do projeto por um período de cinco anos, e então serão incinerados, conforme resolução C.N.S. N. 196/96. Nesse período, os dados poderão ser solicitados pelos integrantes do Comitê de Ética em Pesquisa do IDPC/HCor para quaisquer consultas que sejam pertinentes.

\subsection{Seleção dos Pacientes}

\subsubsection{Critérios de Inclusão}

a) Grupo dos NFA: FA paroxística, persistente ou persistente de longa duração, com evidência clínica de relação com atividade vagal, a qual tenha indicação de ablação conforme a atual Diretriz Brasileira43;

b) Grupo controle: Pacientes encaminhados para ablação de arritmias não relacionadas aos NFA como: arritmias atriais, reentrada nodal, vias acessórias, flutter atrial, extrassístoles ventriculares e/ou taquicardia ventricular idiopática, também com indicação de ablação conforme a atual Diretriz Brasileira. 


\subsubsection{Critérios de Exclusão}
a) idade $<14$ anos;
b) discrasia sanguínea hemorrágica;
c) intolerância ou impossibilidade de uso de anticoagulantes;
d) presença de trombo intracavitário;
e) demais contraindicações para ablação de FA ou de outras arritmias;
f) ausência de resposta vagal na estimulação vagal inicial;
g) impossibilidade técnica de cateterização da veia jugular interna direita e esquerda;
h) fibrilação atrial permanente;
i) ausência de resposta à atropina nos casos de bradicardia funcional;
j) Presença de prótese mecânica em posição mitral;
k) Arritmias cujo foco de origem, pudesse estar relacionado com NFA no grupo controle;
I) recusa em assinar o termo de consentimento livre e esclarecido (TCLE).

\subsection{Tamanho da Amostra}

Devido à ausência de trabalhos pregressos semelhantes no momento da concepção desta tese, foi definido como 30 o número de pacientes que deveriam ser incluídos na fase inicial no GNFA. Este número estaria sujeito a modificações conforme a necessidade e avaliação estatística no decorrer do estudo. Para efeitos de comparação e análise estatística foi criado um grupo controle com o mesmo número de pacientes. Posteriormente, foram acrescidos mais pcts no GNFA que cumpriram os critérios de inclusão durante a formação do grupo controle.

\subsection{Grupo NFA}

A população-alvo deste grupo compreendeu pcts do Serviço de Arritmias SEMAP/HCor com diagnóstico de FA paroxística ou persistente (preferencialmente aqueles que apresentavam história de FA relacionada a estímulos vagais), com indicação de ablação por cateter de radiofrequência, de acordo com a Diretriz 
Brasileira atual ${ }^{43}$, respeitando-se os critérios de inclusão e exclusão do presente estudo. Considerou-se FA de origem vagal a FA induzida durante o sono, relacionada à alimentação (deglutição ou pós-prandial), ou à recuperação de esforços físicos, ou mesmo a que era induzida pela EVEC no início dos procedimentos. Neste grupo também foram incluídos pcts com bradicardia funcional (síndrome neurocardiogênica cardioinibitória), que poderiam ser beneficiados pela atenuação do tônus vagal.

\subsection{Grupo Controle}

A população-alvo deste grupo compreendeu pcts do Serviço de Arritmias SEMAP/HCor com diagnóstico de arritmias que não estavam relacionadas com os NFA, tais como: casos de arritmias atriais focais, reentrada nodal, vias acessórias, flutter atrial, extrassístoles ventriculares ou taquicardia ventricular idiopática, todos com indicação de ablação por cateter de radiofrequência, de acordo com a Diretriz Brasileira atual ${ }^{43}$, respeitando-se os critérios de inclusão e exclusão do presente estudo.

\subsection{Recrutamento}

O recrutamento de pcts começou em 12 de fevereiro de 2016 e terminou em 08 de agosto de 2016. Foi obtido consentimento informado por escrito de todos os casos, antes do procedimento, condição indispensável para inclusão no estudo. Foram distribuídos em portadores de FA e bradicardias funcionais (GNFA), com indicação de ablação dos NFA e em portadores de outras arritmias (GC), com indicação de ablação sem intervenção dirigida aos NFA.

Em ambos os grupos, os pcts apresentavam arritmias clinicamente comprovadas e sem controle clínico adequado com pelo menos dois antiarrítmicos, e com indicação de tratamento através da ablação por radiofrequência termocontrolada ${ }^{43}$. Os casos de bradicardia funcional também eram refratários ao tratamento clínico, com indicação de ablação por meio de radiofrequência aplicada sobre os NFA, conforme métodos publicados anteriormente ${ }^{1,44}$. 


\section{Métodos}

Todos os procedimentos foram realizados nos Laboratórios de Eletrofisiologia 4 e 5 da SEMAP, localizados no centro cirúrgico do HCor, Figura 19.

Figura 19 - Laboratório de Eletrofisiologia.

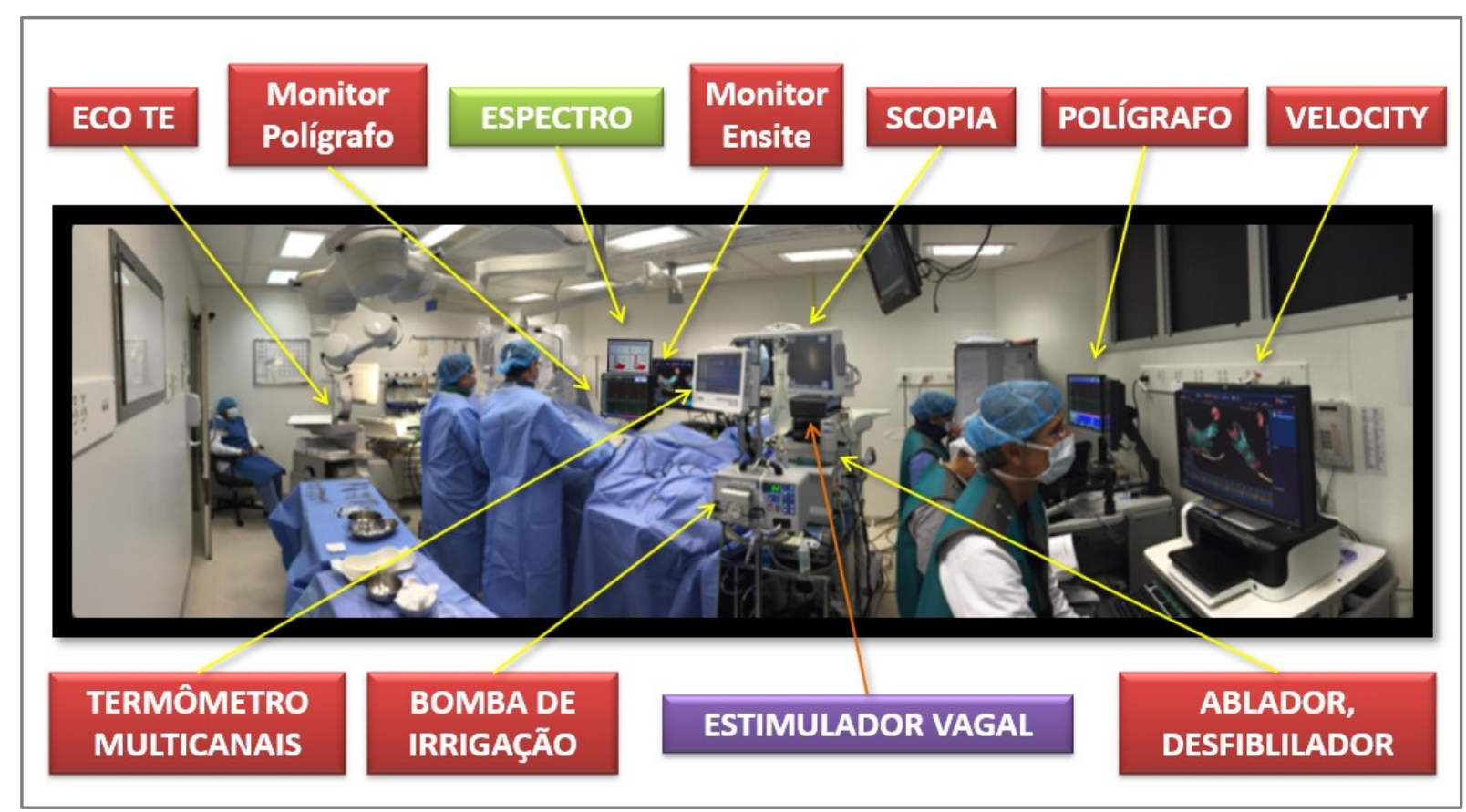

Laboratório de Eletrofisiologia do HCor, utilizado para realizar os procedimentos deste trabalho, com os principais equipamentos identificados. Fonte: Arquivo SEMAP.

\subsection{Grupo NFA}

Os pacientes do GNFA, após serem selecionados conforme os critérios mencionados e após terem assinado o TCLE, foram submetidos à ablação de acordo com a rotina deste procedimento em nossa equipe. 


\subsubsection{Rotina de Ablação de FA Utilizada Neste Trabalho}

a) todos os pacientes eram submetidos à anestesia geral endovenosa e intubação orotraqueal, sendo o nível da anestesia controlado por dados clínicos, hemodinâmicos e por meio da avaliação da atividade cerebral pelo índice BIS

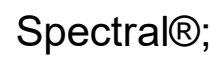

b) todos os fármacos parassimpaticolíticos, incluindo a atropina, eram proscritos com o intuito de impedir interferência na resposta vagal do coração;

c) o transdutor do ecocardiograma transesofágico (ETE) era colocado para: avaliação da presença de trombo, forame oval patente, alterações anatômicas que pudessem interferir no procedimento ou colocar o paciente em risco, e para desviar o esôfago para proteção térmica ${ }^{39}$. Este transdutor foi mantido no paciente durante todo o procedimento, sendo retirado ao final, após avaliação cardíaca e pericárdica;

d) preparo do polígrafo e do sistema de mapeamento eletroanatômico;

e) por meio de uma das punções femorais e sob radioscopia, um cateter quadripolar foi avançado pela veia cava inferior, $A D$, veia cava superior, até a veia jugular interna direita na região do forame jugular, sendo direcionado medialmente, para realizar a estimulação vagal (este procedimento está descrito pormenorizadamente no item 6.3 , página 41 );

f) o cateter quadripolar era mantido nesta posição para as estimulações vagais de controle durante a ablação;

Na sequência, foram realizados o mapeamento e a ablação dos NFA, conforme métodos anteriormente descritos ${ }^{1,4}$.

A ablação da FA era realizada em três etapas sequenciais:

a) eliminação dos NFA na inserção das veias pulmonares;

b) ablação dos NFA fora do antro das VPs (região septal posterior, septo atrial esquerdo e direito, região da crista terminalis, veia cava superior) e

c) ablação da taquicardia residual, quando induzida no final do procedimento

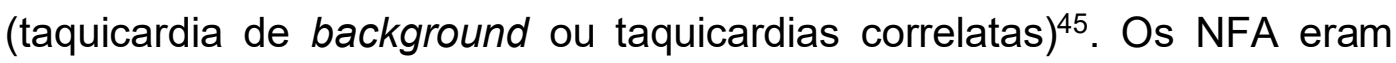
identificados pelo método simplificado e definidos como áreas da parede atrial com miocárdio fibrilar, com potenciais fracionados no domínio do 
tempo, na banda de frequência entre 300 e $500 \mathrm{~Hz}^{1,4,29,45}$. Um cateter duodecapolar era colocado no seio coronário. $O$ átrio esquerdo $(A E)$ era acessado por punção transeptal, utilizando-se a técnica padrão para este procedimento. Apenas uma punção transeptal era realizada para cada paciente e a bainha SL1 era usada para passar o cateter circular até o AE. $\mathrm{O}$ cateter de ablação era introduzido no $\mathrm{AE}$, cateterizando lateralmente o orifício da punção. As anatomias tridimensionais do átrio esquerdo e do átrio direito eram adquiridas pelo sistema Velocity ${ }^{\circledR}$. Heparina intravenosa $(100 \mathrm{Ul} / \mathrm{kg})$, era utilizada para manter o tempo de coagulação ativado de 300 a 400 s. A cada 20 minutos, um tempo de coagulação ativado era refeito, para manter rigorosamente o controle, sendo que doses adicionais de heparina eram administradas de acordo com a necessidade.

As imagens radiológicas exemplificando cada etapa dos procedimentos realizados no GNFA estão demonstradas na Figura 20.

As ablações eram essencialmente aplicadas na inserção das VPs e nos demais locais onde se obtiveram potenciais compatíveis com os NFA, tais como:

a) área do gânglio 2, pelo átrio esquerdo, entre as inserções das veias pulmonares direitas na direção do átrio direito, Figura 9 (pág 14);

b) ponto "P": ablação de toda a área triangular do septo interatrial esquerdo, compreendida entre a inserção das veias pulmonares direitas até o teto do átrio esquerdo e a punção transeptal",

c) antro das veias pulmonares. A eliminação completa dos NFA nestas regiões geralmente resulta no isolamento destas veias, efeito altamente desejável no GNFA, Figura 21;

d) NFA do teto do seio coronário, através do átrio esquerdo, visando à denervação adicional do gânglio 3 (região septal posterior do $\mathrm{AE}$ );

e) área do gânglio 1 (parte inferior medial da veia cava superior) alcançada pelo átrio direito;

f) área do gânglio 3 pelo átrio direito (parte superior medial da veia cava inferior até o óstio do seio coronário);

*Esta área de abordagem específica está descrita de forma completa na Figura 36 (pág 74). 
g) NFA localizados na superfície direita do septo interatrial e na crista terminalis;

h) após cada etapa a EVEC era repetida e a ablação da região do G4 era finalmente abordada de forma mais extensa nos casos em que persistia algum grau de resposta vagal.

Figura 20 - Sequência radiológica durante a ablação de paciente do GNFA.
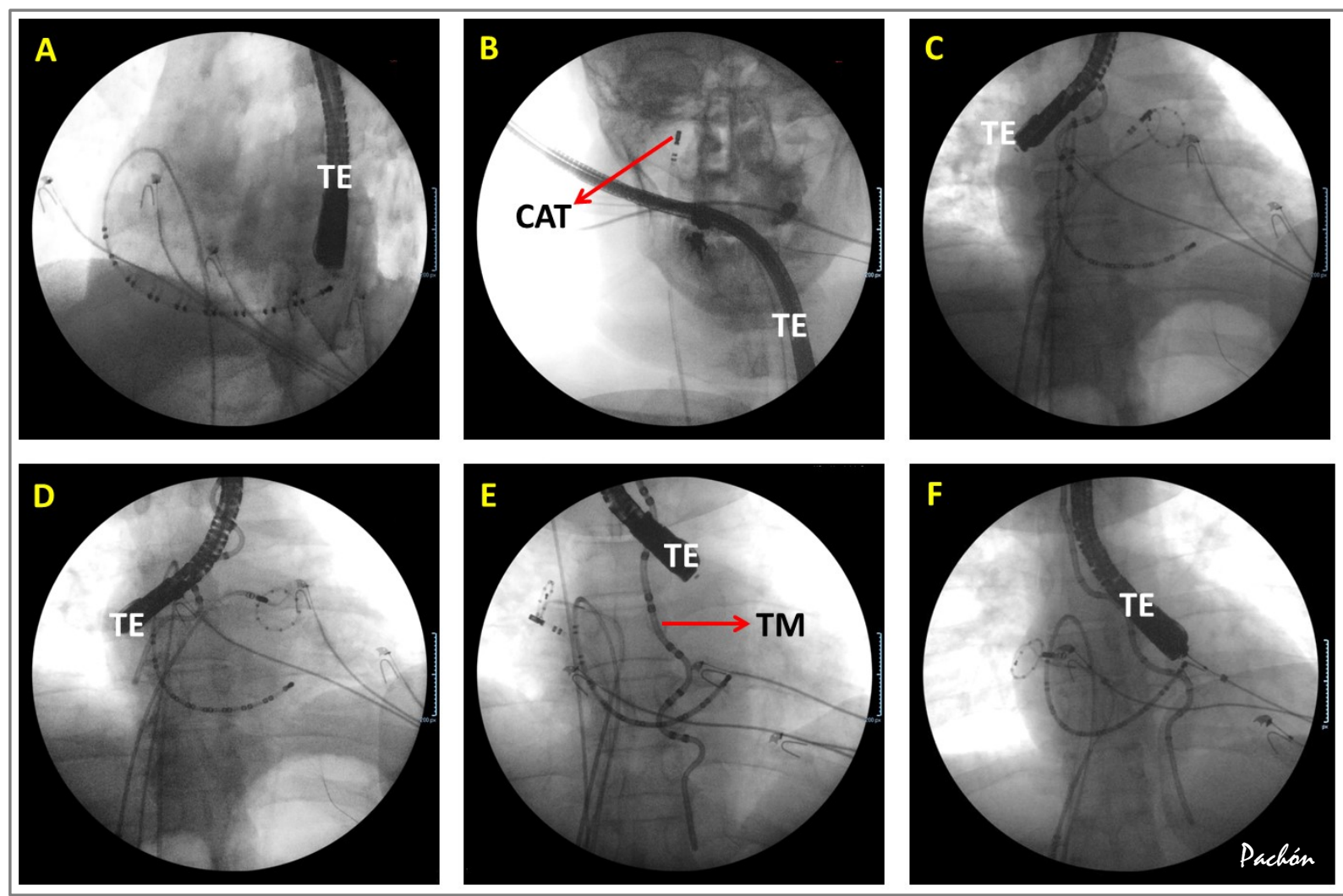

Sequência de imagens radiológicas obtidas durante a ablação de um paciente do GNFA, mostrando o método utilizado neste estudo. Em $A$, imagem em OAE, após cateterização do seio coronário com o cateter duodecapolar via veia femoral, técnica utilizada em todos os casos. Em B, posicionamento de um cateter na região do forame jugular à direita (CAT), para realizar a EVEC inicial. C, D, E e F são imagens mostrando o posicionamento do cateter circular em cada veia pulmonar (VPSE, VPIE, VPID e VPSD respectivamente). Observar adicionalmente que a sonda do ecocardiograma transesofágico (TE) era utilizada para desviar o esôfago e reduzir o risco de lesão térmica do mesmo pela radiofrequência ${ }^{46}$. A imagem do termômetro multipolar intraesofágico (TM) ajuda a avaliar o desvio do esôfago. Fonte: Arquivo SEMAP. 
Figura 21 - Isolamento das veias pulmonares

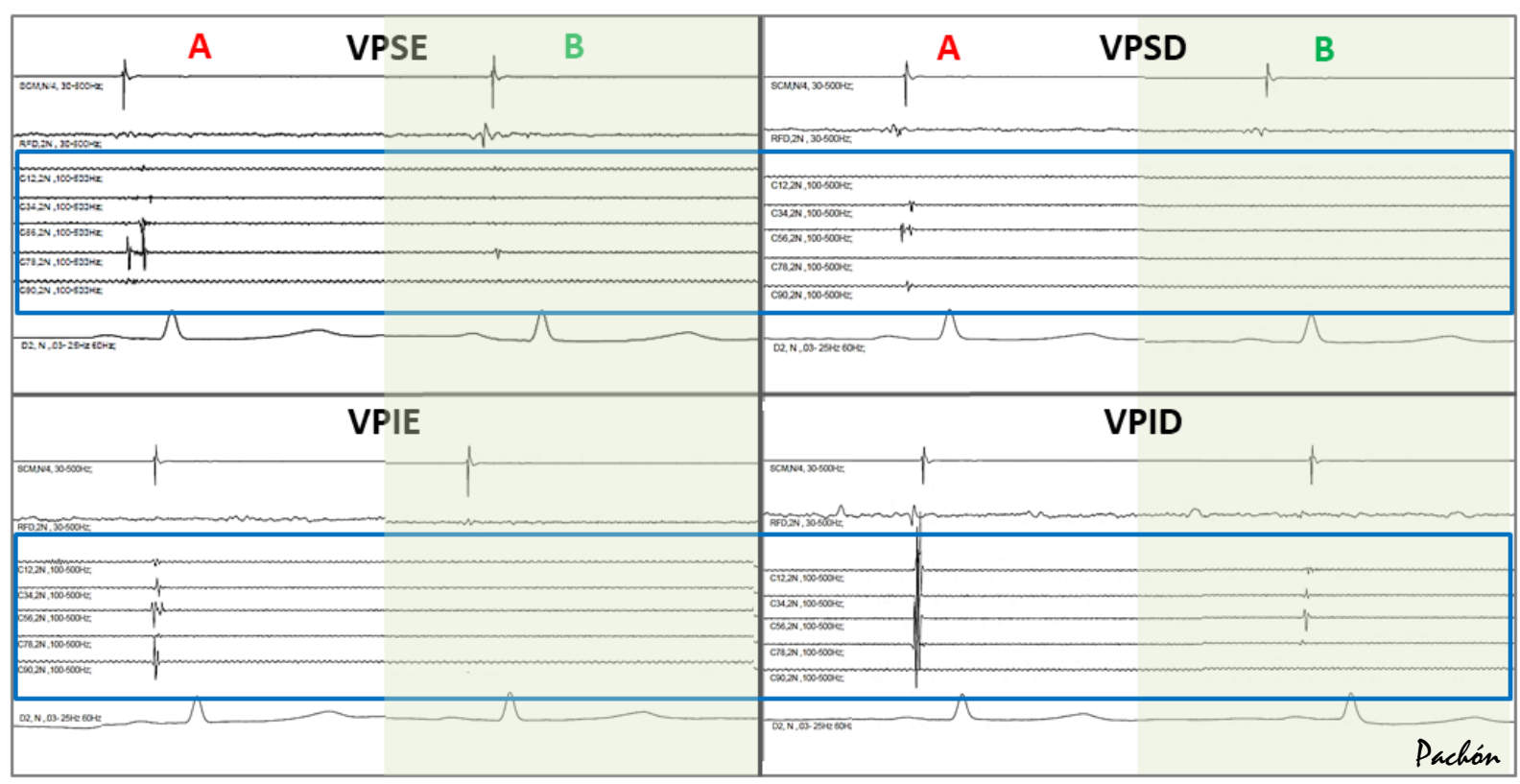

Sequência de traçados de polígrafo mostrando o método utilizado no GNFA. Em muitos casos ocorre o isolamento das veias pulmonares com a eliminação dos NFA no antro das VP's. Em A, estão os traçados antes do isolamento e, em B após o isolamento (área sombreada verde). $\mathrm{O}$ retângulo azul mostra os canais do cateter decapolar circular, por onde se pode confirmar o isolamento elétrico de cada veia. Fonte: Arquivo SEMAP.

Terminada cada etapa do procedimento, novas estimulações vagais eram realizadas com o cateter na mesma posição da EVEC inicial. Os pacientes eram mantidos internados e avaliados por $48 \mathrm{~h}$. No seguimento tardio eram reavaliados clinicamente aos 2, 6 e 12 meses e sempre que houvesse surgimento de algum sintoma ou fato novo.

\subsection{Grupo Controle}

Estes pacientes eram submetidos a uma ablação convencional para o tratamento de: arritmias atriais, reentrada nodal, vias acessórias, flutter atrial, extrassístoles ventriculares e/ou taquicardia ventricular idiopática. A abordagem transeptal não foi utilizada em nenhum caso deste grupo. Os portadores de feixes anômalos à esquerda ou de arritmias do ventrículo esquerdo tiveram esta cavidade abordada por cateterismo retrógrado, através de punção da artéria femoral direita. As ablações eram restritas à parede ventricular no caso das arritmias ventriculares e feixes anômalos, e em regiões atriais pontuais nos outros casos. Estas ablações não eram dirigidas aos 
NFA. Para certificar disto, os potenciais do cateter de ablação eram analisados no polígrafo após a filtragem em faixas de banda conforme descrito anteriormente e demonstrado na Figura 12 (pág 17). Da mesma forma que no GNFA, antes e depois das ablações, eram realizadas estimulações vagais por 5 s com registro das respostas.

\subsection{Estimulação Vagal}

A estimulação vagal era realizada com anestesia intravenosa com Propofol (Diprivan®), sob intubação endotraqueal e controle do índice BIS (avaliação do nível da anestesia por meio do índice espectral da atividade cerebral), utilizando-se a mesma rotina do preparo para a ablação da FA. As estimulações vagais bilaterais eram realizadas de forma idêntica, antes e após a ablação, em ambos os grupos, sendo os resultados registrados para comparação. Todas as estimulações eram aplicadas com o índice BIS entre 40 e 50, que permite anestesia adequada sem depressão autonômica significativa, buscando-se manutenção do tônus autonômico equivalente, em todas as avaliações, além de garantir conforto e segurança. $O$ índice BIS abaixo de 40 é acompanhado de maior depressão da atividade cerebral e autonômica e acima de 60 é indicativo de anestesia superficial, bem próximo do despertar $^{47}$.

A estimulação vagal era obtida gerando um campo elétrico endovascular criado na veia jugular interna, na altura do forame jugular, entre o polo distal e o terceiro polo de um cateter quadripolar, conforme demonstrado na Figura 16-B (pág 22) e disponível em vídeo na plataforma digital no link: Posicionamento do cateter [https:// youtu.be/5egPMmFb3mQ]. A estimulação entre o primeiro e o terceiro polo teve por objetivo aumentar as dimensões do campo elétrico, para permitir estimulação transvascular confiável à distância, sem contato direto com o nervo vago. Como a proximidade entre o nervo e o cateter na veia jugular interna pode ter alguma variação, utilizou-se uma energia de 0,5 a $1 \mathrm{~V} / \mathrm{kg}$ de peso corporal, limitada a $70 \mathrm{~V}$, com $50 \mathrm{~Hz}$ de frequência e largura de pulso extremamente reduzida, de 50 microssegundos $(\mu S)$. Apesar disto, o duty cycle e um limitador de corrente no circuito de saída são fundamentais para reforçar a segurança das aplicações. Estas características de estimulação permitem que se obtenha o campo elétrico necessário para capturar o nervo vago de forma remota, sem que haja qualquer lesão nos tecidos adjacentes. $O$ 
uso de campo elétrico propagado para estimulação à distância já é processo bem conhecido e utilizado em outros procedimentos, como no caso da cardioestimulação transesofágica, em que um cateter no lúmen do esôfago é capaz de capturar o átrio esquerdo ${ }^{48}$. As estimulações foram prévia e extensivamente testadas, num ensaio experimental para confirmar a segurança do procedimento (Anexo B - página 106; vídeo EVEC Experimental [https://youtu.be/fgmNxA1m0pU] e vídeo EVEC Experimental X Ablação [https://youtu.be/Vep0sGnolJw] na plataforma digital).

$\mathrm{Na}$ Figura 22 observamos uma imagem radiológica confirmando a posição do cateter na região onde se obtém a melhor estimulação vagal, tanto pela veia jugular interna direita, quanto pela esquerda.

Figura 22 - Imagem fluoroscópica durante EVEC.

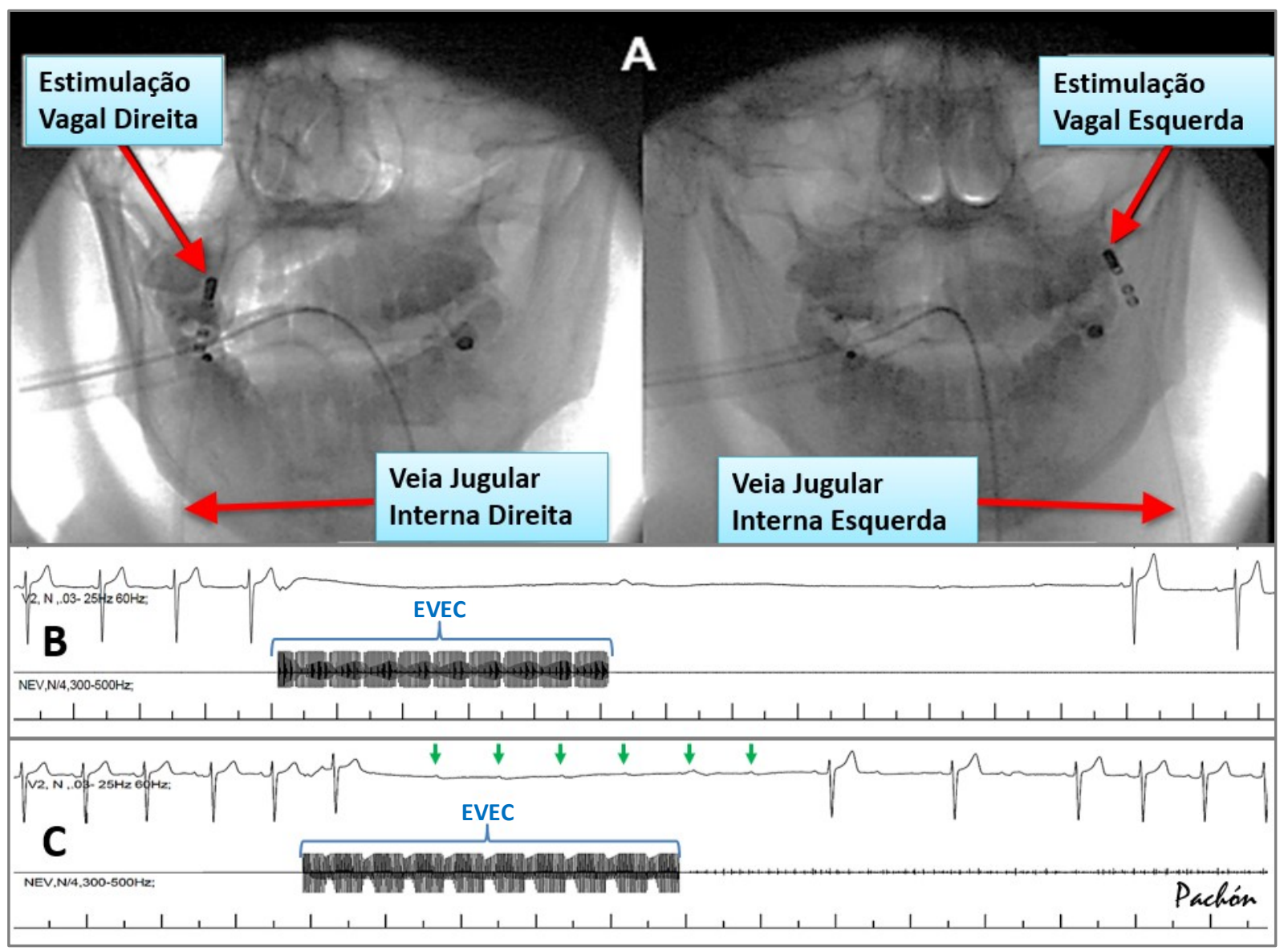

A: Imagem fluoroscópica da posição do cateter para estimulação vagal extracardíaca, através das veias jugulares internas direita e esquerda. Todas as estimulações vagais subsequentes foram realizadas repetindo posição radiológica idêntica. B: Exemplo de estimulação vagal direita e C: esquerda, mostrando a reprodutibilidade da pausa em ambas as jugulares. Neste caso, à esquerda observa-se bloqueio $\mathrm{AV}$ predominante (ondas " $\mathrm{P}$ " bloqueadas indicadas pelas setas verdes), enquanto que à direita ocorre preferencialmente a parada sinusal. EVEC: Estimulação vagal. Fonte: Arquivo SEMAP. 
Na mesma figura temos os registros eletrocardiográficos obtidos com a EVEC à direita e à esquerda, mostrando a resposta vagal cardíaca em ambas as estimulações. Também é possível observar que a EVEC à direita provocou uma parada sinusal enquanto que à esquerda, neste caso, promoveu predominantemente bloqueio AV transitório, ocorrendo várias ondas "P" bloqueadas. Este comportamento, com predomínio de ação na junção AV durante a EVEC à esquerda, é de grande valia para controle da denervação seletiva do nó $\mathrm{AV}$, nos casos de bloqueios $\mathrm{AV}$ funcionais.

A EVEC era realizada sempre por $5 \mathrm{~s}$. Eram realizados pequenos ajustes da posição do cateter, buscando sempre a maior cardioinibição (parada sinusal, bradicardia e/ou bloqueio AV), como demonstrado na Figura 17A (pág 23), e os melhores pontos de resposta eram marcados por fluoroscopia digital, para repetição sempre que necessário, e no final da ablação.

\subsection{Medida da Frequência Cardíaca Durante a EVEC}

Durante a EVEC a média da frequência atrial foi obtida contabilizando-se todas as ondas "P" ocorridas durante $15 \mathrm{~s}$ após o seu início, independentemente da ocorrência ou não de BAV. Este valor foi multiplicado por 4, para se obter a frequência atrial por minuto, Figura 23. O mesmo método foi utilizado para avaliar a frequência ventricular (a qual poderia ser diferente da atrial na presença de bloqueios $A V$ ) e, neste caso, contabilizando-se as ondas "R" no mesmo período de $15 \mathrm{~s}$. Esse método também foi utilizado para avaliar a frequência obtida durante a estimulação neural ao final dos procedimentos, tanto no GNFA como no GC. Este recurso evita a comparação de valores iguais a zero nas pausas longas, permitindo tratamento estatístico adequado. As pausas foram mensuradas sempre entre as duas ondas "R", a última logo após iniciar-se a EVEC e a primeira após a recuperação espontânea do ritmo, independentemente da onda " $\mathrm{R}$ " ter origem a partir de um ritmo supraventricular, juncional ou ventricular. 
Figura 23 - Método para medida da frequência cardíaca durante a EVEC.

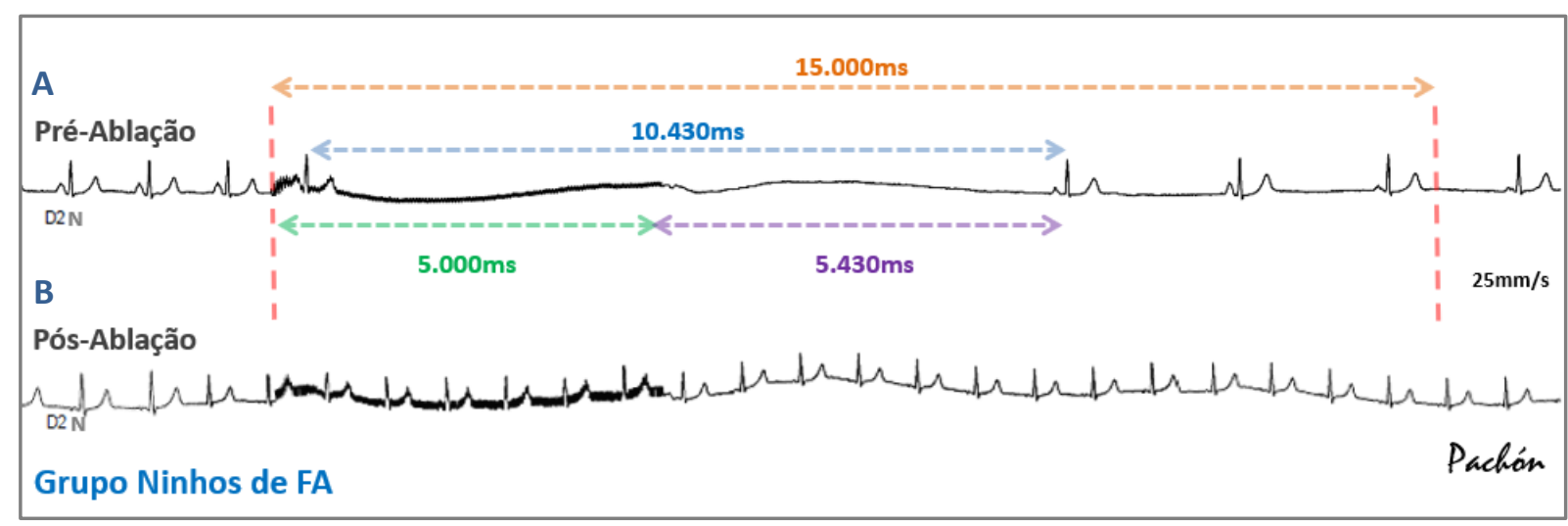

Traçados de paciente do GNFA antes (A) e após (B) a ablação dos NFA. A estimulação neural (linha verde) ocorre por $5 \mathrm{~s}$ e provoca uma pausa total de 10,4s (linha azul), obtida somando-se a pausa produzida durante a EVEC (5 s) e a pausa após a EVEC - Tempo de normalização vagal (TNV - linha roxa) de $5,4 \mathrm{~s}$. Após a ablação (B), a mesma estimulação neural não produz qualquer pausa ou bradicardia. As linhas verticais vermelhas delimitam o período (15 s) que foi utilizado para medir a média da frequência cardíaca resultante da EVEC. Neste exemplo, em A a FC $=16 \mathrm{bpm}$, pois há 4 complexos QRS em 15 s (4 QRS's x $4=16 \mathrm{bpm}$ ) e em B a FC = 76bpm (19 QRS's x $4=76 \mathrm{bpm})$. Fonte: Arquivo SEMAP.

\subsection{Materiais Utilizados Neste Estudo}

\subsubsection{Materiais Convencionais}

Os procedimentos eram realizados com cateteres irrigados ThermoCool [ (Johnson \& Johnson) ou Flexability ${ }^{\circledR}$ (Daig), cateter duodecapolar Daig ${ }^{\circledR}$, Boston Scientific $\circledast$ ou Medtronic $\circledast$, sistema de punção transeptal St Jude ${ }^{\circledR}$, agulha de punção transeptal Medtronic $₫$, cateter decapolar circular Irvine $\AA$, neuroestimulador especialmente desenvolvido para a estimulação vagal sem contato® (Patente provisória nos EUA número: US62485956 e Europa número: EP $3415196 \mathrm{~A} 1)^{49,50} \mathrm{e}$ outros recursos de suporte como: sistema eletroanatômico Velocity $®$, gerador de RF Medtronic Atakr ${ }^{\circledR}$ II ou Daig Ampère $\AA$, sistema de controle de nível anestésico espectral $\mathrm{BIS} \circledast$, estação de Anestesia Dräger $\circledast$, Ecocardiógrafo Transesofágico Phillips $®$, termômetro multipolar intraesofágico Circa $®$, estação de radiologia GE OEM® Elite 9900 e polígrafo eletrofisiológico TEB32® com estimulador cardíaco eletrofisiológico acoplado. Para que não ocorressem variações nas aplicações feitas neste estudo, todas as ablações foram realizadas com o mesmo tipo de cateter 
(irrigado - 3,5mm² de superfície) e com os mesmos dados de aplicação da RF e da irrigação, em ambos os grupos.

\subsubsection{Estimulador Vagal}

O estimulador vagal utilizado neste estudo apresenta as seguintes características: estimulação DC com pulsos de onda quadrada de 50 us de duração, frequência de $50 \mathrm{~Hz}$ e amplitude de 10 a $70 \mathrm{~V}$, ajustada de acordo com as características do paciente (1 V/kg até o máximo de 70V), Figura 16-A (pág 22). A duração extremamente curta do pulso, o duty-cycle reduzido $(0,25 \%)$ e a limitação da corrente foram empregados para prevenir qualquer possibilidade de lesão tecidual, o que foi comprovado experimentalmente (explicação pormenorizada no Anexo B - página 106). Além disso, uma função de temporizador permite a aplicação de trens de pulso com tempo prédefinido, entre 1 e 10 s no máximo. Foi convencionado para este estudo que os trens de pulso seriam sempre de $5 \mathrm{~s}$, para manter a uniformidade dos resultados, exceto quando se testava o posicionamento ideal do cateter, situação em que eram utilizados apenas $2 \mathrm{~s}$ de estimulação.

\subsection{Acompanhamento dos pacientes após a ablação}

No acompanhamento dos pacientes pelo período de 1 ano, foram considerados os seguintes possíveis eventos:

a) novas internações hospitalares após a alta;

b) complicações relacionadas com a lesão térmica do esôfago;

c) arritmias sustentadas, iguais ou diferentes das que foram tratadas;

d) pericardite, derrame pericárdico ou tamponamento tardio;

e) hematomas maiores (> $50 \mathrm{ml}$ ) ou pseudoaneurisma que necessitassem de intervenção (compressão guiada por ultrassom ou cirurgia);

f) bloqueios atrioventriculares a partir do $2^{\circ}$ grau e/ou bradiarritmias sintomáticas;

g) infecções relacionadas ao procedimento;

h) paralisia frênica;

i) estenose de veias pulmonares. 
Caso detectados, os eventos, seriam tabulados e considerados na avaliação tardia dos pacientes, sendo descritos nos resultados. 
7 FLUXOGRAMA DE EXECUÇão 


\section{Fluxograma de Execução}

Figura 24 - Fluxograma de execução.

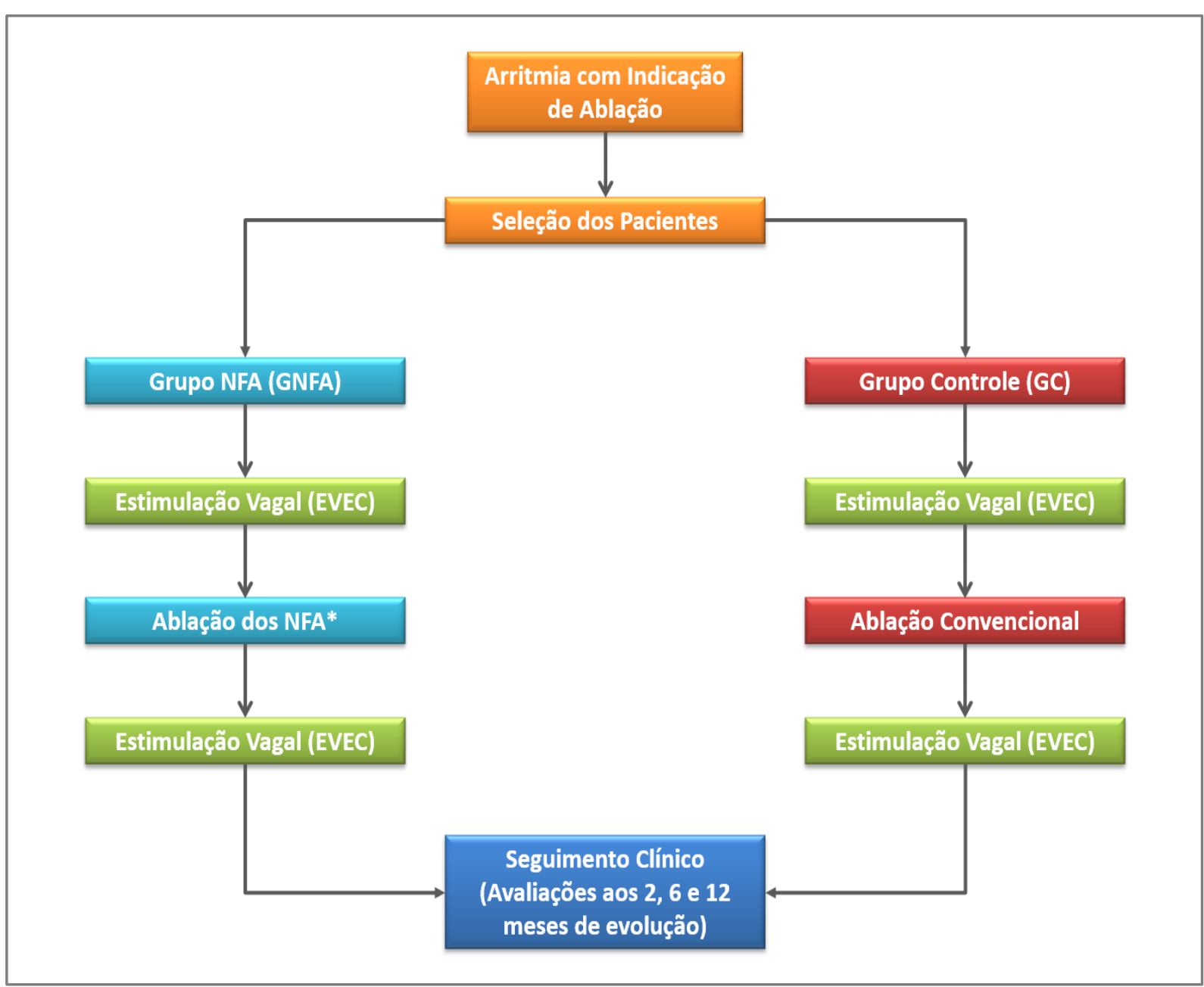

Desenho do estudo. No GNFA foram realizadas EVEC's adicionais e escalonadas ( $\left.{ }^{*}\right)$ durante a ablação, para verificar se havia ou não progressão da denervação. 
8 ANÁLISE ESTATÍSTICA 


\section{Análise Estatística}

Os dados quantitativos foram expressos como o valor médio e desvio padrão. A normalidade foi avaliada pelo teste de Shapiro-Wilk considerando o valor $W>0,9338$.

O t-test bicaudal pareado ou não pareado, dependendo do pareamento das amostras, foi aplicado para estabelecer comparações entre dados contínuos, antes e após a ablação. Todos os valores foram considerados estatisticamente significantes quando o valor de $p$ bicaudal fosse inferior a 0,05 .

A análise de Kaplan-Meier foi utilizada na avaliação da evolução dos pacientes por período de 12 meses.

A análise estatística foi realizada usando o software IBM SPSS Statistics Version $19 \AA$ e Microsoft Excel 2018®. 


\section{Resultados}

\subsection{Pacientes Incluídos no Estudo}

Foram recrutados um total de 79 pacientes consecutivos sendo que 17 foram desqualificados no momento da seleção e assinatura do TCLE por não cumprirem os critérios de inclusão, ou por apresentarem algum critério de exclusão.

Os motivos principais que levaram à exclusão dos pacientes foram:

a) quatro tinham idade inferior a 14 anos;

b) dois pacientes tinham imagem suspeita compatível com trombo no apêndice atrial esquerdo;

c) quatro recusaram assinar o TCLE;

d) três pacientes tinham FA permanente;

e) dois eram portadores de próteses mecânicas em posição mitral e contraindicação relativa para ablação de FA;

f) dois pacientes do GC tinham arritmias atriais próximas às veias pulmonares (com possibilidade de estarem relacionadas aos NFA).

Após o recrutamento, foram incluídos 62 pcts sendo $39(62,9 \%)$ homens com média de idade de 47,7 \pm 16,4 anos, com arritmias sintomáticas e indicação bem definida para a ablação por radiofrequência.

As características gerais dos pcts estão descritas na Tabela 1. 
Tabela 1 - Dados demográficos e indicações de ablação.

\begin{tabular}{|c|c|c|c|}
\hline Variáveis & GNFA & GC & Total \\
\hline № / (\%) & $32(51,6)$ & $30(48,4)$ & $62(100)$ \\
\hline Sexo Masculino - № (\%) & $23(71,8)$ & $16(53,3)$ & $39(62,9)$ \\
\hline Idade - Média anos (DP) & $50,5(17)$ & $44,6(16,4)$ & $47,7(16,4)$ \\
\hline \multicolumn{4}{|l|}{ Indicação da Ablação - № (\%) } \\
\hline FA & $30(93,7)$ & - & $30(48,4)$ \\
\hline SNC & $2(6,3)$ & - & $2(3,2)$ \\
\hline RAV & - & $4(13)$ & $4(6,4)$ \\
\hline WPW & & $6(20)$ & $6(9,7)$ \\
\hline DVN & - & $10(34)$ & $10(16,1)$ \\
\hline EVs & - & $6(20)$ & $6(9,7)$ \\
\hline TA & - & $1(3)$ & $1(1,6)$ \\
\hline Flutter Atrial & - & $3(10)$ & $3(4,8)$ \\
\hline
\end{tabular}

GNFA: Grupo Ninhos de FA; GC: Grupo Controle; DP: Desvio Padrão; SNC: Síncope Neurocardiogênica; RAV: Reentrada Atrioventricular; WPW: Síndrome de Wolff-ParkinsonWhite; DVN: Reentrada Nodal; EVs: Extrassístoles Ventriculares; TA: Taquicardia Atrial.

\subsection{Arritmias Tratadas no Grupo Controle}

Como resultado dos critérios de seleção, os pacientes do grupo controle apresentavam arritmias cujo tratamento por meio da ablação não seria direcionado aos NFA. Na Figura 25, pode-se verificar a distribuição dos diferentes tipos de arritmias incluídos no grupo controle. 
Figura 25 - Arritmias tratadas no grupo controle com as respectivas incidências.

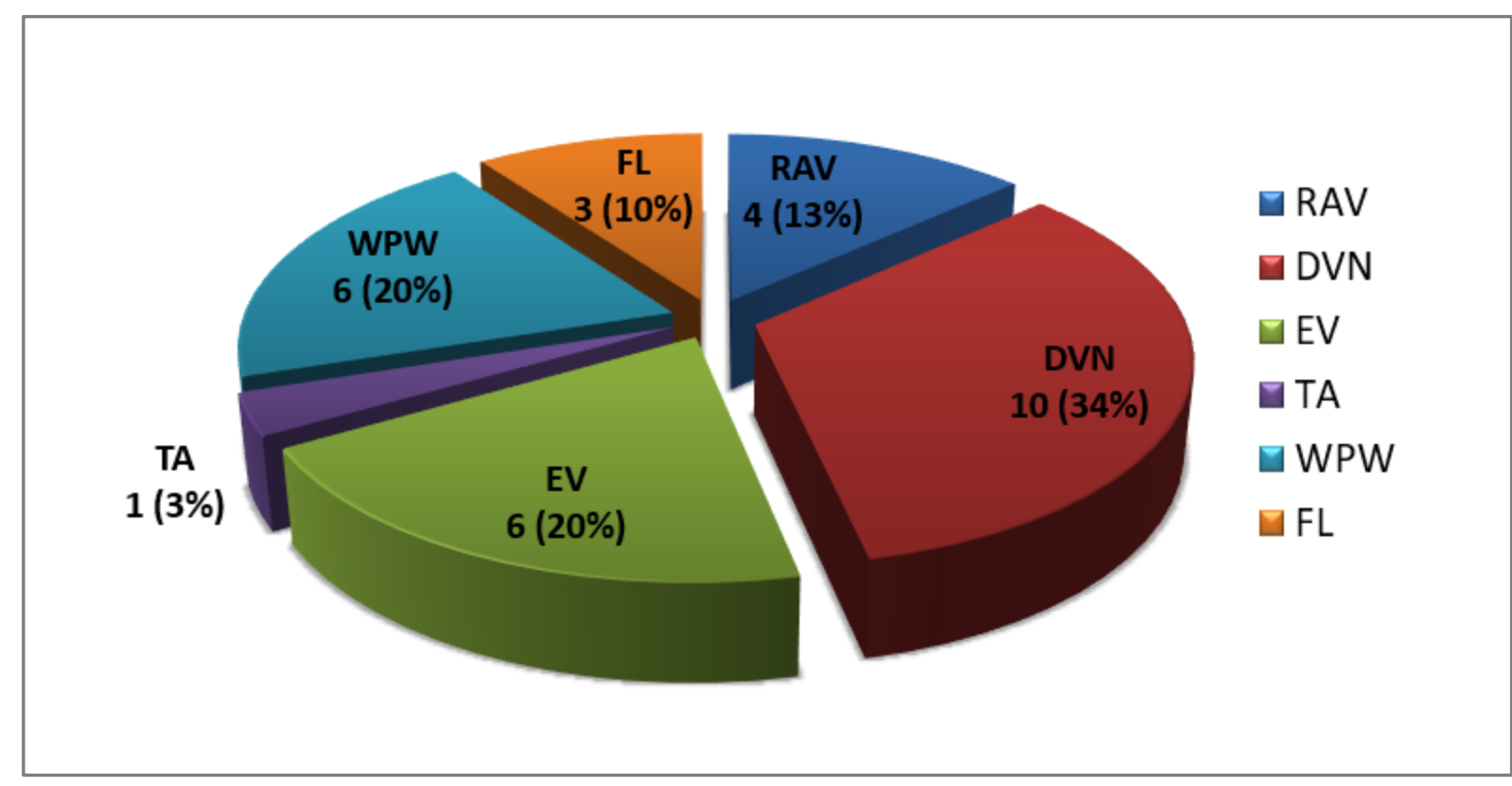

RAV: Reentrada atrioventricular; DVN: Dupla via nodal; EV: Extrassístole ventricular; TA: Taquicardia atrial; WPW: Síndrome de Wolf-Parkinson-White; FL: Flutter atrial istmo dependente.

\subsection{Tipos de Arritmias Tratadas no Grupo NFA}

Os pacientes do grupo NFA apresentavam arritmias relacionadas à efeito vagal, FA paroxística, FA persistente e bradicardias funcionais. $\mathrm{O}$ tratamento por meio da ablação foi direcionado aos NFA, independentemente da forma de apresentação. Apenas casos de fibrilação atrial permanente não foram incluídos por apresentarem geralmente maior grau de deterioração da parede atrial. Nestes casos, a fibrose das paredes pode mascarar o miocárdio desconectado eletricamente (NFA), sem necessariamente ter relação com a interface neuromiocárdica, prejudicando a análise. Na Figura 26, estão elencadas as arritmias dos pacientes do GNFA. Metade dos casos era portadora de fibrilação atrial paroxística, $44 \%$ eram portadores da forma persistente de $\mathrm{FA}$ e os $6 \%$ restantes eram portadores de bradiarritmias funcionais representadas principalmente por síncope neurocardiogênica ${ }^{51,52}$. 
Figura 26- Distribuição das diferentes arritmias no grupo NFA.

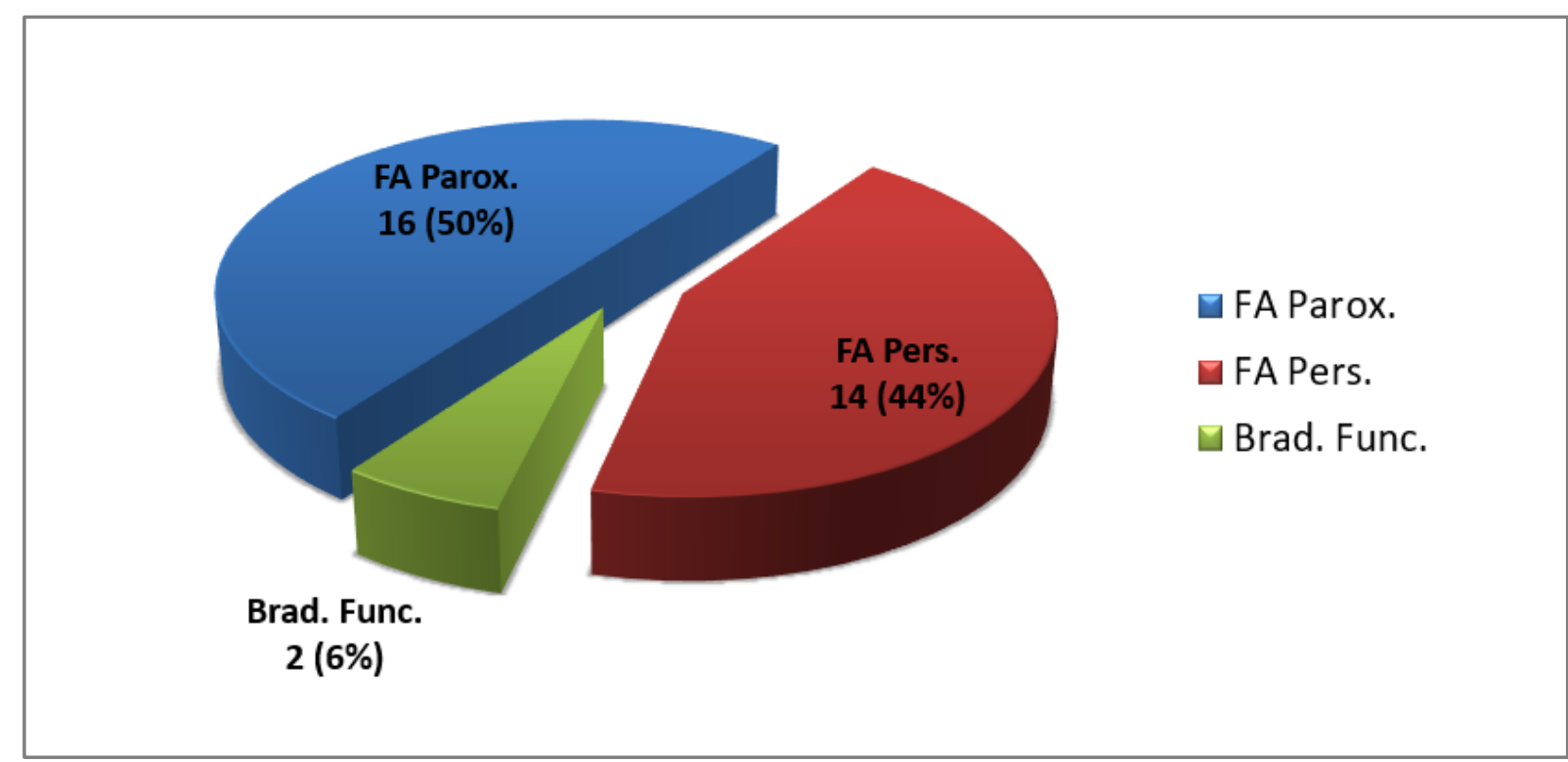

FA Parox.: Fibrilação atrial paroxística; FA Pers.: Fibrilação atrial persistente; Brad. Func.: Bradicardia funcional (SNC).

A distribuição total dos pacientes e sua divisão em grupo NFA e grupo controle, assim como dados basais da função ventricular, tamanho do átrio esquerdo e dados da ablação são mostrados na Tabela 2.

Tabela 2 - Comparação entre os dados dos pacientes do GNFA (Grupo Ninhos de Fibrilação Atrial) e GC (Grupo Controle).

\begin{tabular}{lcccc}
\hline & GNFA & GC & Total & $p$ \\
\hline Pacientes & 32 & 30 & 62 & - \\
AE & $40,2 \pm 9,1$ & $36,4 \pm 4,4$ & $38,9 \pm 7,9$ & 0,27 \\
FE & $64,4 \pm 8,8$ & $66,8 \pm 6,23$ & $65,4 \pm 7,7$ & 0,25 \\
Peso (kg) & $83,1 \pm 13,9$ & $76 \pm 17,7$ & $79,7 \pm 16,1$ & 0,08 \\
\hline Radioscopia (min) & $15,5 \pm 9,4$ & $7,2 \pm 5,1$ & $11,4 \pm 6,6$ & $<0,00$ \\
Duração (horas: $\min$ ) & $3: 42 \pm 56$ & $3: 13 \pm 44$ & $3: 28 \pm 16$ & 0,025 \\
\hline
\end{tabular}

M/F: gênero: masculino/feminino. A Duração representa o tempo total dos procedimentos (média e desvio padrão). 
A estimulação vagal foi facilmente conseguida na altura do forame jugular em 59 pacientes $(95,2 \%)$. Em três casos $(4,8 \%)$, devido às variações anatômicas das veias, houve certo grau de dificuldade que foi solucionada modificando a posição da cabeça do paciente, e/ou avançando o cateter com discretas modificações de curvatura. Manobras adicionais, como colocação do paciente em Trendelenburg e passagem de uma guia longa, também foram utilizadas em casos com alguma dificuldade. Este processo foi visivelmente facilitado com o aumento da experiência do operador. Na maioria dos casos, foi possível posicionar o cateter para realizar a EVEC em dois a cinco min (4,1 $\pm 3,2 \mathrm{~min})$. O tempo de radioscopia nesta parte do procedimento foi reduzido, em média de 0,4 \pm 0,8 min (radioscopia pulsada). $A$ voltagem média utilizada na EVEC foi de $67,3 \pm 5,5 \mathrm{~V}$; sendo $68,7 \pm 4 \mathrm{~V}$ no GNFA e $65,9 \pm 6,5 \vee$ no $\mathrm{GC}(p=0,04)$. Apesar de valores semelhantes, houve diferença significante em relação à amplitude de pulso de estimulação vagal discretamente maior no GNFA, tendo em vista que a média do peso corporal foi maior neste grupo, Figura 27.

Figura 27- Comparativo entre peso dos pacientes e energia utilizada na EVEC.

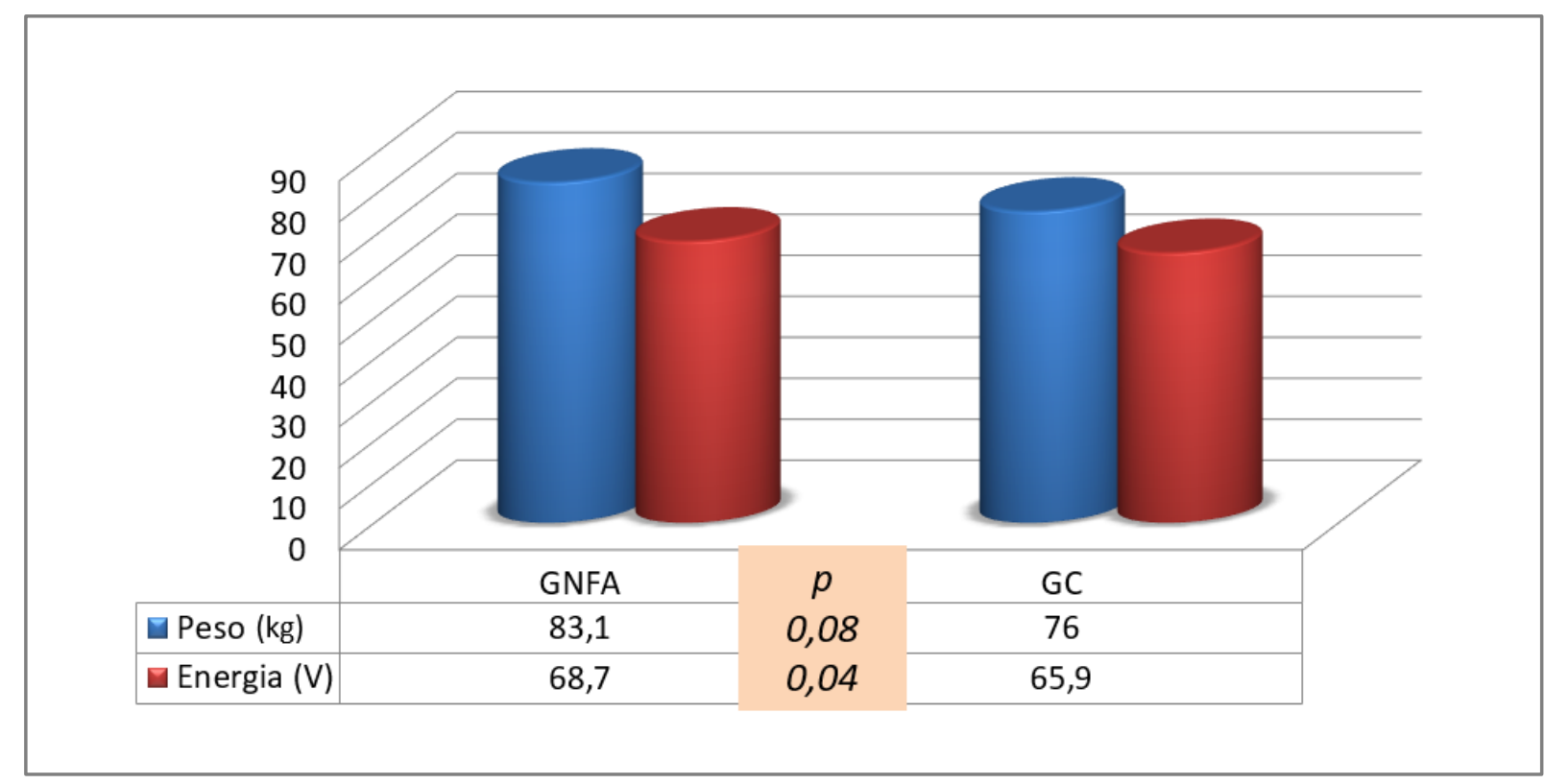

Gráfico comparando a média dos pesos dos pacientes no GNFA e no GC com a média da energia utilizada para se obter a EVEC e a significância estatística entre os valores obtidos. 
Todos os pacientes desenvolveram assistolia com a EVEC. Em um caso $(1,6 \%)$, ocorreu bloqueio AV total transitório inicialmente, com bradicardia sinusal. Neste caso, a resposta à estimulação vagal à direita foi reduzida, mas a estimulação vagal esquerda produziu bloqueio AV total transitório consistente e reprodutível, que permitiu avaliar a denervação vagal.

Não houve nenhum caso de sintomas ou de lesão vascular relacionados à estimulação vagal, em média de seguimento de 19,7 \pm 8,7 meses. Os resultados do GNFA e do GC são apresentados na Tabela 3.

Tabela 3 - Dados comparativos dos valores obtidos no GNFA e no GC, pré e pósprocedimento.

\begin{tabular}{|c|c|c|c|}
\hline & GNFA & GC & $p$ \\
\hline Pausa Pré-Procedimento (ms - média, DP) & $8370 \pm 2727$ & $6899 \pm 3019$ & 0,96 \\
\hline Pausa Pós-Procedimento (ms - média, DP) & 0 & $5971 \pm 2724$ & $<0,00$ \\
\hline$p$ - pausa pré e pós & $<0,00$ & 0,35 & - \\
\hline $\begin{array}{l}\text { Frequência Cardíaca antes da ablação (bpm - } \\
\text { média, DP) }\end{array}$ & $62,5 \pm 19$ & $66,9 \pm 11,1$ & 0,27 \\
\hline $\begin{array}{l}\text { Frequência Atrial média durante Estimulação } \\
\text { Neural (bpm - média, DP) }\end{array}$ & $31 \pm 13,2$ & $36,7 \pm 16,8$ & 0,06 \\
\hline $\begin{array}{l}\text { Frequência Ventricular média durante } \\
\text { Estimulação Neural (bpm - média, DP) }\end{array}$ & $29,2 \pm 13,6$ & $36,7 \pm 16,8$ & 0,06 \\
\hline Frequência Pós-Procedimento (bpm - média, DP) & $72 \pm 12,9$ & $67,6 \pm 9$ & 0,51 \\
\hline
\end{tabular}

GNFA: Grupo Ninhos de Fibrilação Atrial; GC: Grupo controle.

Ambos os grupos apresentaram resposta vagal intensa antes da ablação, que desapareceu completamente apenas no GNFA após o procedimento, Figura 23 (pág 44) (disponível em vídeo EVEC gerando assistolia pré-RF [https:// youtu.be/5mouiqxpE6k] e vídeo EVEC não gera assistolia pós-RF [https:// youtu.be/xAj1ezJ9CGA] na plataforma digital). No entanto, no GC esta resposta vagal persistiu praticamente sem modificação (comparação de pausa pré e pós-ablação: $p=0,35)$. A resposta pré-ablação não foi significantemente diferente entre os grupos $(p=0,96)$, Figura 28 . 
Quatro pacientes do GNFA (12,5\%) apresentaram algum grau de resposta vagal positiva ao final do procedimento, que foi corrigida, retomando-se a ablação de NFA adicionais, na mesma sessão. Estes casos teriam sua avaliação prejudicada se ao invés da EVEC, tivesse sido utilizada a atropina ${ }^{53}$ como forma de avaliação da resposta vagal.

Figura 28 - Exemplo do Grupo Controle.

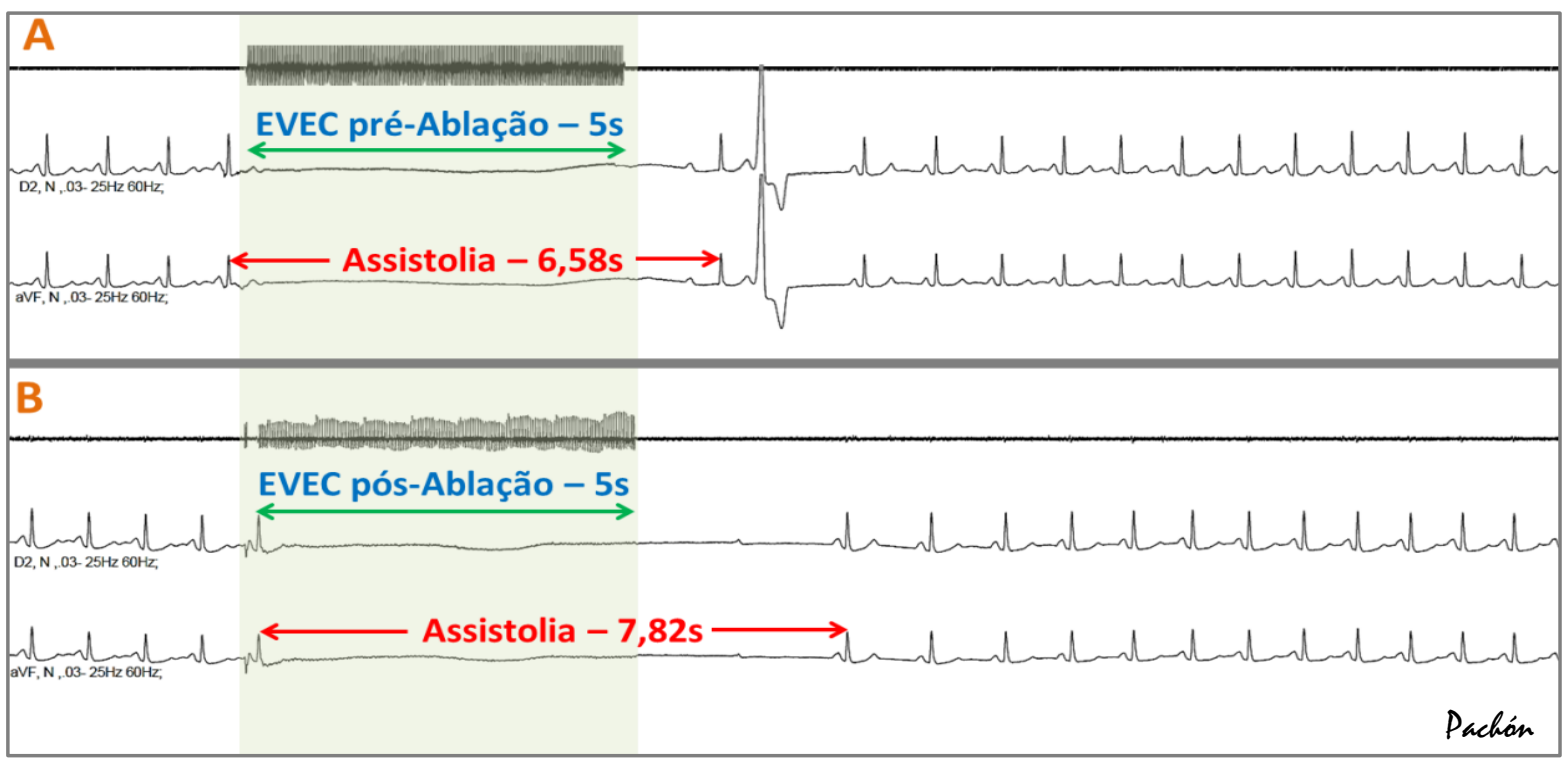

Este paciente do GC apresentava extrassístoles ventriculares muito sintomáticas, que foram tratadas com sucesso pela ablação com RF no ventrículo direito. A: Antes da ablação, $5 \mathrm{~s}$ de estimulação vagal causaram uma pausa de $6,58 \mathrm{~s}$ seguida do aparecimento da extrassístole. B: Após a ablação, uma nova estimulação vagal de $5 \mathrm{~s}$ produziu outra pausa de $7,82 \mathrm{~s}$ e ausência da extrassístole. Antes e após a ablação, a EVEC produziu também bloqueio AV, mostrando a ação concomitante no nodo AV. Este ensaio mostra a importância da EVEC, a reprodutibilidade deste método e também demonstra que não há alteração na função vagal e, portanto, não há denervação, nos casos em que não foi realizada a ablação dos NFA. Fonte: Arquivo SEMAP.

A significância estatística da comparação da frequência cardíaca pré e pósablação dos NFA foi extremamente elevada, atingindo $p<0,000$ usando-se a frequência ventricular ou atrial, enquanto que no grupo controle este mesmo dado não apresentou diferença, não atingindo significância estatística $(p=0,51)$. Também foram avaliadas as pausas pré e pós-ablação com os seguintes resultados: $8370 \pm 2727 \mathrm{~ms}$ (pré-ablação) versus $0 \mathrm{~ms}$ (pós-ablação) (não ocorreram pausas com a EVEC ao final dos procedimentos neste grupo). 
Quando comparadas as pausas nos dois grupos, no GNFA a diferença estatística foi significante $\left(p<0,00\left[1,5 \times 10^{-17}\right]\right)$ enquanto que no GC não houve significância estatística $(p=0,35)$, Figura 29.

Figura 29- Gráfico comparativo entre as pausas pré e pós-ablação em ambos os grupos.

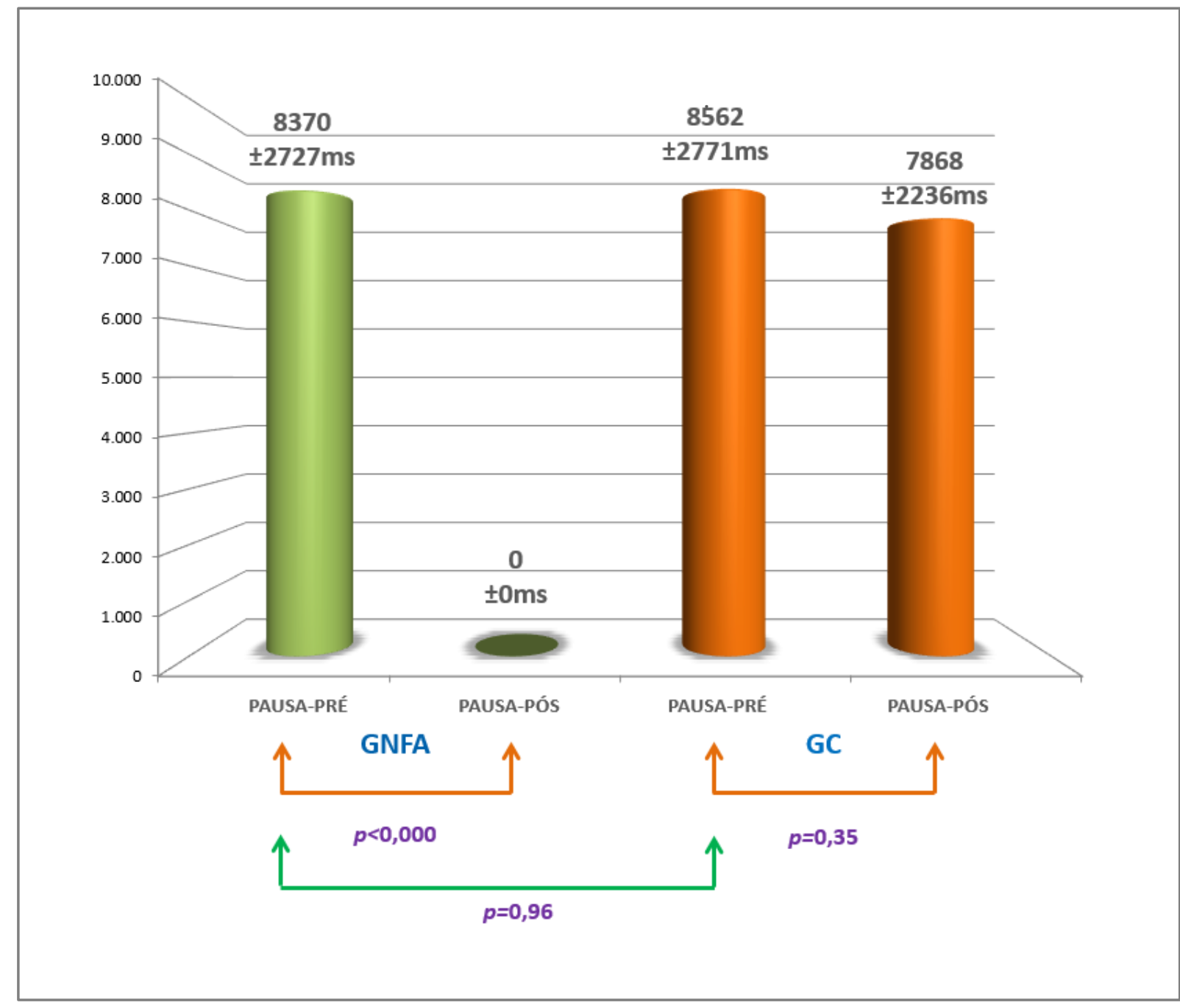

Os números sobre as colunas representam a média do valor em milissegundos das pausas obtidas pré e pós-ablação. As colunas de cor verde representam o GNFA e as de cor laranja, o GC. Os números em cor roxa representam a significância estatística entre os elementos indicados pelas setas.

A Tabela 4 mostra o tratamento estatístico das frequências cardíacas resultantes após as aplicações de radiofrequência nos diferentes locais e sua respectiva significância estatística entre as diferentes combinações de possibilidades. 
Em todas as comparações os aumentos mais significantes de frequência cardíaca foram obtidos com a ablação do "ponto P" e inserção das veias pulmonares direitas.

Tabela 4 - Dados da média da frequência sinusal do GNFA após cada etapa da ablação dos NFA.

\begin{tabular}{|c|c|c|c|c|c|}
\hline Alvo & FC (média, DP) & \multicolumn{4}{|c|}{ Valor de $p$} \\
\hline FC Pré & $62,5 \pm 19$ & \multirow{2}{*}{$\begin{array}{l}\text { FC Inicial X VPE } \\
\rightarrow 0,623\end{array}$} & \multirow{3}{*}{$\begin{array}{l}\text { VPE X ESP } \\
\rightarrow 0,928\end{array}$} & \multirow{4}{*}{$\begin{array}{c}\text { FC Inicial } \\
x \\
\text { VPD e } \\
\text { Ponto "P" } \\
0,004\end{array}$} & \multirow{3}{*}{$\begin{array}{c}\text { FC Inicial } \\
x \\
\text { FC Final } \\
\\
\\
0,023\end{array}$} \\
\hline VPE & $60,4 \pm 15$ & & & & \\
\hline ESP & $60,8 \pm 13$ & \multirow{2}{*}{$\Rightarrow \begin{array}{c}\text { ESP X VPD e } \\
\text { Ponto "p" } \\
0,00004\end{array}$} & & & \\
\hline $\begin{array}{l}\text { VPD e } \\
\text { Ponto "P" }\end{array}$ & $74,0 \pm 11$ & & $\begin{array}{l}\text { VPD e Ponto } \\
\text { "P" X AD }\end{array}$ & & \\
\hline AD & $72,0 \pm 13$ & & & & \\
\hline
\end{tabular}

Foi calculada a significância estatística entre os grupos, mostrando que as aplicações de RF nos NFA das veias pulmonares direitas (incluindo o ponto "P") são as que apresentam maior interferência sobre a frequência cardíaca espontânea com maior grau de denervação do nó sinusal.

As pausas com o desvio padrão para cada etapa da ablação no GNFA estão demonstradas na Figura 30. Observa-se que a variação mais significativa da FC $(p<0,000)$ ocorre com a abordagem próxima ao antro da VPD, região que denominamos de "ponto P", pelo seu intenso efeito sobre as células "P" (explicação pormenorizada nas págs 74 e 75). Consequentemente, há também uma grande diferença estatística quando comparamos todas as pausas no início e no final dos procedimentos, pois esta análise inclui a abordagem do "ponto P".

Não houve diferença estatística significante entre as pausas ocasionadas pela EVEC pré e pós ablação no GC (8562 \pm 2271 ms x $7868 \pm 2236$ ms; p=0,35). 
Figura 30- Gráfico comparativo entre as pausas pré e pós-ablação ocasionadas pela EVEC, em ambos os grupos.

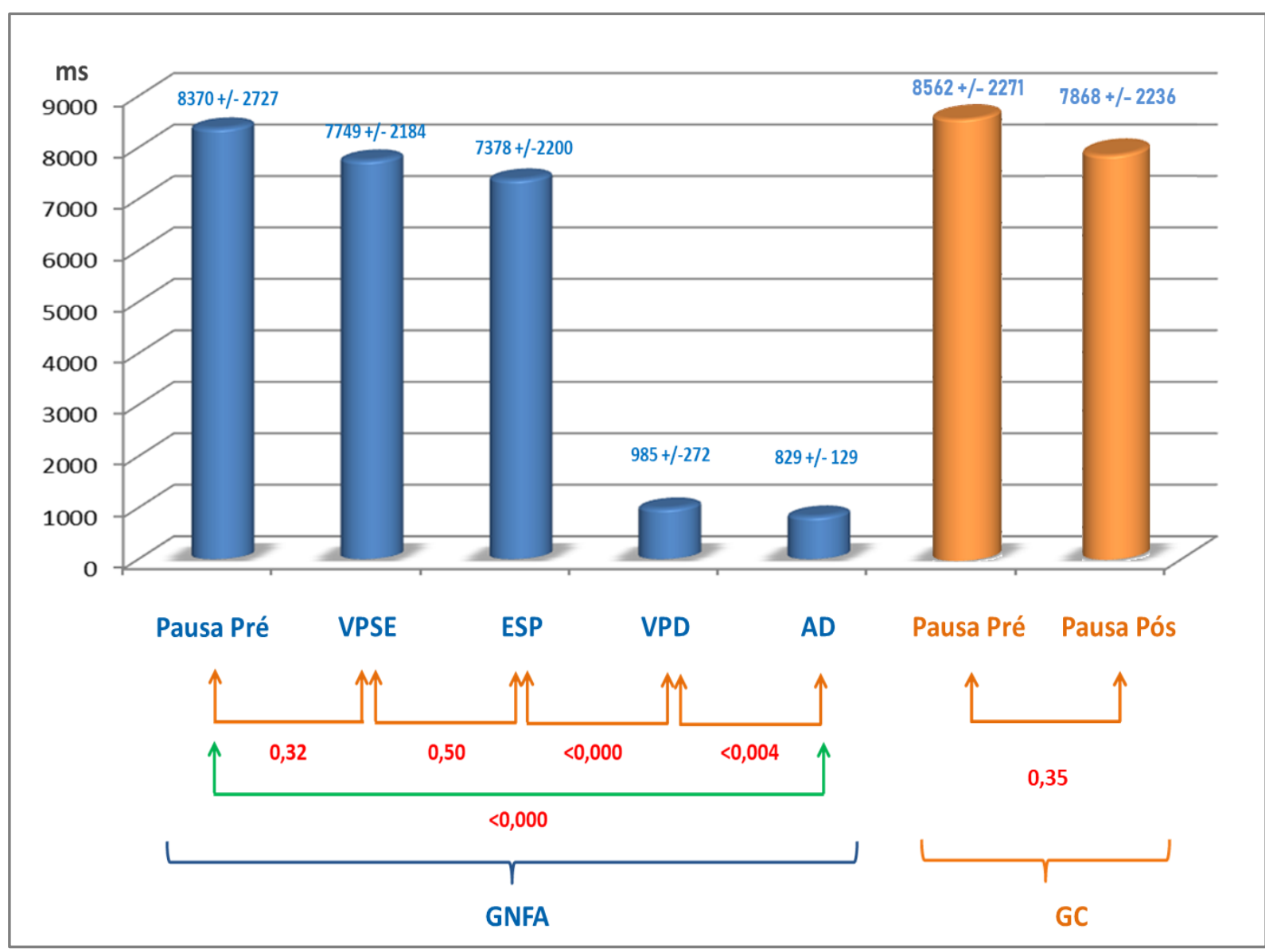

Representação das médias e desvios padrão das pausas obtidas durante a estimulação vagal, em cada etapa do procedimento do GNFA e no GC. A significância estatística $(p)$ está mostrada pelos números na cor vermelha. Observa-se que a cada etapa no GNFA ocorre redução da duração das pausas e, claramente, que as mesmas desaparecem após o tratamento dos NFA das veias pulmonares direitas e do ponto "P". No GC, nota-se uma pequena diferença atribuída às modificações fisiológicas apresentadas pelo paciente, que ocorreram entre o início e o final do procedimento, porém essa diferença não apresentou significância estatística.

Na Figura 31, podemos observar o comportamento em cada fase da ablação por RF no GNFA, mostrando a reprodutibilidade desta resposta em todos os pacientes. Interessante observar que duas etapas consecutivas apresentam alta significância estatística: a abordagem das veias pulmonares direitas e sua etapa anterior, a abordagem do espaço septal posterior. 
Figura 31- Evolução da frequência sinusal após cada etapa no GNFA

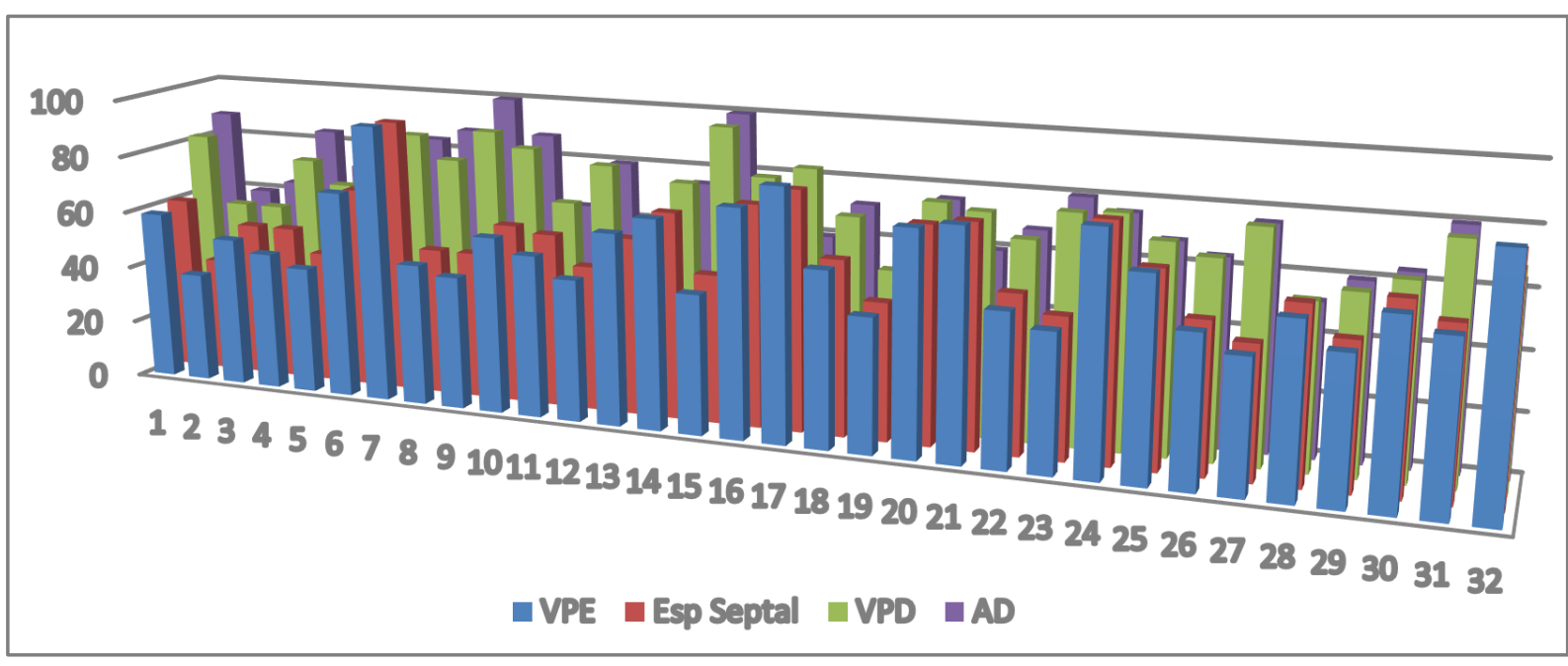

Evolução da frequência sinusal após cada etapa da ablação dos NFA no GNFA em todos os pacientes. Observa-se aumento gradual e progressivo da frequência sinusal na quase totalidade dos pacientes, sendo este fenômeno mais evidente quando a ablação é direcionada para as veias pulmonares direitas (cor verde), etapa que inclui o "ponto P".

\subsection{Complicações e Seguimento}

Os pacientes foram acompanhados por um ano desde o procedimento ablativo, independentemente de pertencerem ao GNFA ou GC e foram avaliados clinicamente e com ECG e Holter aos 2, 6 e 12 meses após a ablação. Tanto no grupo NFA como no GC, não ocorreram complicações de maior gravidade tais como: tamponamento, derrame pericárdico, lesão térmica do esôfago, bloqueios $\mathrm{AV}$, necessidade de marcapasso temporário ou definitivo ou infecções. Apenas um paciente do GNFA teve um hematoma no pós-operatório, na região inguinal direita, próximo às punções, que foi resolvido clinicamente com compressa fria, compressão local e repouso. O ultrassom neste caso não mostrou pseudoaneurisma ou coleção sanguínea que necessitasse de drenagem, reposição sanguínea ou intervenção vascular.

Todos os pacientes do GNFA tiveram o esôfago deslocado (disponível em vídeo: Deslocamento do Esôfago com Sonda do ETE-1 [https://youtu.be/wBQOhKKIMbk]; vídeo: Deslocamento do esôfago com a sonda do ETE-2 [https://youtu.be/F6NDrUya54] e vídeo: Deslocamento do Esôfago com Sonda do ETE-3 [https://youtu.be/ Di5DzzeLktM] na plataforma digital) pelo transdutor do ecocardiograma transesofágico, além da monitoração por termômetro intraesofágico multicanal (12 
canais), para evitar qualquer risco de aquecimento e de fístula atrioesofágica, conforme técnica desenvolvida e patenteada por Pachón et al. ${ }^{39,54}$ (Anexo A4 - pág 105). Estas manobras foram muito importantes para proteger o esôfago de lesões térmicas, já que muitas aplicações de RF ocorrem em regiões superpostas com esta víscera.

No GNFA ocorreram quatro recidivas nesse período de acompanhamento. Um caso $(3 \%)$ foi relacionado à descompensação metabólica por diabetes e hipotireoidismo. Seis casos $(18,75 \%)$ tinham queixas de palpitações leves, sendo que três evoluíram com arritmias sustentadas aos 4, 5 e 9 meses de evolução. Dois pacientes $(6,25 \%)$ foram submetidos a nova ablação e dois $(6,25 \%)$ estão em controle clínico com antiarrítmicos e sem queixas. Os outros dois casos $(6,25 \%)$ apresentam apenas extrassístoles supraventriculares isoladas e pareadas que responderam bem ao uso de metoprolol VO e estão sob controle clínico até a data atual. Na Figura 32, podemos verificar a curva de Kaplan-Meier da evolução geral do GNFA e do GC no período de 13 meses.

Figura 32- Curvas de Kaplan-Meier mostrando a evolução livre de eventos:

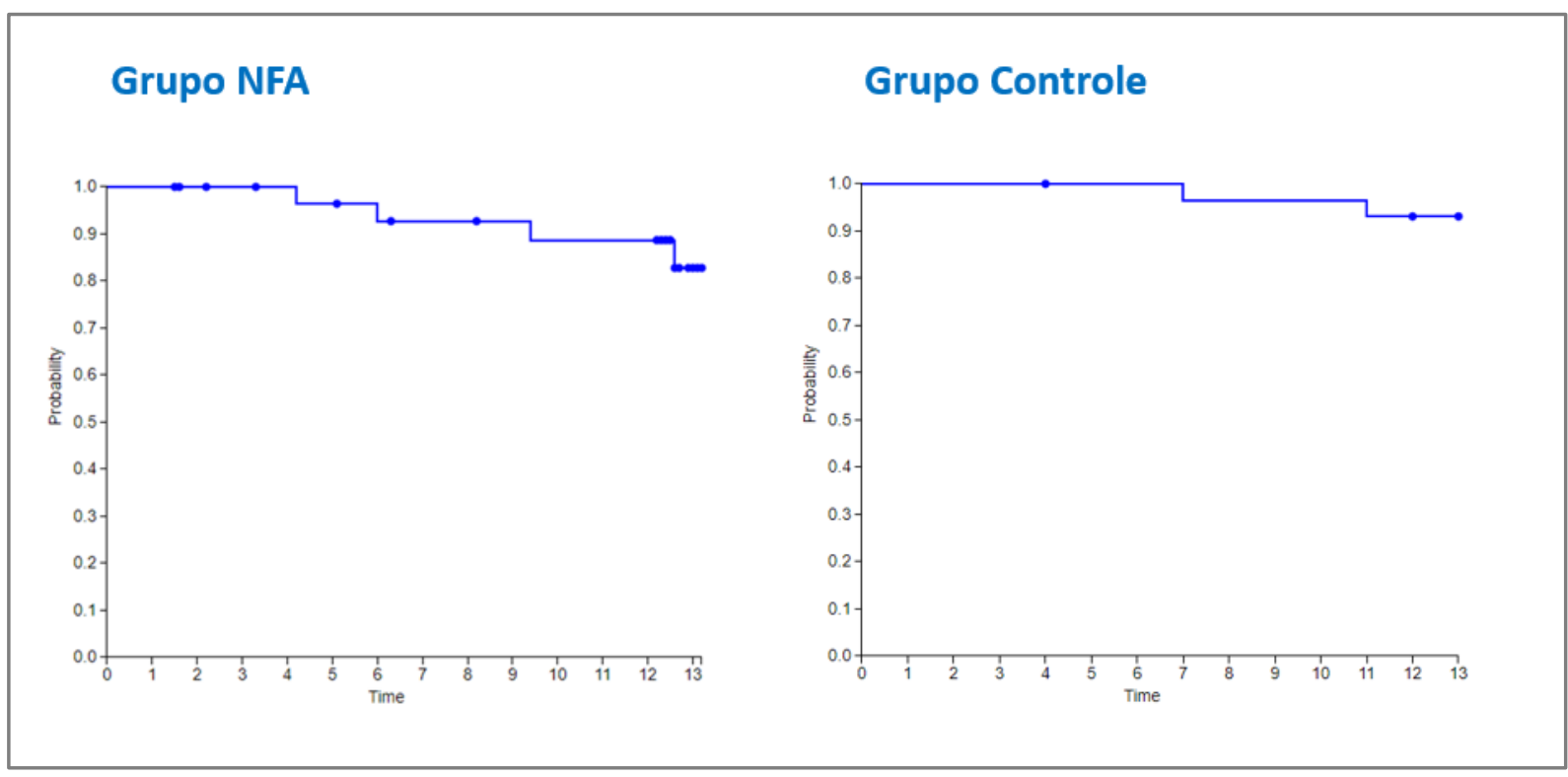

À esquerda, curva de Kaplan-Meier mostrando a evolução livre de eventos dos pacientes do GNFA e à direita, dos pacientes do Grupo controle, em 13 meses. 
No GC, ocorreram duas recidivas tardias. Um paciente tratado de extra-sístole ventricular apresentou reaparecimento da arritmia após sete meses de evolução e outro paciente tratado em decorrência de foco de taquicardia atrial, que já vinha se queixando de palpitações eventuais, teve um episódio de taquicardia sustentada registrada após onze meses de evolução. No caso da extrassístole ventricular, a avaliação criteriosa confirmou tratar-se da mesma arritmia que havia sido tratada pela ablação, já que existe a possibilidade da ocorrência de outras arritmias que não teriam sido o foco do tratamento, e por esse motivo foi considerada uma recidiva tardia.

Três pacientes $(9,4 \%)$ que apresentaram palpitações discretas, na avaliação inicial (60 dias), tiveram o desaparecimento desses sintomas na avaliação de 6 meses (provável síndrome pós-ablação ${ }^{55}$ ). O paciente com recidiva de extrassístoles foi submetido a nova ablação e o da taquicardia atrial está em controle clínico, com medicação antiarrítmica. Todos os pacientes do GC foram acompanhados pelo período mínimo de 1 ano e, a seguir, receberam alta definitiva do Serviço de Arritmias, exceto o caso da taquicardia atrial que mantém acompanhamento clínico. No GC também não ocorreu qualquer complicação relacionada ao procedimento, às punções ou qualquer sinal ou sintoma que pudesse ser relacionado às EVECs.

Todos os dados coletados foram obtidos nas avaliações da evolução durante o período de um ano, que foram acompanhadas de avaliação clínica, exame físico completo, eletrocardiograma de 12 derivações e um questionário com questões apropriadas e iguais para todos os casos. Um Holter foi solicitado sempre que houvessem sintomas suspeitos ou quando completassem seis meses de evolução.

Na Tabela 5 e na Tabela 6 estão tabulados todos os pacientes dos dois grupos e seus respectivos seguimentos de 2 meses, 6 meses e 12 meses. Alguns pacientes que não retornaram nas datas previstas, ou que residem fora do país (2 casos $6,25 \%$ ), foram contatados por telefone, sendo solicitados exames para cumprir-se o protocolo do estudo e obter-se as informações que foram igualmente tabuladas. 
Tabela 5 - Seguimento dos pacientes do GC, após: 60 dias, 6 meses e 1 ano do procedimento, até o momento do levantamento destes dados.

\begin{tabular}{|c|c|c|c|}
\hline NOME & 60 dias & 6 meses & 1 ano \\
\hline ENM & Assintomático & Assintomático & Assintomático \\
\hline MEDN & Assintomático & Não veio & Assintomático \\
\hline LBC & Assint EVs raras & Assint Evs raras & Recidiva \\
\hline SCM & Sd pós-Ablação & Assintomático & Assintomática \\
\hline HAG & Assintomático & Assintomático & Assintomático \\
\hline LFTM & Palpitações raras & Assintomático & Recidiva \\
\hline MRM & Assintomático & Assintomático & Assintomático \\
\hline ACC & Assintomático & Assintomático & Assintomático \\
\hline GF & Assintomático & Assintomático & Assintomático \\
\hline TLLS & Assintomático & Assintomático & Assintomático \\
\hline CNP & Assintomático & Assintomático & Assintomático \\
\hline LAAM & Assintomático & Assintomático & Assintomático \\
\hline RPS & Assintomático & Assintomático (sem Delta) & Assintomático \\
\hline RASGF & Palpitações (ESVS) & Assintomático & Assintomático \\
\hline LNC & Assintomático & Assintomático & Assintomático \\
\hline AMCLF & Assintomático & Assintomático & Assintomático \\
\hline ALLL & Assintomático & Assintomático & Assintomático \\
\hline GAA & Assintomático & Assintomático & Assintomático \\
\hline ASS & Assintomático & Assintomático & Assintomático \\
\hline VB & Assintomático & Assintomático & Assintomático \\
\hline SLCRH & Assintomático & Assintomático & Assintomático \\
\hline FRBO & Assintomática (ESVs raras) & Assintomático & Assintomático \\
\hline ZAG & Assintomático & Assintomático & Recidiva \\
\hline ANP & Assintomático & Assintomático & Assintomático \\
\hline EGO & Assintomático & Assintomático & Assintomático \\
\hline JC & Assintomático & Assintomático & Assintomático \\
\hline LKF & Assintomático & Assintomático & Assintomático \\
\hline ABB & Assintomático & Assintomático & Assintomático \\
\hline MJAZ & Assintomático & Assintomático & Assintomático \\
\hline LFS & Assintomático & Assintomático & Assintomático \\
\hline
\end{tabular}

FA: Fibrilação Atrial; ESV: Extrassístole Supraventricular. 
Tabela 6 - Seguimento dos pacientes do GNFA, após: 60 dias, 6 meses e 1 ano do procedimento, até o momento do levantamento destes dados.

\begin{tabular}{|c|c|c|c|}
\hline NOME & 60 dias & 6 meses & 1 ano \\
\hline APC & Assintomático & Assintomático & Recidiva \\
\hline ASN & Leves extrassístoles & Extrassístoles & Poucas Extrassístoles \\
\hline ABM & Leves palpitações & Assintomático & Assintomático \\
\hline AYM & Leves tonturas & Assintomática & $\begin{array}{l}\text { Leves tonturas } \\
\text { eventuais }\end{array}$ \\
\hline APS & Assintomático & Palpitações & Assintomático \\
\hline ASO & Assintomático & Assintomático & Assintomático \\
\hline CY & Cansaço leve & Assintomático & Assintomático \\
\hline CEB & Assintomático & Assintomático & Assintomático \\
\hline CMAB & Assintomático & não compareceu & Assintomático \\
\hline DCS & Assintomático & Assintomático & Assintomático \\
\hline EL & Palpitações leves & Assintomática & Assintomático \\
\hline EGDM & Palpitações & Palpitações leves & $\begin{array}{l}\text { Palpitações leves, sem } \\
\text { Fibrilação atrial }\end{array}$ \\
\hline FCP & Raras extrassístoles & Curtas taquicardias & Raras arritmias \\
\hline FLG & Assintomático & Assintomático & Flutter atrial \\
\hline GRBZ & Assintomático & Assintomático & Assintomático \\
\hline JBS & Palpitações 2 a $3 x /$ semana & Palpitações menos frequentes & Palpitações raras \\
\hline JGR & Palpitações leves & Extrassístoles eventuais & Assintomático \\
\hline JGB & $\begin{array}{l}\text { Tonturas rotatórias, sem } \\
\text { arritmias }\end{array}$ & Sem arritmias & Assintomático \\
\hline JY & Cansaço & Bradicárdico & Implante de MP DDDR \\
\hline JLD & Palpitações eventuais & Assintomático & Assintomático \\
\hline LMM & Leves palpitações & Eventuais palpitações & Assintomático \\
\hline LCS & Assintomático & Palpitações -> PS HCor & Recidiva \\
\hline MFRB & Assintomático & Palpitações Curtas/Propafenona & $\begin{array}{l}\text { Palpitações } \\
\text { Curtas/Sem FA }\end{array}$ \\
\hline OCS & Assintomática & Palpitações leves & Assintomático \\
\hline OMW & Assintomático & Assintomático & Assintomático \\
\hline PF & Palpitações leves & Assintomático & Assintomático \\
\hline PP & Cansaço & Assintomático & Assintomático \\
\hline RFL & Assintomático & não veio & Assintomático \\
\hline RGA & Cansaço & Discreto cansaço & Recidiva \\
\hline VSGS & Assintomática & Leves tonturas & Assintomática \\
\hline VA & Assintomático & Assintomático & Assintomático \\
\hline WC & Assintomático (em FA) & $\begin{array}{l}\text { FA, diabetes e tireoide } \\
\text { descompensados }\end{array}$ & Recidiva \\
\hline
\end{tabular}

FA: Fibrilação Atrial. 


\section{Discussão}

A possibilidade de tratar bradiarritmias funcionais por meio da ablação por $\mathrm{RF}$, sem implante de marca-passo, é bastante atrativa e intrigante. Além da ação hormonal, a frequência cardíaca é o resultado permanente do tônus vagal e do tônus simpático. Quando interrompemos as fibras vagais, seja por secção ou por ação farmacológica com atropina, ocorre imediatamente um aumento da frequência cardíaca e desaparecimento de bloqueios $\mathrm{AV}$ funcionais. Isto está diretamente relacionado ao tônus vagal, que ocorre mesmo que o simpático esteja totalmente bloqueado ${ }^{3}$. A disposição peculiar do sistema nervoso autônomo do coração, com somente o neurônio pós-ganglionar parassimpático na parede atrial, favorece que se obtenha uma significativa e seletiva denervação vagal, por meio da ablação endocárdica por RF. Desta premissa procedem dois grandes desafios diretamente desenvolvidos neste estudo: como mapear a interface neuromiocárdica e como controlar e confirmar o grau de denervação.

\subsection{Denervação Parassimpática}

No processo de denervação é fundamental a eliminação do corpo celular, tendo em vista que os axônios e dendritos regeneram-se na sua maior parte, desde que o corpo celular esteja preservado. No sistema nervoso cardíaco, somente os neurônios pósganglionares parassimpáticos estão localizados no coração (intramurais ou ganglionares epicárdicos), sendo que os simpáticos e sensoriais têm os corpos celulares longe do coração. Deste modo, a energia de RF aplicada no endocárdio promove essencialmente uma denervação parassimpática, já que as fibras simpáticas e sensoriais regeneram-se rapidamente ${ }^{56}$, visto que os corpos celulares destes neurônios não são atingidos pela RF. No GNFA, a denervação vagal foi facilmente observada pela total ausência de resposta à EVEC após a ablação, conforme mostrado nos resultados e reproduzido na Figura 33. Entretanto, para confirmar que a eliminação da resposta vagal foi realmente relacionada à ablação dos NFA e não à manipulação eletrofisiológica do procedimento ablativo, decidimos incluir um grupo controle submetido a toda a rotina de estudo e ablação, porém sem tratar os NFA com 
a ablação. Deste modo comparamos dois grupos igualmente tratados com ablação: GNFA e GC. Ambos foram submetidos à anestesia, a manipulações e testes eletrofisiológicos semelhantes, porém, somente no primeiro grupo foi realizada a ablação dirigida aos NFA.

Não houve diferença significativa entre GNFA e GC no que se refere à idade, ao tamanho do átrio esquerdo e à fração de ejeção. O peso corporal, embora bastante semelhante em ambos os grupos apresentou uma tendência a ser menor no GC $(p=0,08)$. O tempo de radioscopia e a duração do procedimento foram também discretamente menores no GC, já que as arritmias envolvidas neste grupo exigem menor tempo de ablação.

Figura 33 - Ilustração de caso do GNFA comparando a EVEC antes e após a ablação dos NFA.

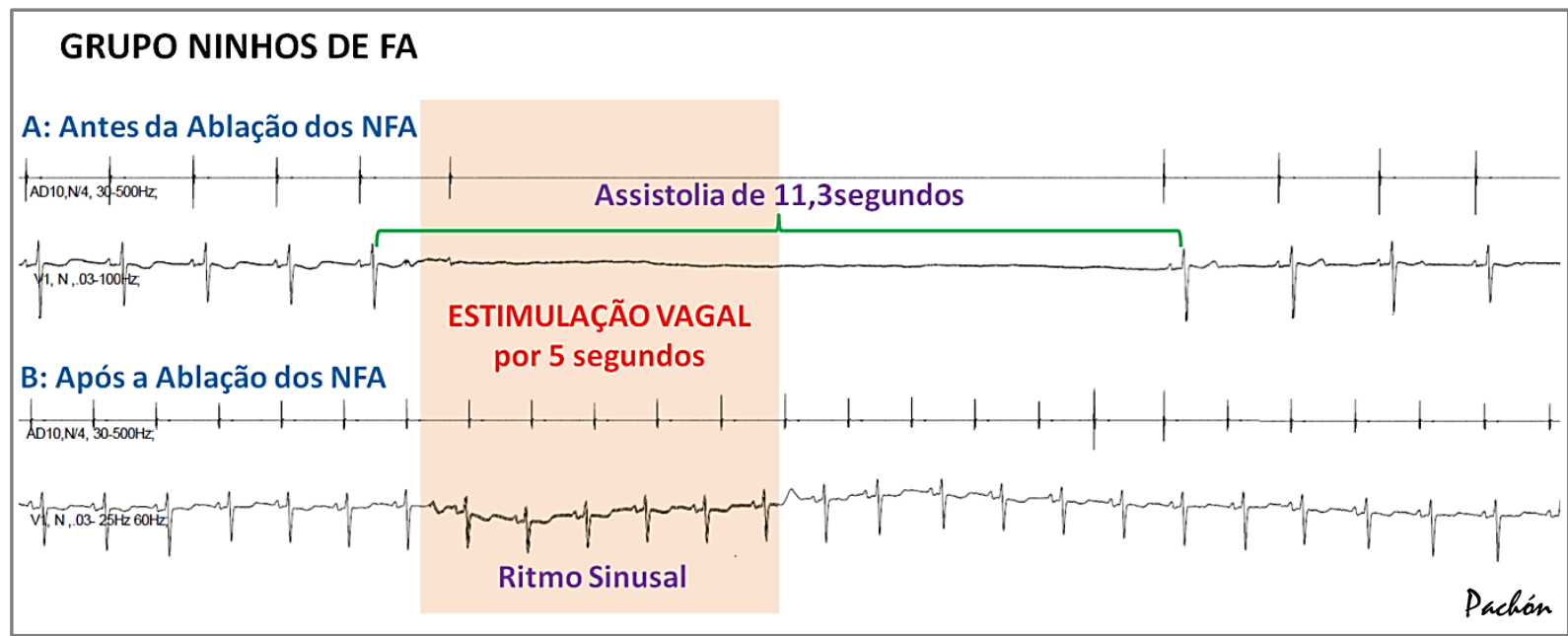

Exemplo de um paciente do GNFA. A tira superior (A) mostra $5 \mathrm{~s}$ de estimulação vagal, causando uma pausa total (assistolia) de 11,3 s pré-ablação. Após a ablação dos NFA, a EVEC idêntica é repetida observando-se ritmo sinusal regular sem nenhuma pausa e sem alteração da frequência cardíaca e da condução AV (traçado inferior - B), demonstrando uma evidente denervação vagal. Fonte: Arquivo SEMAP.

Todos os pacientes de ambos os grupos foram submetidos à EVEC padrão por $5 \mathrm{~s}$, registrando-se e medindo-se a pausa obtida, assim como as médias das frequências sinusal e ventricular durante $15 \mathrm{~s}$ após iniciada a EVEC, Figura 23 (pág 44) antes e depois da ablação. Nos casos nos quais os procedimentos foram iniciados em FA, estes dados foram igualmente obtidos após a cardioversão elétrica e a 
estabilização do ritmo sinusal, posto que o mapeamento dos NFA somente pode ser realizado em ritmo sinusal. A comparação das pausas obtidas pré-ablação no GNFA e no $G C$ não apresentou significância estatística $(p=0,96)$, evidenciando que os grupos eram bastante semelhantes do ponto de vista de ação vagal. Além do mais, as longas pausas induzidas pela EVEC mostram que todos os pacientes apresentavam uma inervação cardíaca vagal preservada e normal, ou seja, não havia denervação por outra causa. Ao compararmos a EVEC pré e pós-ablação verificamos que no GC não houve nenhuma diferença estatística entre as pausas obtidas antes e após a ablação $(p=0,35)$, demonstrando que a ablação, que não envolve os NFA, não altera a inervação vagal de forma significante. Adicionalmente, a obtenção da mesma resposta antes e após a ablação no GC demonstra que a EVEC tem boa reprodutibilidade.

Entretanto, o desfecho mais importante foi a total eliminação da resposta vagal testada pela EVEC no grupo submetido à ablação dos NFA, conforme demonstrado nos resultados e também reproduzido na Figura 34-E.

Este fato sugere, fortemente, que os NFA estão altamente relacionados à inervação vagal e à presença dos neurônios intramurais, Figura 4-2A (pág 7), fundamentado pela ausência de denervação pós-ablação no GC. Estes achados complementam um objetivo primário deste estudo. Na Figura 34, há cinco traçados obtidos de um paciente do GNFA, durante a progressão da denervação, conforme indicado no desenho do estudo, confirmando os achados mencionados anteriormente e comentados pormenorizadamente a seguir.

O primeiro traçado (A) foi obtido no início do procedimento, após estabilização completa do paciente sob anestesia e índice BIS de 40. Neste momento, a EVEC promove uma resposta vagal máxima, seguida de um "tempo de normalização vagal (TNV)" (pausa total de $6.800 \mathrm{~ms}$ com TNV de $2.700 \mathrm{~ms}$ ). Esta pausa adicional além da EVEC se deve à metabolização da acetilcolina e às propriedades automáticas do nó sinusal. No segundo traçado (B), a estimulação neural foi realizada após as ablações dos NFA dos antros das veias pulmonares esquerdas. Mesmo não atuando diretamente nos principais GPs, ocorreu uma redução da pausa (6.500 ms) e do TNV $(2.500 \mathrm{~ms})$, sem outras modificações no ritmo. Adicionalmente, observou-se uma pequena alteração do ponto de Wenckebach (incremento de 12 batimentos, de 132 para $144 \mathrm{bpm})$. 
Figura 34 - Exemplo de ablação de NFA escalonada.

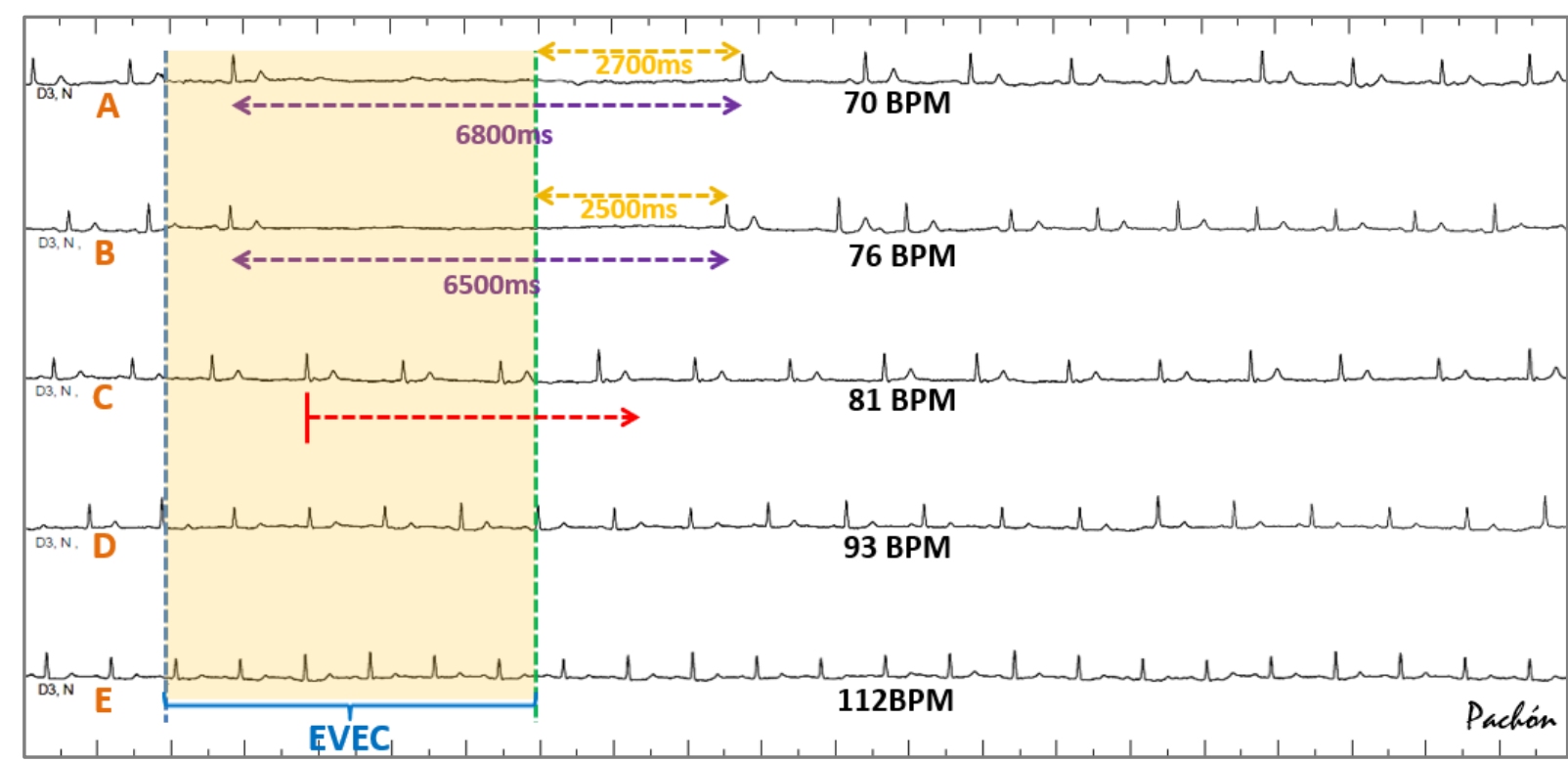

Exemplos de traçados obtidos em momentos diferentes, durante a ablação sequencial em um mesmo paciente do GNFA. Em A, temos a resposta vagal no início do procedimento, antes de qualquer aplicação de RF. Em B, a mesma estimulação vagal, após aplicação de RF nos NFA do antro das VPs esquerdas. Em C, a mesma estimulação vagal após a aplicação de RF sobre os NFA do espaço septal posterior (observa-se o ritmo de escape juncional, que inicia na seta de cor vermelha e permanece até o final do traçado). Em D, a mesma estimulação vagal após a ablação do antro das VPs direitas e em $E$, após a ablação do $A D$, sendo que neste último já não há qualquer resposta vagal). $A$ área de cor amarela mostra o exato momento em que ocorre a EVEC em todos os traçados. A frequência sinusal é mostrada em cada traçado, para se ter uma ideia das modificações da mesma durante o progresso da denervação. A linha de cor roxa mostra a pausa total e a de cor laranja o tempo de normalização vagal. Fonte: Arquivo SEMAP.

No terceiro traçado (C), a mesma estimulação vagal foi aplicada após as ablações nos NFA do espaço septal posterior. Neste momento, já não existem mais pausas, porém o ritmo de resposta é juncional com captura retrógrada do átrio e do nó sinusal. $O$ ponto de Wenckebach foi significativamente aumentado, fato também observado na maioria dos pacientes após tratar-se esta região (Figura 35), sugerindo que a ablação desta área pode ser indicada de forma independente para promover uma melhora da condução $A V^{1}$. Este fato foi reproduzido por outros autores ${ }^{57,58}$. No traçado (D), a estimulação vagal foi aplicada após o tratamento dos NFA dos antros das veias pulmonares direitas, incluindo também o "Ponto P". Não ocorrem mais as pausas, mas agora a resposta sinusal é superior à juncional e não mais se observa ação vagal. As aplicações de RF nos NFA do antro das veias pulmonares direitas favoreceram predominantemente a resposta sinusal, sugerindo que devem ser cuidadosamente tratadas, para promover aumento da frequência sinusal de forma 
seletiva, em pacientes selecionados com bradicardia sinusal funcional, mas com ponto de Wenckebach normal. Finalmente, o traçado (E) foi obtido após completarem-se as aplicações no AD. A EVEC neste momento não modificou em nada a frequência sinusal nem a condução $A V$, mostrando que, neste caso, houve uma completa denervação parassimpática, antes da abordagem do átrio direito. Também podemos observar o aumento gradual da frequência sinusal, em cada etapa da denervação, até o valor máximo com a denervação completa, Tabela 4 (pág 60), (disponível em vídeo EVEC após Ablação do óstio das VPs Esquerdas [https://youtu.be/9HKuAaLIIOs] e vídeo EVEC após Ablação das VPs Esquerdas e Espaço septal [https://youtu.be/ oQmLF5gwlJ8] na plataforma digital). A EVEC demonstrou ser uma ferramenta de grande valor na denervação escalonada. O eletrodo de estimulação vagal foi mantido na jugular interna, durante todo o procedimento, sendo a EVEC repetida ao final de cada etapa, permitindo observar, de forma objetiva, a denervação progressiva e a reprodutibilidade dos resultados.

Figura 35 - Modificação do ponto de Wenckebach durante a denervação.

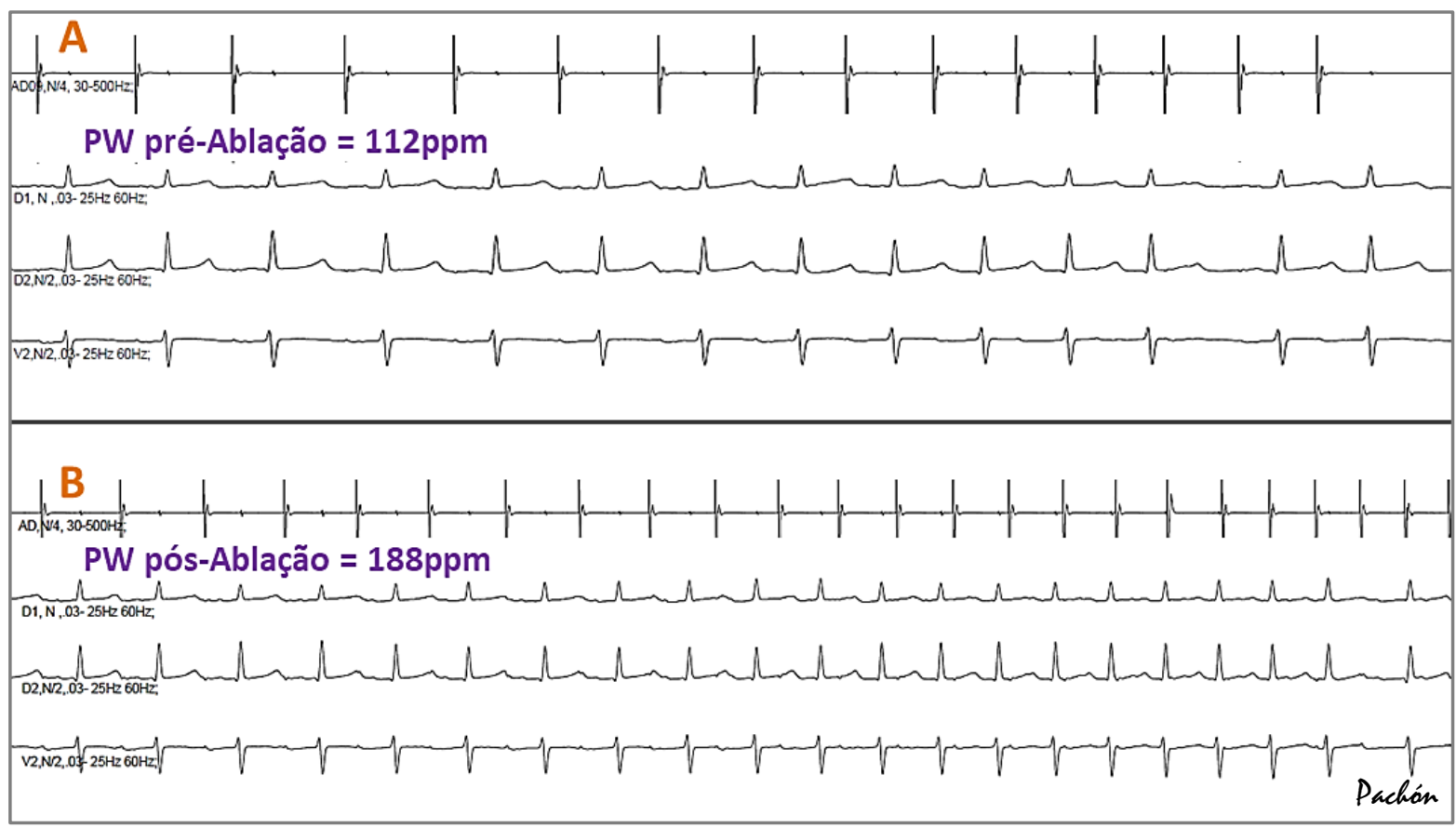

Exemplo de traçados de um mesmo paciente do GNFA, durante a ablação dos NFA. O traçado $A$ foi obtido no início dos procedimentos, mostrando um Ponto de Wenckebach de $112 \mathrm{ppm}$. O traçado $B$ foi registrado ao final dos procedimentos, após tratados os NFA, observando-se importante aumento do Ponto de Wenckebach para 188 ppm. Fonte: Arquivo SEMAP. 
O lado esquerdo do septo interatrial, numa área triangular entre os antros das veias pulmonares direitas e a fossa oval, tipicamente apresenta maior número de NFA. A aplicação de RF nesta área promoveu, de forma reprodutível em todos os pacientes, um aumento imediato, persistente e significativo da frequência sinusal. Isto sugere que esta região tem grande número de subplexos vagais relacionados à inervação do nó sinusal.

Devido à íntima relação funcional desta área com o automatismo das células P, passamos a denominá-la "Ponto P", Figura 36 A e B. Esta observação, realizada no estudo inicial por Pachón et al., posteriormente foi comprovada pelos estudos de imuno-histoquímica tecidual com marcadores de acetilcolinesterase, realizados por Pauza et al. que demonstraram a existência de grande número de neurônios intraparietais nesta área, relacionados à inervação do nó sinusa ${ }^{59}$.

Outro local de concentração de NFA é óstio do seio coronário, o qual foi abordado nos casos nos quais, ao final dos procedimentos, ainda era possível induzir FA com estimulação atrial "ultra-rápida" (até 300 ppm) ou quando ainda ocorria algum grau de bloqueio AV, durante a EVEC, realizada no decorrer desta etapa da ablação.

A estimulação com 300 ppm foi adotada em todos os pacientes submetidos à ablação da FA, para avaliar a estabilidade das paredes atriais após o tratamento dos NFA e a impossibilidade de indução de taquicardias residuais ou da taquicardia de background $d^{45}$.

Adicionalmente, nos casos que ainda se observava algum grau de resposta vagal à EVEC ao final dos procedimentos, foram realizadas aplicações de RF no sulco de Waterston, região também relacionada à inervação na parede atrial direita, porém, em apenas um paciente esta abordagem mostrou-se necessária. Uma representação dessa região anatômica está demonstrada na Figura 36-C.

Um fato relevante é que a região do "ponto P" é um local onde se encontra um grande número de NFA provavelmente relacionados à inervação oriunda do GP 2 predominantemente. 
Figura 36 - Representação esquemática do "ponto P" e do sulco de Waterston.

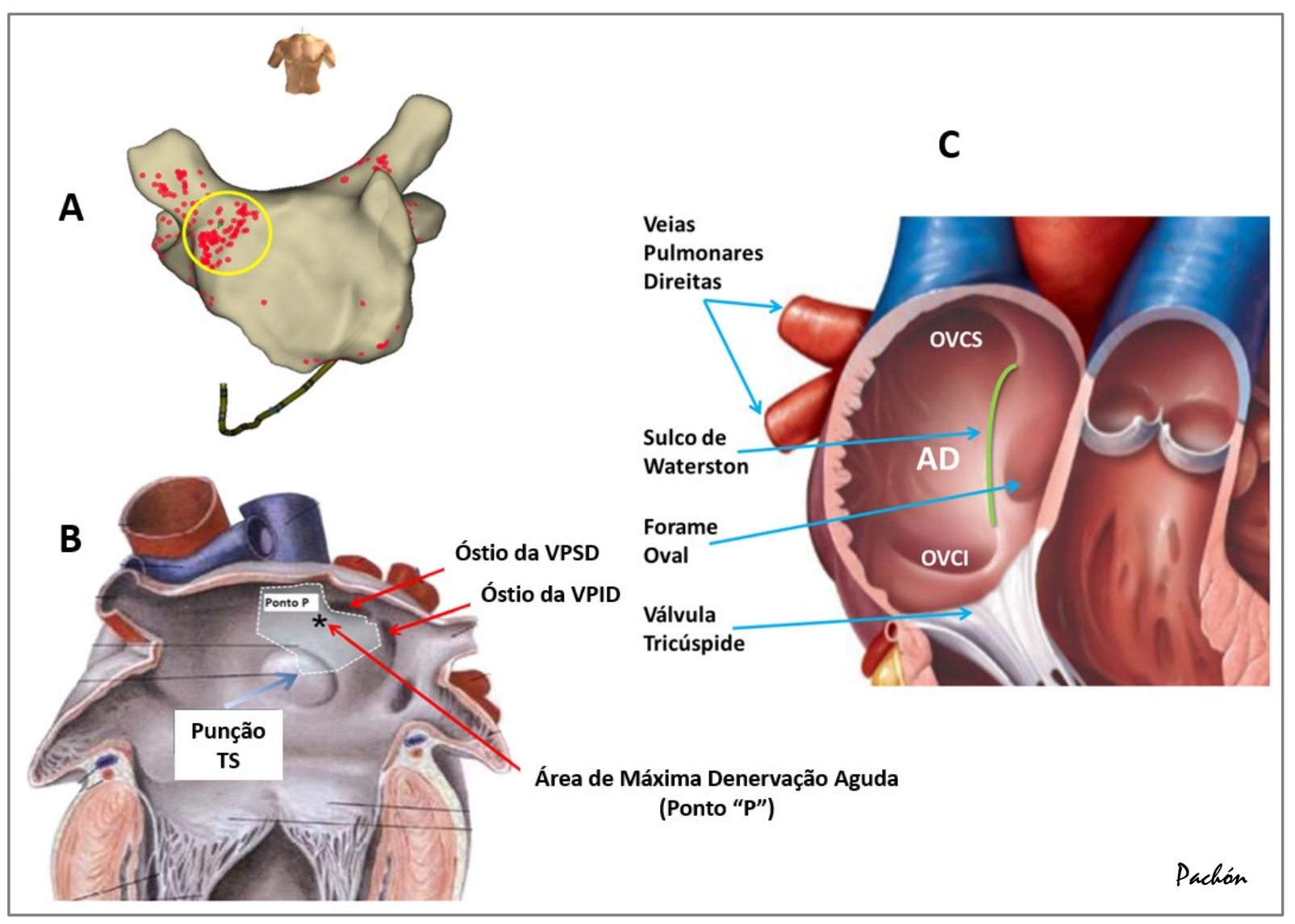

A: Imagem obtida pelo sistema de mapeamento eletroanatômico tridimensional Ensite $₫$ de um paciente do GNFA. O modelo representa o volume do AE na projeção AP. Os pontos na cor vermelha correspondem aos NFA ablacionados. O círculo amarelo mostra a região de grande densidade de NFA, a qual denominamos "ponto P". B: Esquema da localização do "ponto P" projetado em uma peça anatômica. C: Esquema da anatomia do átrio direito (AD) destacando o sulco de Waterston (linha imaginária na cor verde). OVCS: óstio da veia cava superior; OVCI: Óstio da veia cava inferior, TS: Transeptal. Fonte: http://clipart-library.com/unlabelled-diagram-of-the-heart.html e arquivo SEMAP.

As aplicações de RF nestes ninhos promovem um aumento gradual e sustentado da frequência sinusal observado progressivamente com a liberação da RF, conforme pode ser visto na Figura $37 \mathrm{~A}$ e B e na Figura 35 (pág 72). O aumento da FC assim obtido, tende a permanecer e reflete a redução do tônus vagal, sendo de grande valia no tratamento das bradicardias sintomáticas funcionais e síndrome neurocardiogênica cardioinibitória. 
Figura 37 - Aplicação de RF no "Ponto P".

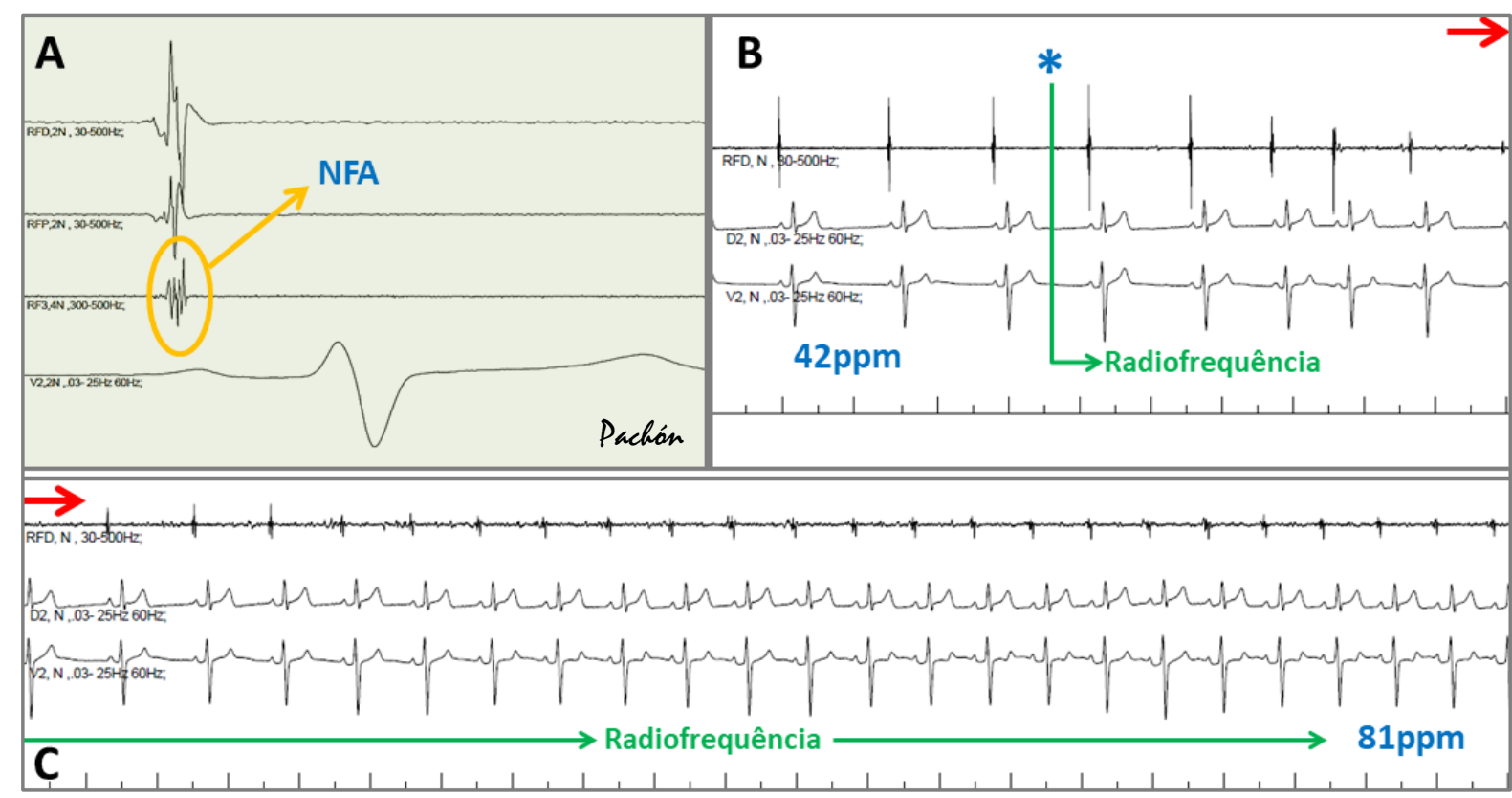

Exemplo obtido durante a ablação de paciente do GNFA portador de bradicardia funcional sintomática. Em A podemos observar um típico NFA identificado pelo método simplificado no polígrafo. Observar as altas frequências detectadas no canal 3 (círculo de cor laranja), que identificam os NFA. B e C são traçados contínuos obtidos durante a aplicação de RF no NFA indicado em A. A RF é liberada a partir da linha vertical de cor verde $\left(^{*}\right)$ e é mantida até o final do registro $C$. Observar o aumento gradual da FC, que variou de 42 ppm no início para 81 ppm ao final da aplicação, em decorrência da denervação vagal imediata obtida. Fonte: Arquivo SEMAP.

A EVEC, quanto realizada após a ablação do "ponto P", geralmente mostra o ritmo sinusal mantido, porém com bloqueio $A \bigvee$ variável, pois a inervação tratada neste local está relacionada principalmente com o nó sinusal, na maioria dos pacientes, com pouca ou mínima participação no nó AV.

Como foi realizada a EVEC após o tratamento de cada região do átrio esquerdo e átrio direito, foi possível analisar a mudança de comportamento de forma escalonada em cada região tratada. $\mathrm{Na}$ Tabela 7 , há um resumo das respostas mais frequentemente obtidas à EVEC, de acordo com os locais de ablação dos NFA. Estas observações permitem direcionar os locais de abordagem dos NFA para cada paciente, conforme o resultado desejado, porém, o resultado final depende da distribuição individual da inervação. Por conta disto, consideramos recomendável realizar a EVEC a cada etapa de ablação, até obter-se o resultado almejado. 
Tabela 7 - Resumo dos comentários a respeito das tendências dos comportamentos do ritmo sinusal e da junção AV observados no GNFA de acordo com a localização dos NFA ablacionados.

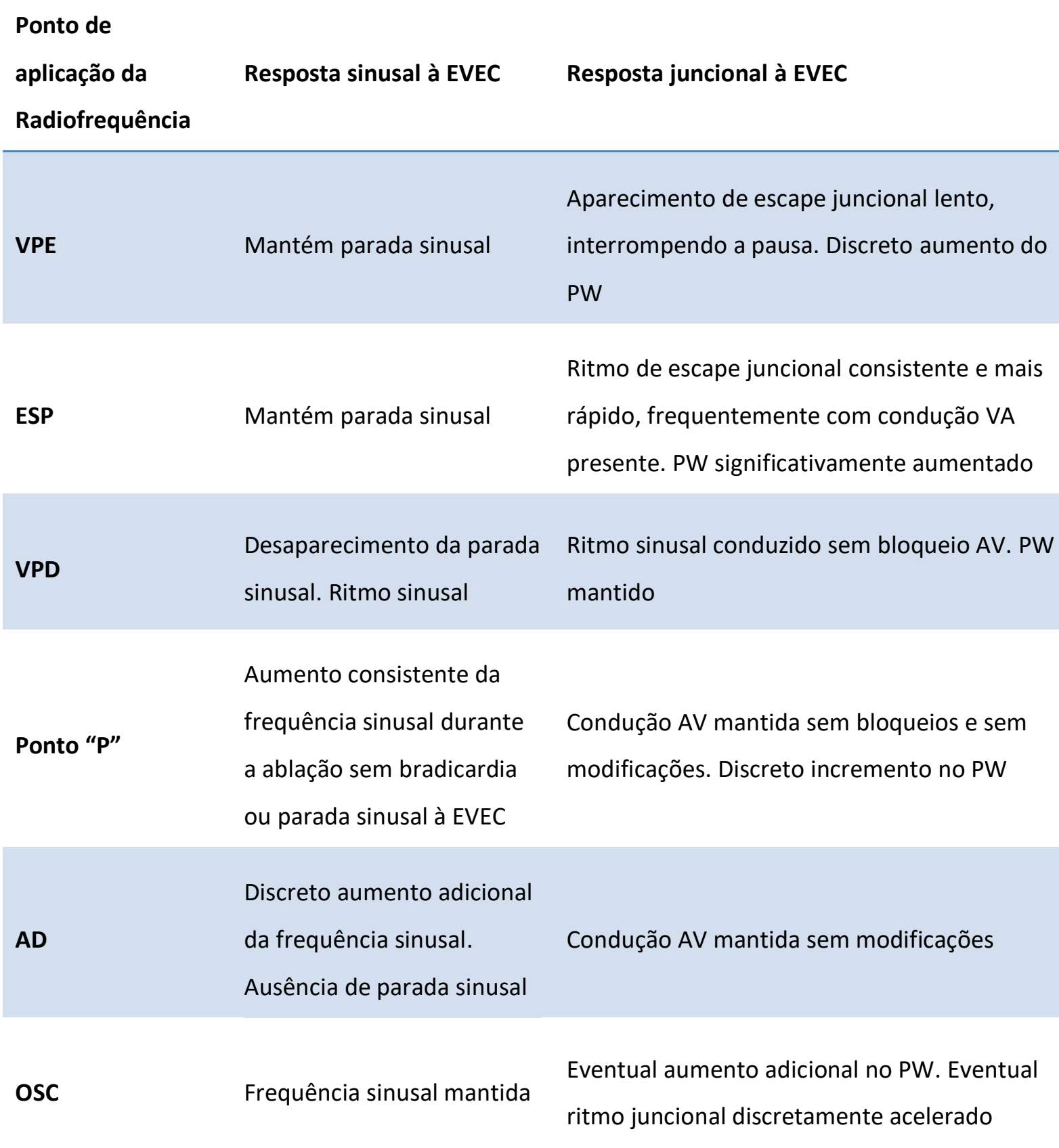

VPE: Antro das veias pulmonares esquerdas; ESP: Espaço septal posterior; VPD: Antro das veias pulmonares direitas; AD: Átrio direito; OSC: Óstio do seio coronário; PW: Ponto de Wenckebach.

A mesma análise, quando realizada no grupo controle, mostra que a aplicação de RF sobre focos isolados de arritmias, não relacionados aos NFA, não modifica a 
resposta vagal à EVEC, Figura 38. A comparação das pausas pré e pós-ablação nestes pacientes, mostra que não houve modificação significativa deste dado $(p=0,35)$, confirmando que a aplicação de RF fora dos NFA não produz denervação vagal, conforme descrito anteriormente. Este fato reforça a importância da EVEC nesta avaliação e a relação dos NFA com a inervação vagal. As pequenas variações encontradas nas pausas pré e pós-ablação no GC, foram atribuídas às alterações fisiológicas que ocorrem durante o procedimento, relacionadas à anestesia, às variações metabólicas e à temperatura, entre outras; porém, estas flutuações estiveram presentes em ambos os grupos avaliados, permitindo perfeita comparação entre eles.

Figura 38- Gráfico comparativo entre as pausas pré e pós-ablação pela EVEC no GC.

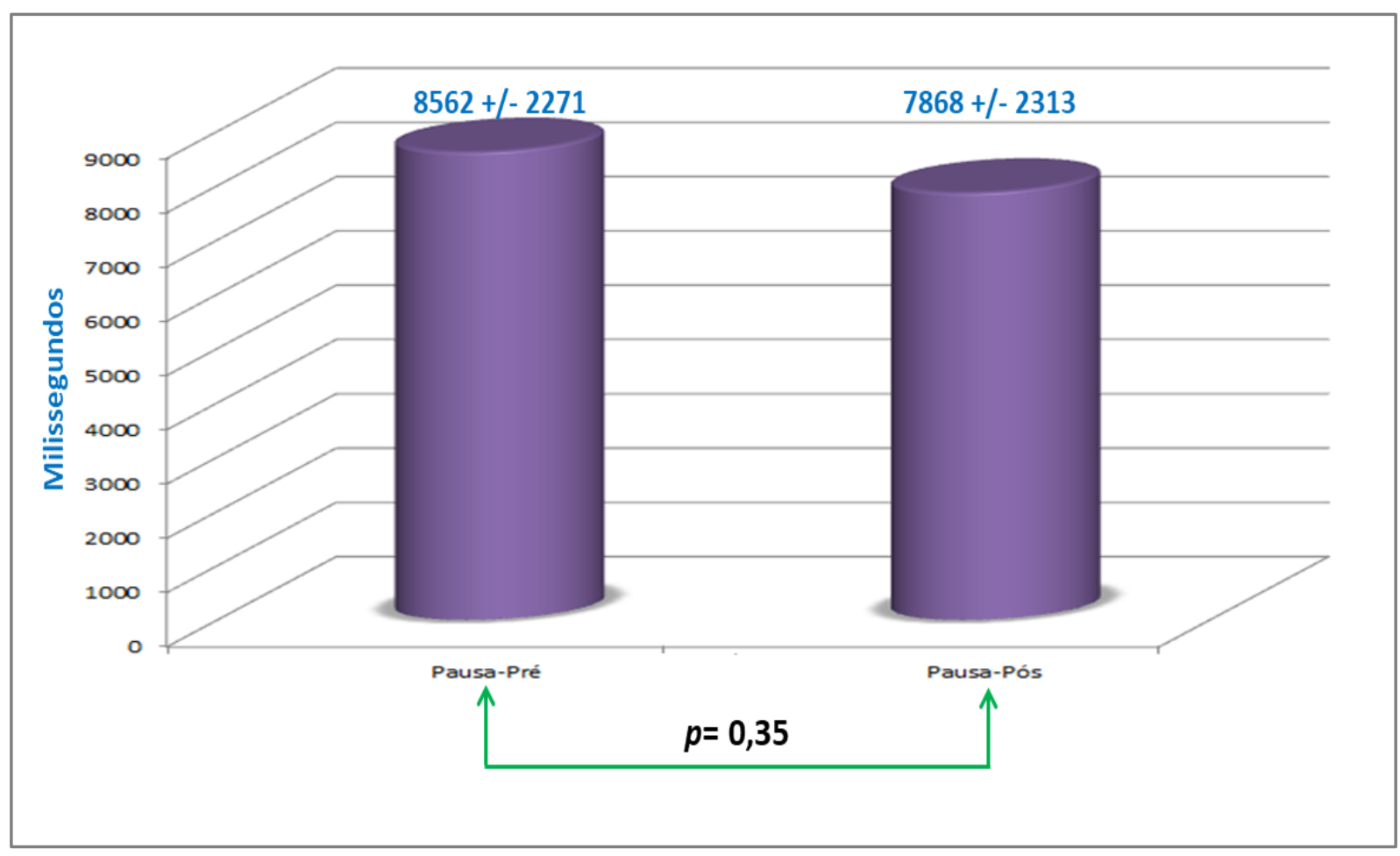

A EVEC no grupo controle produziu pausas pré e pós-ablação muito semelhantes entre si. Ocorreu uma pequena diferença atribuída às modificações fisiológicas do paciente que ocorrem entre o início e o final do procedimento, porém essa diferença não apresentou significância estatística.

A EVEC nos pacientes do GC produziu diferentes respostas no nó sinusal e no nó atrioventricular, as quais auxiliaram tanto no diagnóstico da arritmia de base como no 
controle de sucesso da ablação em alguns casos. As principais respostas observadas nas funções do nó sinusal e do nó AV estão tabuladas na Tabela 8 , sendo estas, informações adicionais que poderão ser utilizadas em procedimentos direcionados.

Tabela 8 - Resumo dos comentários a respeito das tendências dos comportamentos do ritmo sinusal e da junção AV observados no GC, conforme a localização do foco arritmogênico.

\begin{tabular}{lll}
\hline $\begin{array}{l}\text { Ponto de } \\
\text { aplicação da } \\
\text { Radiofrequência }\end{array}$ & Resposta sinusal à EVEC & Resposta juncional à EVEC \\
\hline RAV & Parada sinusal & Assistolia \\
\hline WPW & Parada sinusal & $\begin{array}{l}\text { Assistolia (condução exclusiva pelo } \\
\text { feixe quando o AD é estimulado) }\end{array}$ \\
\hline Foco de EV & Parada sinusal & Assistolia \\
\hline Foco no AD & Parada sinusal & Assistolia \\
\hline $\begin{array}{l}\text { Flutter atrial } \\
\text { tricúspide }\end{array}$ & Parada sinusal & Escape juncional em alguns casos \\
\hline Via lenta (RN) & Parada sinusal & $\begin{array}{l}\text { Escape juncional ou ritmo juncional em } \\
\text { alguns casos }\end{array}$ \\
\hline
\end{tabular}

RAV: Reentrada atrioventricular; WPW: Wolf-Parkinson-White; EV: Extrassístole ventricular; AD: Átrio direito; RN: Reentrada nodal.

\subsection{Achados Adicionais Relevantes}

\subsubsection{Reversão de Taquicardias Supraventriculares Pela EVEC}

Adicionalmente, a EVEC mostrou-se muito útil para a reversão das taquicardias supraventriculares, Figura 39 (disponível em vídeo Reversão de TPSV pela EVEC [https://youtu.be/MVKQc GwKZ6s] na plataforma digital), permitindo também confirmar a participação do nó AV ou do nó sinusal na taquicardia. Esta observação 
não era objetivo deste estudo, porém, foi um recurso utilizado durante as ablações de taquicardias supraventriculares no GC, para reversão reprodutível dessas taquicardias demonstrando que a EVEC é um recurso de grande valor nos procedimentos de Eletrofisiologia. Uma observação notável é que a EVEC, na medida que provoca grandes oscilações do sistema nervoso autonômico, induz o surgimento de extrassístoles ventriculares do coração normal. Deste modo, no GC, nas ablações das extrassístoles ventriculares que desapareciam espontaneamente, a EVEC foi útil para induzir o seu reaparecimento e permitir o mapeamento.

Figura 39 - Exemplo de aplicação adicional da EVEC na reversão de taquicardia supraventricular sustentada.

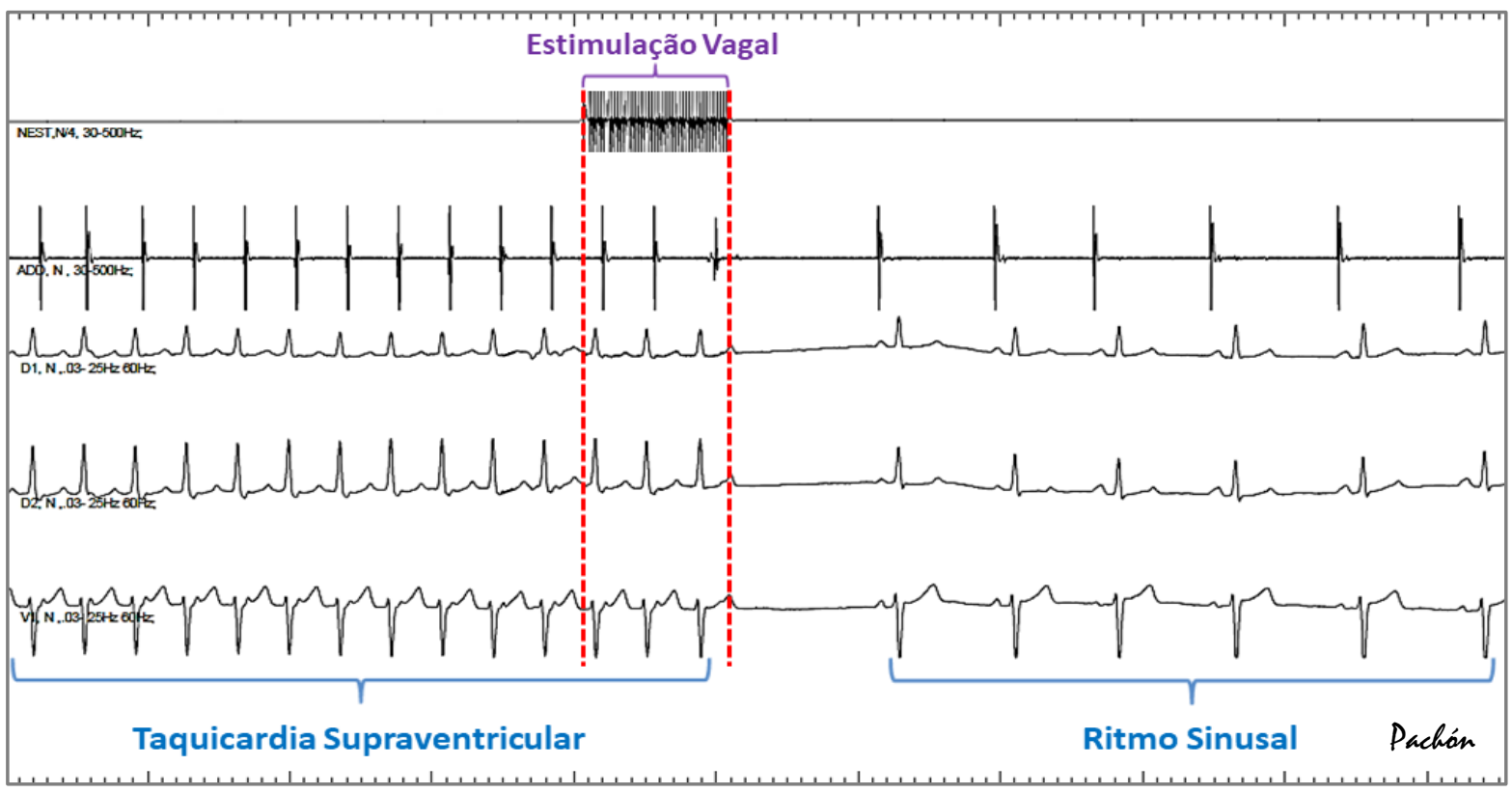

Conforme comentado no texto, uma EVEC de $1 \mathrm{~s}$ promove a reversão imediata da taquicardia supraventricular sem efeito residual. A reversão ocorreu por bloqueio de uma onda $\mathrm{P}$ mostrando que $\mathrm{o}$ braço anterógrado da taquicardia inclui o nó AV. Neste cenário, consideramos esta alternativa preferível à infusão de adenosina IV. Tal recurso foi utilizado nos pacientes do GC, tanto para a reversão como para auxiliar no diagnóstico diferencial de vias de condução acessórias e para induzir o reaparecimento de extrassístoles ventriculares. Fonte: Arquivo SEMAP.

Devido à enorme eficiência da acetilcolinesterase, a estimulação vagal pode ser aplicada inúmeras vezes durante os procedimentos, sem efeito residual e sem risco de toxicidade, como ocorre com a adenosina. Durante os estudos e no acompanhamento de mais de um ano destes pacientes não ocorreram quaisquer 
alterações clínicas que pudessem ser relacionadas à EVEC mesmo utilizada repetidas vezes durante os procedimentos.

\subsubsection{Denervação Parcial Transitória da Junção AV}

No GC verificamos que os pacientes, tratados de taquicardia por reentrada nodal e de flutter atrial apresentaram comportamento peculiar. Nestes, apesar da resposta sinusal não ter tido qualquer modificação com as aplicações de RF, houve discreta modificação no comportamento do nó AV, tendo-se observado surgimento de ritmo juncional, durante a EVEC após a ablação, denotando um incremento da função do nó AV por provável denervação parcial. Isto provavelmente ocorreu porque as aplicações de RF nestes dois grupos foram bem próximas ao óstio do seio coronário, local relacionado ao GP3. Esta observação sugere que nestes locais, podem ter sido parcialmente eliminados subplexos neurais parietais e mesmo neurônios do GP3 durante a ablação da via lenta (na reentrada nodal) ou durante o bloqueio no istmo cavo-tricuspídeo (no flutter típico) por ação transmural da RF. Entretanto, como o procedimento é pontual e menos abrangente há uma tendência de regeneração da inervação e normalização completa do nó AV na evolução. Desde o estudo inicial da CNA observamos hiperautomatismo do nó AV em ablações da região da via lenta e do istmo do flutter. Este achado também foi relatado por outros autores, porém, sem o entendimento sobre a denervação endocárdica identificado neste estudo. Posteriormente, outros autores repetiram nossas observações ${ }^{60,61,62}$.

\subsubsection{Tratamento das Bradiarritmias Funcionais}

A possibilidade tratar pela ablação, os NFA, obtendo alto grau de denervação vagal, permite uma importante aplicação clínica no tratamento das bradiarritmias sem cardiopatia aparente. Este grupo compreende as bradicardias reflexas, como a síncope cardioinibitória e mista, bradiarritmias funcionais por aumento persistente do tônus vagal, síndrome bradi-taquicardia e síncope do seio carotídeo hipersensível sem doença do nó sinusal. Com esta alternativa, muitos destes pacientes podem ser tratados sem o implante de marca-passo ${ }^{1,28,61,62}$. Os resultados em longo prazo estão se mostrando relevantes, reforçando seu potencial valor terapêutico ${ }^{29}$ sendo 
reproduzidos e publicados por diversos autores, em metanálise ou na forma de casereports ${ }^{12,58,63}$. Entretanto, o sucesso deste método depende da abordagem correta dos sítios que permitem ampla e duradoura denervação parassimpática, além da comprovação imediata da denervação vagal, durante a ablação, obtida pela EVEC. Neste sentido, é essencial eliminar os corpos celulares dos neurônios parassimpáticos pós-ganglionares intramural e ganglionar ${ }^{59}$. As fibras eferentes simpáticas e aferentes sensoriais eliminadas, regeneram-se desde que o corpo neuronal seja preservado ${ }^{64}$, fato largamente estudado nos pacientes com transplante cardíaco ${ }^{65,66}$. O mesmo grau de reinervação não ocorre com o sistema nervoso parassimpático, sendo observada uma denervação permanente ou uma atenuação importante do efeito vagal em longo prazo, devido à eliminação de grande quantidade dos neurônios parassimpáticos pósganglionares localizados nas paredes atriais (NFA) e nos GP.

Exemplo deste fato pode ser comprovado na Figura 40, na qual um paciente do GNFA que apresentou uma recidiva tardia (não por FA mas por taquicardia de background ${ }^{45}$ ) foi submetido a novo procedimento um ano após.

Figura 40 - Manutenção da denervação no longo prazo.

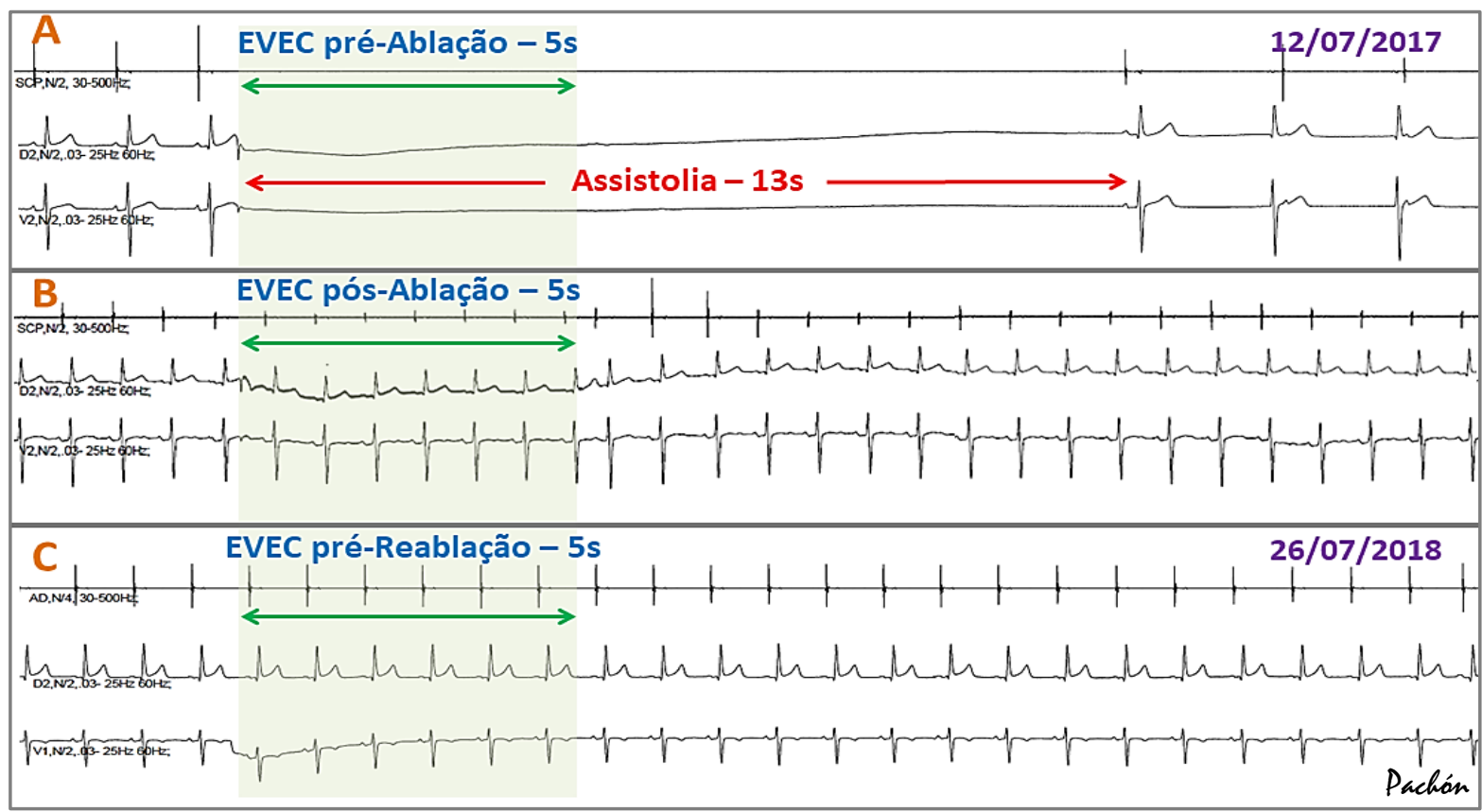

Traçados de um mesmo paciente durante EVEC (área sombreada). Em A: Início do procedimento, ocorre pausa de $13 \mathrm{~s}$ com a estimulação neural. Em B: Final do procedimento com a EVEC comprovando a denervação plena. Em C: reablação do mesmo paciente 1ano após a ablação inicial, mostrando que houve manutenção da denervação inicial. Fonte: Arquivo SEMAP. 
A EVEC no início do segundo procedimento mostrou ausência de resposta vagal, o mesmo resultado obtido ao final do procedimento de um ano antes. Este fato corrobora as afirmações deste estudo em relação à reduzida reinervação parassimpática em longo prazo, desde que a EVEC demonstre total eliminação da resposta vagal no primeiro procedimento.

\subsubsection{Tratamento da FA Vagal}

Outra utilidade potencial da denervação vagal obtida com a ablação dos NFA é no tratamento da $F A$ vagal ${ }^{67}$, na qual, a validação da denervação vagal pela EVEC após a ablação é desfecho fundamental para a confirmação do resultado. Neste grupo comumente observa-se o aparecimento espontâneo de FA causada pela ação vagal durante a EVEC, Figura 41 (disponível em vídeo Indução de FA com a EVEC-01 [https://youtu.be/rrl6oUPmzWs] e vídeo Indução de FA com a EVEC-02 [https://youtu.be/dOOrMT33BIA] na plataforma digital) e a não reindução da arritmia com nova EVEC, ao final da ablação, permitindo a validação do desfecho desejado.

Figura 41 - Exemplo de surgimento de FA após a EVEC em paciente do GNFA.

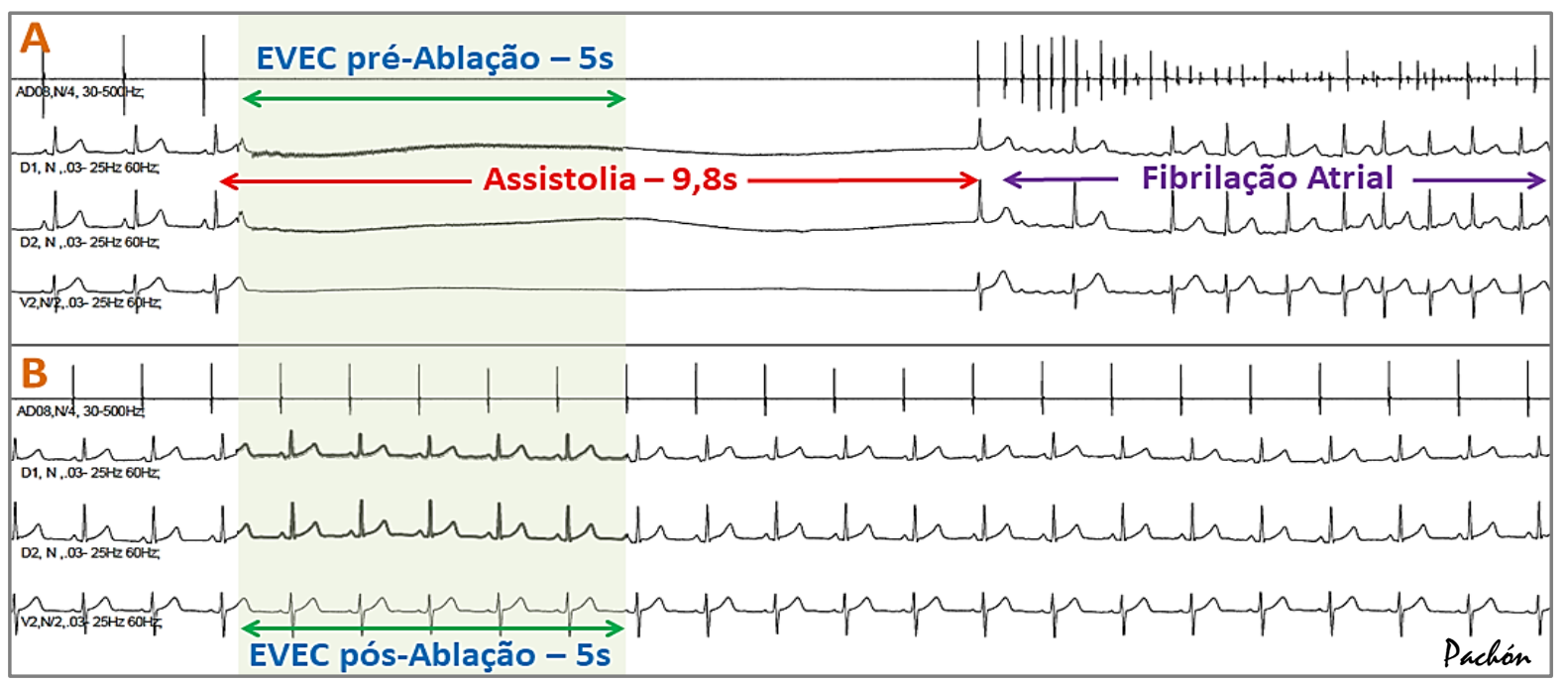

Exemplo de um paciente do GNFA apresentando FA tipicamente relacionada ao efeito vagal. O traçado superior (A) mostra uma estimulação vagal durante $5 \mathrm{~s}$ (área destacada na cor verde) que causa uma pausa imediata com assistolia de $9,8 \mathrm{~s}$ seguida pelo surgimento de FA. O canal atrial superior (AD) mostra o RS no início, a pausa sinusal no meio e a FA ao final do traçado. Este paciente foi tratado com a ablação de FA e denervação, por meio da abordagem dos NFA. No final do procedimento, a estimulação vagal foi repetida igualmente por $5 \mathrm{~s}$ (traçado inferior - B), e nenhuma pausa ou FA foram observadas. Houve ausência completa da resposta vagal, mostrando que foi alcançado um importante desfecho imediato do tratamento, comprovado pela EVEC. Fonte: Arquivo SEMAP. 
Outro achado adicional e expressivo deste estudo é que o surgimento da FA pode ser sensibilizado pela EVEC após infusão de isoproterenol. Também notamos que a EVEC facilita a ocorrência de FA quando se realiza a estimulação atrial durante a resposta vagal. Estes dados estão aqui mencionados apenas como observação complementar no espectro dos achados resultantes da estimulação vagal.

\subsection{Outros Achados Correlatos}

Também observamos que a estimulação endovascular da artéria pulmonar direita é outra fonte de estimulação vagal, ocorrendo preferencialmente bloqueio $A V$, com menor efeito sobre o nó sinusal. Nos pacientes com extrassístoles ventriculares da via de saída do VD, a EVEC na artéria pulmonar favoreceu o aparecimento das EVs, que não ocorriam espontaneamente durante o procedimento. A EVEC aplicada na região do forame jugular também reproduziu esse comportamento, em alguns pacientes, sendo utilizado como recurso adicional durante o mapeamento destas arritmias. Este fenômeno foi observado principalmente após o "Tempo de normalização vagal”. A Figura 28 (pág 58), mostra um exemplo destes casos do GC, no qual a EV não ocorria espontaneamente, prejudicando seu mapeamento, mas aparecia sempre após a EVEC. Esta, além de auxiliar no mapeamento, possibilitou comprovar a ausência da EV após ablação com sucesso.

No GNFA, o mapeamento foi complementado com aplicação de RF em regiões anatômicas relacionadas aos principais GPs cardíacos conforme já mencionado nos métodos. Diversos estudos têm mostrado que existem pelo menos três GPs principais localizados em coxins de gordura epicárdica. A maior parte da inervação vagal do nó sinusal é originária da VCS-GP (primeiro GP) e da VPSD-GP (segundo GP), enquanto a maior parte da inervação vagal do nó AV é originária da VCl-GP (terceiro GP). Assim, é possível obter denervação vagal adicional, por ablação anatômica endocárdica atrial atuando sobre as áreas dos $\mathrm{GP}^{32}$. A Figura 42 mostra esquematicamente, os locais onde foram identificados a maioria dos NFA, com o propósito do tratamento do GNFA. 
Figura 42 - Mapa dos locais dos NFA.

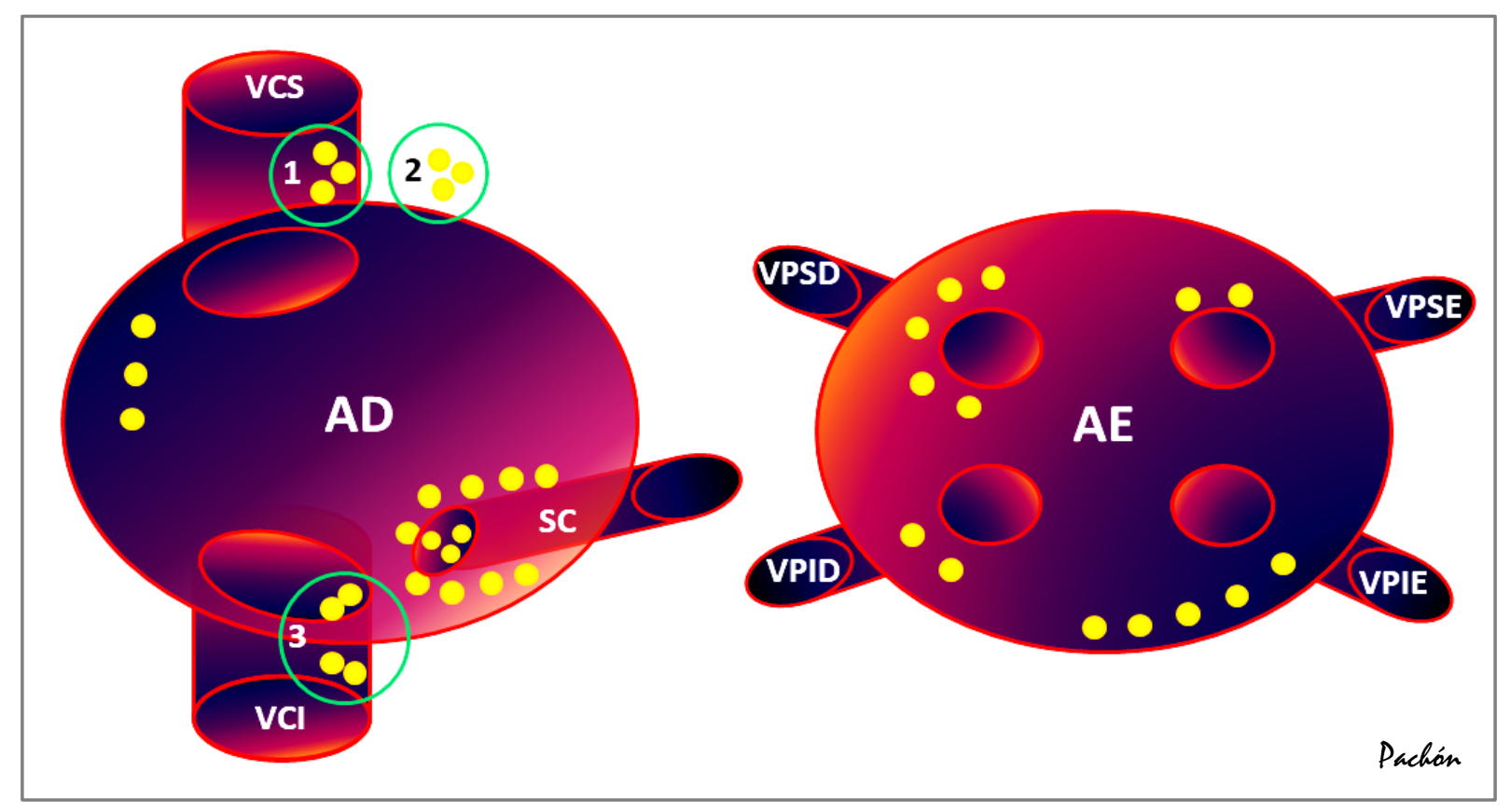

Esquema mostrando as áreas do coração ("mapa") onde foram identificados, em $82 \%$ dos casos do GNFA, os NFA (círculos amarelos). VCS: Veia cava superior; VCl: Veia cava inferior; AD: Átrio direito; SC: Seio coronário; AE: Átrio esquerdo; VPSD: Veia pulmonar superior direita; VPSE: Veia pulmonar superior esquerda; VPID: Veia pulmonar inferior direita; VPIE: Veia pulmonar inferior esquerda; 1, 2 e 3 representam os gânglios paracardíacos. Fonte: Arquivo SEMAP.

Este esquema cumpre um dos objetivos deste estudo, que é o de produzir um "mapa" demonstrando os locais onde identificamos os NFA, na maioria dos pacientes, com o propósito de auxiliar outros investigadores a obter resultados semelhantes.

\subsection{Teste de Atropina Versus Estimulação Vagal Extracardíaca}

A elaboração de um método simples de estimulação vagal, durante os procedimentos eletrofisiológicos, é muito oportuna e apropriada no momento atual, devido ao crescente interesse nas intervenções cardíacas autonômicas ${ }^{1,13,63,68,69,70}$.

No primeiro estudo de cardioneuroablação ${ }^{1}$, empregou-se a atropina intravenosa no final dos procedimentos, para confirmar se a denervação vagal estava completa. Caso houvesse resposta à atropina, a denervação não estava completa e aplicações adicionais de RF teriam que ser realizadas. No entanto, o longo efeito da atropina (média de 4,1 horas) tornava difícil quaisquer conclusões posteriores, Figura $43^{71}$. Por 
este motivo a EVEC, que pode ser repetida a qualquer momento durante as ablações passo a passo e que não causa interferência autonômica residual, mostra-se muito superior para controle escalonado da denervação.

Devido à dirigibilidade para cateterizar as veias, o cateter de RF pode ser usado para a estimulação vagal, desde que desconectado do gerador de RF e conectado ao estimulador vagal. Foram utilizados os polos distais e o terceiro anel do cateter para a EVEC, com o propósito de constituir um campo elétrico mais abrangente, ao mesmo tempo que se evita a concentração de energia em uma área muito pequena, como já foi anteriormente explicado. Entretanto o cateter de ablação não é o ideal e, neste sentido, projetamos um cateter eletrodo com características especiais para estimulação vagal que está em processo de patente nos EUA (Anexo A3 - página 104).

Figura 43 - Exemplo de eliminação completa da resposta induzida pela EVEC após a atropina.

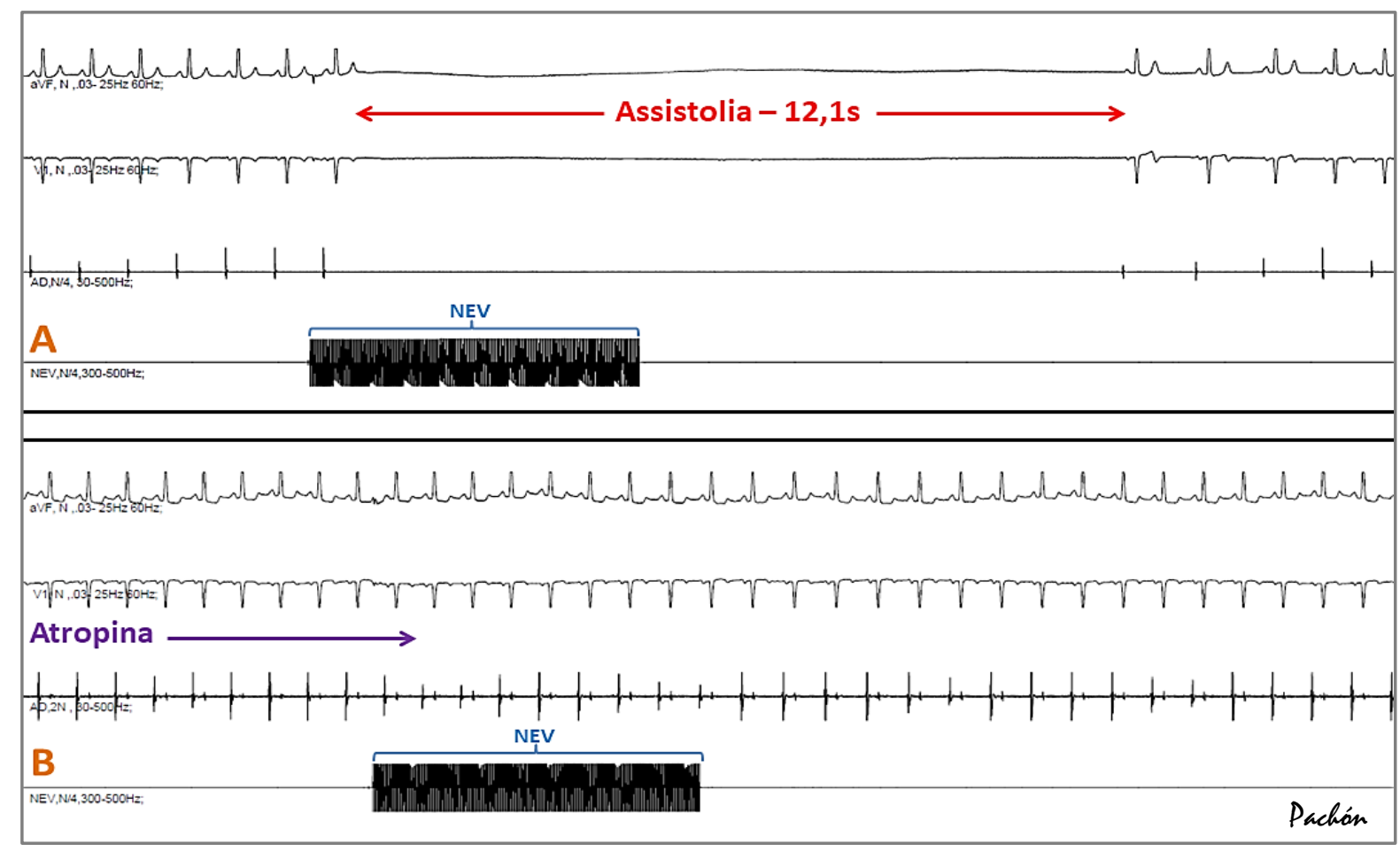

Traçados exemplo de paciente do GC. A EVEC inicial (A) produziu uma pausa prolongada, que se manteve 7,1s após terminada a estimulação vagal. Em seguida (B), após infusão de atropina (0,04 $\mathrm{mg} / \mathrm{kg}$ ), a mesma estimulação vagal não produz qualquer modificação da frequência sinusal ou da condução $\mathrm{AV}$, comprovando o bloqueio químico da inervação vagal pela atropina, cujo efeito se mantém por cerca de $4 \mathrm{~h}$. Fonte: Arquivo SEMAP. 
A EVEC foi confiável, pois não foi alterada pela anestesia ou pela manipulação dos cateteres, mostrando especificidade para a denervação vagal. Além disso, não mostrou efeitos residuais em média de seguimento de 12,5 \pm 0,4 meses. Adicionalmente, tem baixo custo e grande potencial de emprego na Eletrofisiologia diagnóstica, terapêutica e de pesquisa. Dentre as possibilidades que observamos durante o estudo, uma relevante foi o surgimento de FA durante ou logo após a EVEC, comprovando facilmente a FA vagal. Ocorreram 7 casos entre os 32 pacientes do GNFA o que corresponde a $22 \%$. Estes pacientes eram portadores da "fibrilação atrial vagal" $^{72,73}$ que foi racionalmente identificada com este método. $O$ mais interessante era a reprodutibilidade deste comportamento, o que permitiu prontamente identificar qual era o foco ou as veias pulmonares que originavam a "FA vagal" (trigger), orientando de forma objetiva para onde deveríamos direcionar a ablação. Após as aplicações de RF neste sítio, a FA não mais era induzida, mesmo após repetidas EVECs. A Figura 41 (pág 82) ilustra um destes casos, no qual podemos verificar a indução da FA com a estimulação vagal no início do procedimento e a não indutibilidade da mesma ao final, quando também não se observa qualquer resposta vagal sobre a frequência sinusal ou nó $A V$, apesar de repetidas EVECs (ver vídeo: Reprodutibilidade da EVEC [https://youtu.be/MJZcl mefs7w] na plataforma digital). Um dado bastante consistente foi a não indução de FA em nenhum caso do GC com o mesmo método de estimulação vagal, mostrando que a indução de FA sob efeito vagal está relacionada com a presença clínica de FA.

Além da detecção de FA (na "FA vagal"), outro uso potencial da EVEC foi detectar a presença de uma segunda via acessória, durante a ablação de pacientes com WPW (principalmente útil em casos com contraindicação à adenosina). Na Figura 44, pode-se observar o efeito da EVEC em paciente do grupo controle, portador de WPW, forma inaparente. A combinação da EVEC (provocando bloqueio nodal imediato) com a da estimulação atrial torna evidente a pré-excitação ventricular inaparente. Ao final da ablação, a mesma técnica comprova a ausência do feixe anômalo, o que também foi confirmado pela infusão de adenosina (18mg IV em bolus), a qual, além do bloqueio AV (confirmando a ausência do feixe anômalo), produziu episódio de fibrilação atrial não sustentada. Ambas, a EVEC direita e esquerda, 
causam parada sinusal imediata; no entanto, para a identificação de via acessória, a EVEC esquerda é mais apropriada, por atuar com maior intensidade no nó AV, conforme as observações desta pesquisa.

Em todos os pacientes do GC com feixes anômalos foi realizada esta técnica, a qual se mostrou muito útil. Estimulações atrial e ventricular durante a EVEC foram utilizadas para identificar a presença pré-ablação e a eliminação pós-ablação das conduções AV e/ou VA pelas vias acessórias, de forma consistente e reprodutível (disponível em vídeo: Reprodutibilidade e Bloqueio VA com a EVEC [https:// youtu.be/vFZ4kkylLOc] na plataforma digital).

Figura 44 - Exemplo dos efeitos da EVEC em paciente do GC com pré-excitação ventricular.

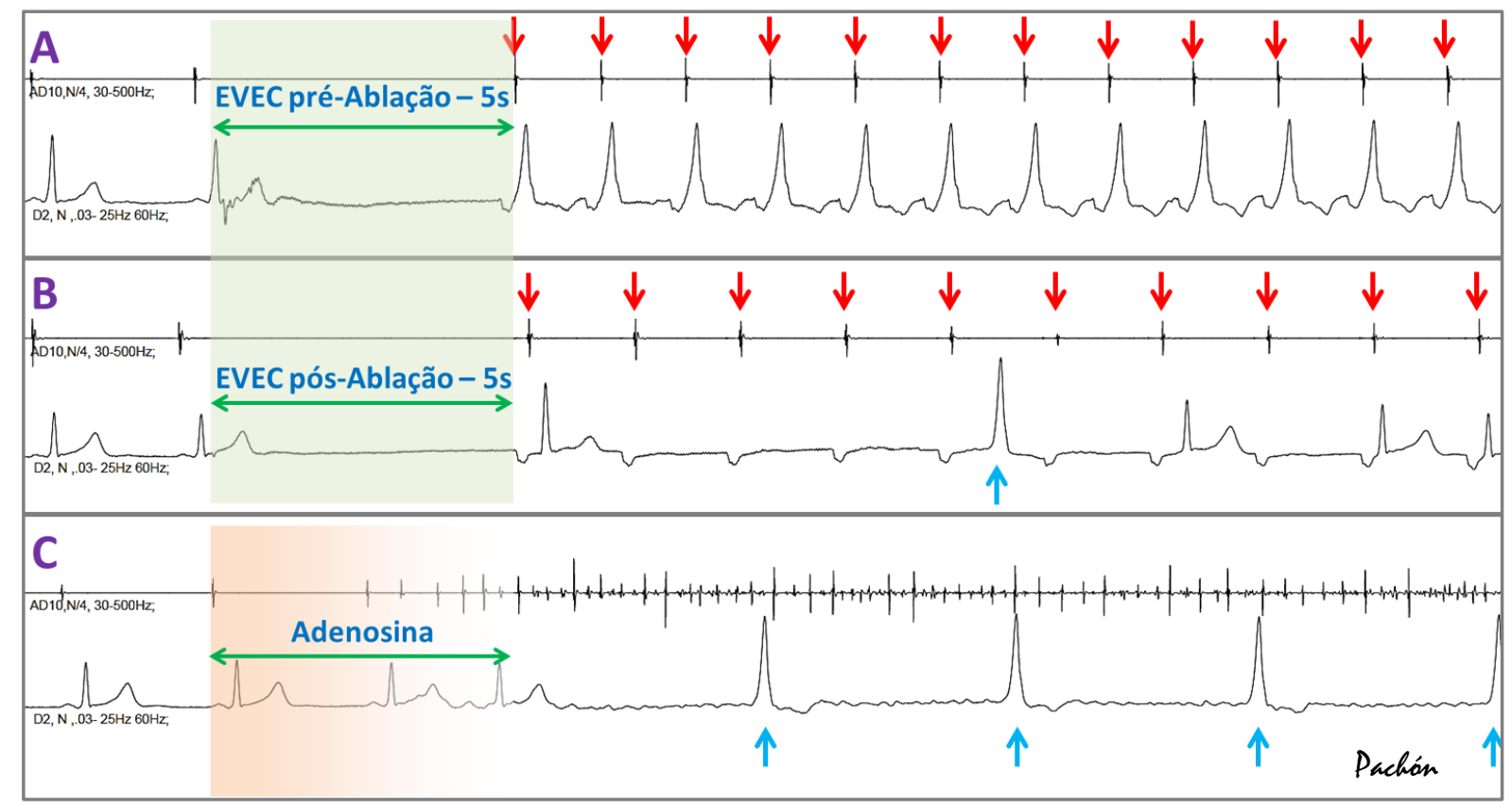

Paciente do GC portador de WPW. No traçado superior (A), a estimulação vagal (EVEC) foi aplicada durante $5 \mathrm{~s}$. Há uma pausa sinusal imediata seguida de um período de estimulação atrial (setas de cor vermelha). Neste momento, apesar do bloqueio nodal, o paciente apresenta condução pela via acessória, não bloqueada pela ação vagal. O QRS estreito prévio (WPW inaparente) tornou-se aberrante, revelando a presença de condução anômala. O traçado central (B) mostra uma nova estimulação vagal, no final da ablação, após a eliminação da via acessória. Ocorre uma assistolia, sendo em seguida iniciada uma estimulação em $A D$ (setas de cor vermelha), comprovando que não há mais condução pelo feixe anômalo ou pelas vias normais e que permanece a ação vagal, já que a ablação foi fora dos NFA. Ocorre um batimento de escape (seta de cor azul). No traçado inferior (C), a infusão de adenosina produziu um episódio de FA sustentada seguida de bloqueio AV e escape ventricular (setas de cor azul). Este comportamento também comprovou a ausência de feixes anômalos neste paciente. Fonte: Arquivo SEMAP. 
Esta resposta foi igualmente obtida com o teste da adenosina: a pré-excitação anterógrada e/ou a condução VA por feixe anômalo foi eliminada em todos os pacientes. A adenosina foi utilizada também em todos os casos com feixes anômalos, confirmando a ausência dos feixes e confrontando os achados com a EVEC. Em um caso foi necessária aplicação adicional de RF, na mesma sessão, pois a EVEC, juntamente com a estimulação ventricular, mostrou que ainda persistia condução anômala ventrículo-atrial. A adenosina não foi infundida neste momento, pois a EVEC já havia demonstrado a presença residual do feixe anômalo. É interessante acrescentar que a duração do bloqueio AV e/ou parada sinusal pela EVEC podem ser definidos pelo tempo da estimulação vagal, ao contrário da adenosina, cujo efeito na condução ventrículo-atrial é muitas vezes variável e fugaz. Devido a este efeito, passamos a denominar a EVEC como "adenosina eletrônica", sendo utilizada sempre que necessário em qualquer estudo eletrofisiológico, Figura 45.

Figura 45 - Comparação entre a EVEC e a adenosina em paciente do GC.

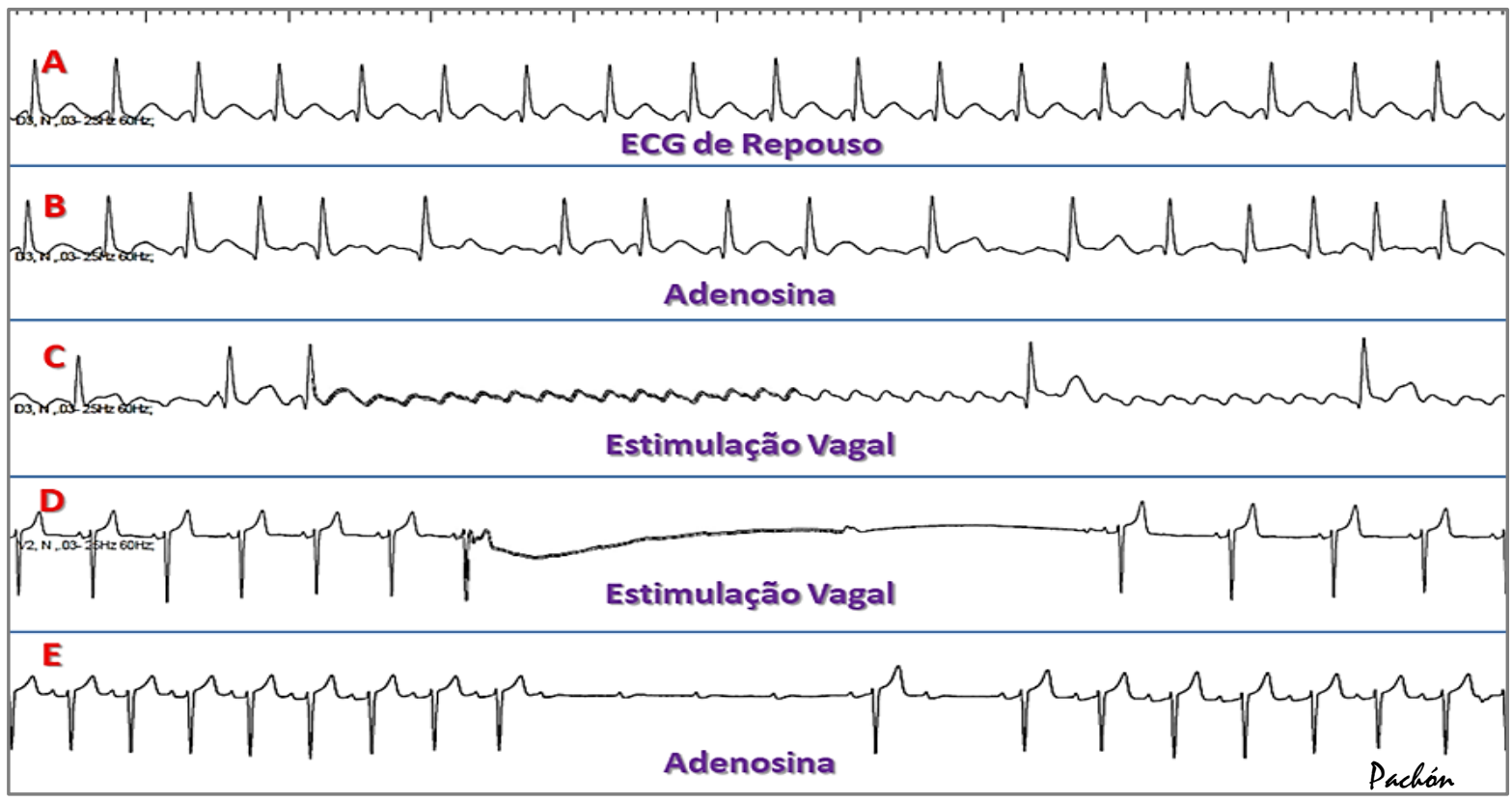

Traçados obtidos durante o estudo eletrofisiológico de paciente do GC. O traçado "A" representa o início do procedimento, em repouso. O traçado "B" mostra a resposta à infusão de $18 \mathrm{mg}$ IV de adenosina e o traçado "C", $5 \mathrm{~s}$ de estimulação vagal. Observa-se que apenas a estimulação vagal permitiu um bloqueio AV transitório consistente, facilitando o diagnóstico. Os traçados " $D$ " e " $E$ " são de outro paciente do GC, em ritmo sinusal, comparando a estimulação vagal e a infusão de adenosina. Neste caso (D) ocorreu bloqueio AV e parada sinusal durante a estimulação vagal. Fonte: Arquivo SEMAP. 
Apesar da adenosina ter efeito semelhante à EVEC, sua ação reside em receptores distintos, de forma que as duas técnicas produzem informações complementares e devem ser adequadamente interpretadas.

Adicionalmente, a EVEC, por ser rapidamente reversível, pode ser utilizada inúmeras vezes durante os procedimentos, o que não seria possível nos casos com alguma contraindicação para o uso de adenosina. Outra interessante observação foi que a pausa produzida pela estimulação vagal persiste enquanto houver estimulação elétrica, e permanece ainda após interromper a estimulação por um tempo variável, ao qual denominamos Tempo de Normalização Vagal, Figura 23 (pág 44) e Figura 34 (pág 71). Não ocorreram complicações. Apesar de abrir um enorme campo de investigação, a utilização da EVEC no estudo eletrofisiológico não foi abordada de forma mais pormenorizada neste momento, pois não é objetivo deste estudo, devendo ser considerada com maior propriedade em investigação apropriada e dirigida com este fim. 


\section{Limitações do Estudo}

Neste estudo, utilizamos predominantemente a resposta à EVEC do vago direito e, em alguns casos, do vago esquerdo, no entanto se a EVEC fosse aplicada regularmente aos dois vagos poderia ampliar as informações. Apesar de os dois vagos atuarem tanto no nó sinusal como no nó $\mathrm{AV}$, a estimulação do vago esquerdo produz uma resposta mais intensa sobre o nó $A V$, enquanto que a estimulação do vago direito produz uma resposta intensa sobre o nó sinusal. Entretanto, a avaliação da lateralidade da EVEC não foi incluída neste estudo, assim como a EVEC bilateral simultânea.

Notamos que, após a denervação do antro das VPEs, na maioria das vezes houve modificação do ponto de Wenckebach, no entanto esta avaliação não foi realizada de forma sistemática, devendo ser motivo de investigação para estudos futuros.

Não realizamos a avaliação em longo prazo da denervação vagal, pois o objetivo era mostrar a resposta vagal imediata sob a EVEC, antes e após a ablação dos NFA. Apesar disso, em um paciente submetido a nova ablação, foi possível observar o efeito prolongado da denervação (um ano após o procedimento inicial). Desta forma, este estudo não foi projetado para avaliar a denervação obtida pela CNA em longo prazo, sendo este um tema relevante para ser abordado em trabalhos futuros. 
12 CONGLUSÕES 


\section{Conclusões}

\subsection{Conclusão Primária}

Os ninhos de fibrilação atrial estão diretamente relacionados com a inervação vagal do coração, e a ablação isolada destes promove importante denervação vagal, comprovada por meio da estimulação vagal extracardíaca a qual, mostrou ser uma ferramenta altamente eficaz para esta finalidade. As aplicações de radiofrequência fora dos ninhos de FA não provocam denervação e não modificam a resposta vagal conforme demonstrado pelo grupo controle.

\subsection{Conclusões Secundárias}

A) A EVEC criada para o controle da CNA é relevante para a Eletrofisiologia, já que permite realizar uma estimulação vagal específica, de forma inócua e de fácil reprodutibilidade. Mostrou-se útil no diagnóstico das arritmias, na sua reversão e no estudo do mecanismo, assim como na comprovação dos resultados da ablação, sem contraindicações e sem efeitos residuais.

B) Dependendo do local do coração, onde os NFA são tratados pela ablação, há respostas diferentes e bem definidas dispostas a seguir.

1. As aplicações no antro das veias pulmonares esquerdas atuam de forma discreta na modificação da frequência sinusal e na melhora do ponto de Wenckebach.

2. As aplicações na região septal posterior, assim como no gânglio 3, aumentam de forma consistente e adicional, o ponto de Wenckebach.

3. As aplicações no "ponto P" (relacionadas ao gânglio 2) são as que promovem de forma mais intensa a denervação vagal sinusal, apesar de que também denervam o nó AV.

4. As aplicações nos ninhos de fibrilação atrial na região do gânglio 1 promovem comumente aumento adicional da frequência.

5. As aplicações de RF no átrio direito contribuíram na denervação, porém, com menor efeito do que as aplicações no átrio esquerdo. 
6. Para se obter uma denervação completa e consistente, são necessárias aplicações de radiofrequência nos dois átrios, em todas as áreas descritas.

C) Houve excelente resposta clínica dos pacientes com FA, principalmente aqueles cuja FA estava relacionada à estimulação vagal, mostrando também a relação entre os NFA e essa arritmia, já que a eliminação destes resultou em excelente evolução ambulatorial em longo prazo.

Estes achados são relevantes para a prática clínica pois, além de contribuírem para esclarecimento da fisiologia cardíaca e fisiopatologia das arritmias cardíacas e inervação do coração, abrem uma nova possibilidade de tratamento para a fibrilação atrial de origem vagal e/ou para as afecções relacionadas à excessiva ação vagal, sem a necessidade do implante de marca-passo ${ }^{74}$. 


\section{REFERÊNGIAS BIBLIOGRÁFICAS}




\section{Referências Bibliográficas *}

\footnotetext{
${ }^{1}$ Pachon JC, et al. "Cardioneuroablation"--new treatment for neurocardiogenic syncope, functional AV block and sinus dysfunction using catheter RF-ablation. Europace. 2005 Jan;7(1):1-13.
}

2 Jose AD, Collison D. The normal range and determinants of the intrinsic heart rate in man. Cardiovasc Res. 1970 Apr;4(2):160-7. PubMed PMID: 4192616.

${ }^{3}$ Marcus B, Gillette PC, Garson A Jr. Intrinsic heart rate in children and Young adults: an index of sinus node function isolated from autonomic control. Am Heart J. 1990 Apr;119(4):911-6. PubMed PMID: 2321510.

${ }^{4}$ Pachon M JC, et al. A new treatment for atrial fibrillation based on spectral analysis to guide the catheter RFablation. Europace. 2004 Nov;6(6):590-601.

${ }^{5}$ Oketani N, Lockwood E, Nademanee K. Incidence and mode of AF termination during substrate ablation of AF guided solely by complex fractionated atrial electrogram mapping (abstr). Circulation 2008;118. Suppl: S925.

${ }^{6}$ Aksu T, et al. Electroanatomic-mapping-guided cardioneuroablation versus combined approach for vasovagal syncope: a cross-sectional observational study. J Interv Card Electrophysiol. 2018 Jul 28. doi: 10.1007/s10840018-0421-4.

7 Oral $\mathrm{H}$, et al. A randomized assessment of the incremental role of ablation of complex fractionated atrial electrograms after pulmonary vein isolation for long-lasting persistent atrial fibrillation. J Am Coll Cardiol 2009; 53:782-9.

${ }^{8}$ Driessen AH, et al. Ganglion Plexus Ablation in Advanced Atrial Fibrillation: The AFACT Study. J Am Coll Cardiol. 2016 Sep 13;68(11):1155-65. doi: 10.1016/j.jacc.2016.06.036.

${ }^{9}$ Cui B, et al. Acute effects of ganglionated plexi ablation on sinoatrial nodal and atrioventricular nodal functions. Auton Neurosci. 2011 Apr 26;161(1-2):87-94. doi:10.1016/j.autneu.2011.01.004. PubMed PMID: 21316313.

${ }^{10}$ Roman Piotrowski, Jakub Baran, Piotr Kułakowski. Cardioneuroablation using anatomical approach: new and promising method for the treatment of cardioinhibitory neurocardiogenic syncope. Kardiologia polska September 2018. DOI: 10.5603/KP.a2018.0200.

${ }^{11}$ Sakamoto S, et al. Vagal denervation and reinnervation after ablation of ganglionated plexi. J Thorac Cardiovasc Surg. 2010 Feb;139(2):444-52. doi: 10.1016/j.jtcvs.2009.04.056. Epub 2009 Sep 9. PubMed PMID: 19740492; PubMed Central PMCID: PMC2813372.

12 Scanavacca M, et al. Selective vagal denervation of the sinus and atrioventricular nodes, guided by vagal reflexes induced by high frequency stimulation, to treat refractory neurally mediated syncope. J Cardiovasc Electrophysiol. 2009 May;20(5):558-63.

${ }^{13}$ Scanavacca $M$, et al. Selective atrial vagal denervation guided by evoked vagal reflex to treat patients with paroxysmal atrial fibrillation. Circulation. 2006 Aug 29;114(9):876-85.

${ }^{14}$ S. P. Krul A, et al. "Thoracoscopic video-assisted pulmonary vein antrum isolation, ganglionated plexus ablation, and periprocedural confirmation of ablation lesions: first results of a hybrid surgical electrophysiological approach for atrial fibrillation," Circulation: Arrhythmia and Electrophysiology, vol. 4, no. 3, pp. 262-270, 2011.

\footnotetext{
${ }^{*}$ De acordo com Estilo Vancouver.
} 
${ }^{15}$ Takahashi K, et al. Anatomical proximity between ganglionated plexi and epicardial adipose tissue in the left atrium: implication for 3D reconstructed epicardial adipose tissue-based ablation. Journal of Interventional Cardiac Electrophysiology, 47(2), 203-212. doi:10.1007/s10840-016-0130-9.

${ }^{16}$ Pachon, José Carlos \& Pachon, Enrique I., inventors; Apparatus and Methods for Arrhythmia Treatment Based on Spectral Mapping During Sinus Rhythm; United States patent US20110098699 A1. 2011 Jan 18.

${ }^{17}$ Pachón Mateos JC. Marca-passos, Desfibriladores e Ressincronizadores Cardíacos - Noções fundamentais para o clínico. 2014 - Editora Atheneu. ISBN 978-85-388-0498-7.

${ }^{18} \mathrm{Oh} \mathrm{S}$, et al. Complex fractionated electrograms and AF nests in vagally mediated atrial fibrillation. Pacing Clin Electrophysiol. 2010 Dec;33(12):1497-503. doi: 10.1111/j.1540-8159.2010.02834.x. PubMed PMID:20636313.

${ }^{19}$ Armour JA. Potential clinical relevance of the 'little brain' on the mammalian heart. Exp Physiol. 2008 Feb;93(2):165-76. Epub 2007 Nov 2.

${ }^{20}$ Singhal R, et al. Intrinsic Cardiac Autonomic Ganglionated Plexi within Epicardial Fats Modulate the Atrial Substrate Remodeling: Experiences with Atrial Fibrillation Patients Receiving Catheter Ablation. Acta Cardiol Sin. 2016 Mar;32(2):174-84.

${ }^{21}$ Taylor EW, Jordan D, Coote JH. Central control of the cardiovascular and respiratory systems and their interactions in vertebrates. Physiol Rev. 1999 Jul. 79(3):855-916.

${ }^{22}$ Chang HY, et al. Relationship between intrinsic cardiac autonomic ganglionated plexi and the atrial fibrillation nest. Circ J. 2014;78(4):922-8. Epub 2014 Feb 24. PubMed PMID: 24562675.

${ }^{23}$ Yenn-Jiang Lin, et al - Mapping of the Atrial Electrogram in Sinus Rhythm and Different Atrial Fibrillation Substrates. Shenasa M, Hindricks G, Borggrefe M, Breithardt, G - Cardiac Mapping, Wiley-Blackwell 4th Edition, 2013, pg: 323-338.

${ }^{24}$ Arruda M, Natale A. Ablation of permanent AF: adjunctive strategies to pulmonary veins isolation: targeting AF NEST in sinus rhythm and CFAE in AF. J Interv Card Electrophysiol. 2008 Oct;23(1):51-7.

25 Verheule S, et al. - Tissue structure and connexin expression of canine pulmonary veins, Cardiovascular Research, Volume 55, Issue 4, 1 September 2002, Pages 727-738, https://doi.org/10.1016/S0008$\underline{6363(02) 00490-X}$

${ }^{26}$ Pauza DH, Skripka V, Pauziene N. Morphology of the intrinsic cardiac nervous system in the dog: a wholemount study employing histochemical staining with acetylcholinesterase. Cells Tissues Organs. 2002;172(4):297-320.

27 Pachon M JC, et al. Simplified method for vagal effect evaluation in cardiac ablation and electrophysiological procedures. JACC ClinElectrophysiol 2015; 1:451-60.

28 Pachon M JC, et al. Syncopal high-degree AV block treated with catheter RF ablation without pacemaker implantation. Pacing Clin Electrophysiol. 2006 Mar;29(3):318-22.

29 Pachon JC, et al. Catheter ablation of severe neurally meditated reflex (neurocardiogenic or vasovagal) syncope: cardioneuroablation long-term results. Europace. 2011 Sep;13(9):1231-42.

${ }^{30}$ Pauza DH, et al. Morphology, distribution, and variability of the epicardiac neural ganglionated subplexuses in the human heart. Anat Rec. 2000 Aug 1;259(4):353-82.

${ }^{31}$ Pauza DH, Skripka V, Pauziene N. Morphology of the intrinsic cardiac nervous system in the dog: a wholemount study employing histochemical staining with acetylcholinesterase. Cells Tissues Organs. 2002;172(4):297320. 
${ }^{32}$ Chiou CW, Eble JN, Zipes DP. Efferent vagal innervation of the canine atria and sinus and atrioventricular nodes. The third fat pad. Circulation 1997; 95:2573e84.

${ }^{33}$ Van Stee EW. Autonomic Innervation of the Heart. Environmental Health Perspectives. Vol. 26, pp 151-158, 1978.

${ }^{34}$ Lazzara R, et al. Selective in situ parasympathetic control of the canine sinoatrial and atrioventricular nodes. Circ Res 1973; 32:393e401.

${ }^{35}$ Randall WC, et al. Selective vagal innervation of the heart. Ann Clin Lab Sci 1986; 16:198e208.

${ }^{36}$ Chuen-Wang and Zipes - Circulation, 1997;95.2573.

${ }^{37}$ Calzolari V, et al. In Vitro Validation of the Lesion Size Index to Predict Lesion Width and Depth After Irrigated Radiofrequency Ablation in a Porcine Model. JACC Clin Electrophysiol. 2017 Oct;3(10):1126-1135. doi: 10.1016/j.jacep.2017.08.016. Epub 2017 Oct 16. PubMed PMID: 29759495.

${ }^{38}$ Chavez $\mathrm{P}$, et al. Atrioesophageal fistula following ablation procedures for atrial fibrillation: systematic review of case reports. Open Heart. 2015 Sep 10;2(1): e000257. doi: 10.1136/openhrt-2015-000257. eCollection 2015. Review. PubMed PMID: 26380098; PubMed Central PMCID: PMC4567782.

${ }^{39}$ Mateos JC, et al. Simplified method for esophagus protection during radiofrequency catheter ablation of atrial fibrillation-- prospective study of 704 cases. Rev Bras Cir Cardiovasc. 2015 Mar-Apr;30(2):139-47. doi: 10.5935/1678-9741.20150009. PubMed PMID: 26107444; PubMed Central PMCID: PMC4462958.

${ }^{40}$ Dorwarth U, et al. Radiofrequency catheter ablation: different cooled and noncooled electrode systems induce specific lesion geometries and adverse effects profiles. Pacing Clin Electrophysiol. 2003 Jul;26(7 Pt 1):1438-45. PubMed PMID: 12914619.

${ }^{41}$ Santini M, et al. The effect of atropine in vasovagal syncope induced by head-up tilt testing. Eur Heart J. 1999 Dec;20(23):1745-51.

42 Morillo CA, et al. Vagal and sympathetic mechanisms in patients with orthostatic vasovagal syncope. Circulation. 1997 Oct 21;96(8):2509-13.

43 Magalhães LP, et al. Sociedade Brasileira de Cardiologia. II Diretrizes Brasileiras de Fibrilação Atrial. Arq Bras Cardiol-ISSN-0066-782X • Volume 106, № 4, Supl. 2, Abril 2016.

${ }^{44}$ Fuganti CJ et al. Diretrizes:- Implante de Marcapasso nas Bradicardias e em Outras Situações Especiais- Estratificação de Risco de Morte Súbita na Cardiomiopatia Chagásica. Diretrizes da AMB 2015. Disponível em: https://online.flippingbook.com/view/1031663/4/

45 Pachón-M JC, et al. Ablation of "Background Tachycardia" in Long Standing Atrial Fibrillation: Improving the Outcomes by Unmasking a Residual Atrial Fibrillation Perpetuator. J Atr Fibrillation. 2017 Aug 31;10(2):1583. doi: 10.4022/jafib.1583. eCollection 2017 Aug-Sep. PubMed PMID: 29250230; PubMed Central PMCID: PMC5673289.

${ }^{46}$ Amarante, RC. Eficácia e Segurança da Técnica do Desvio Mecânico na Prevenção do Aquecimento do Esôfago na Ablação da Fibrilação Atrial com Cateter por Radiofrequência. Tese apresentada ao Instituto Dante Pazzanese de Cardiologia São Paulo - 2019 - USP/IDPC/Biblioteca/088/18.

47 Bojan Musizza, Samo Ribaric. Monitoring the Depth of Anaesthesia. Sensors (Basel) 2010; 10(12): 1089610935. Published online 2010 Dec 3. doi: 10.3390/s101210896. PMCID: PMC3231065

48 Pachón M., José Carlos. Estudo Eletrofisiológico Transesofágico - Contribuição ao Diagnóstico e Tratamento Intervencionista das Taquicardias Supraventriculares através de Ablação por Radiofrequência. Tese de 
Doutorado, defendida em São Paulo, 1997. Instituição: Faculdade de Medicina da Universidade de São Paulo USP.

${ }^{49}$ Pachon, José Carlos; inventor. Extracardiac Autonomic Nerve Stimulation. United States Patent Reserv (USPTO) 62485956. 2017 Apr 16.

50 Pachon Mateos, JC; Pachón Mateos, El; Cunha Pachón, CT; inventors. European Patent Application. Extracardiac Autonomic Nerve Stimulation. EP 3415196 A1 - 2018 Jun 15.

${ }^{51} \mathrm{Aksu} \mathrm{T}$, et al. Cardioneuroablation in the treatment of neurally mediated reflex syncope: a review of the current literature. Turk Kardiyol Dern Ars. 2017 Dec;45(1):33-41. doi: 10.5543/tkda.2016.55250.

${ }^{52}$ Aksu T, et al. Simplified Cardioneuroablation in the Treatment of Reflex Syncope, Functional AV Block, and Sinus Node Dysfunction. Pacing Clin Electrophysiol. 2016 Jan;39(1):42-53. doi: 10.1111/pace.12756. Epub 2015 Oct 26.

${ }^{53}$ Leier CV, et al. Effects of Commonly Used Cardioactive Drugs on Atrial and Sinoatrial Conduction in Man. Journal of Cardiovascular Pharmacology - 2:553-566 - Raven Press, New York.

${ }^{54}$ Pachon, José Carlos; inventor. Mechanical Esophageal Displacement for Safe Ablation System - MEDSA System. United States Patent Reserv (USPTO) 62551204. 2017 Aug 28.

${ }^{55}$ Horta José Antônio de, et al. Palpitações Persistentes após Ablação por Cateter com Radiofreqüência. Arq Bras Cardiol, volume 68 (n-2), 103-106, 1997.

${ }^{56}$ Arrowood JA, et al. Evidence against reinnervation of cardiac vagal afferents after human orthotopic cardiac transplantation. Circulation 1995; 92:402e8.

${ }^{57} \mathrm{Aksu} \mathrm{T}$, et al. Selective right atrial cardioneuroablation in functional atrioventricular block. Europace. $2017 \mathrm{Feb}$ 1;19(2):333. doi: 10.1093/europace/euv413.

58 Shan Zhaoliang, Wang Yutang, Guo Hongyang. Anatomical-guided 'cardioneuroablation' to treat neurocardiogenic syncope associated with functional AV block. Heart, October, 2011 Vol 97 Suppl 3, A171. http://dx.doi.org/10.1136/heartinl-2011-300867.505.

59 Pauza DH, et al. Morphology, distribution and variability of the epicardial neural ganglionated subplexuses in the human heart. Anat Rec. 2000; 259:353-382.

${ }^{60}$ Xiaomeng Yin, et al. Atrioventricular Node Slow-Pathway Ablation Reduces Atrial Fibrillation Inducibility: A Neuronal Mechanism. J Am Heart Assoc. 2016;5: e003083 doi: 10.1161/JAHA.115.003083

${ }^{61} \mathrm{Aksu} \mathrm{T}$, et al. Functional permanent 2:1 atrioventricular block treated with cardioneuroablation: Case report. HeartRhythm Case Rep. 2015 Jan 29;1(2):58-61. doi: 10.1016/j.hrcr.2014.12.012. eCollection 2015 Mar.

${ }^{62}$ Fukunaga $\mathrm{M}$, et al. Differential effect of ganglionic plexi ablation in a patient with neurally mediated syncope and intermittent atrioventricular block. Europace Advance Access published May 18, 2016; pag 2-8. doi:10.1093/europace/euw100.

${ }^{63}$ Fukunaga $\mathrm{M}$, et al. Differential effect of ganglionic plexi ablation in a patient with neurally mediated syncope and intermittent atrioventricular block. Europace Advance Access published May 18, 2016; pag 2-8. doi:10.1093/europace/euw100.

${ }^{64}$ Grupper A, Gewirtz H, Kushwaha S. Reinnervation post-Heart transplantation. Eur Heart J. 2017 Jan 12. pii: ehw604. doi: 10.1093/eurheartj/ehw604. [Epub ahead of print] PubMed PMID: 28087606.

${ }^{65}$ Murphy DA, et al. The heart reinnervates after transplantation. Ann Thorac Surg. 2000 Jun;69(6):1769-81. 
${ }^{66}$ Gallego Page JC, et al. Angina pectoris in the heart transplant recipient: evidence of reinnervation. Rev Esp Cardiol. 2001 Jun;54(6):799-802.

67 Pappone $\mathrm{C}$, et al. Pulmonary vein denervation enhances long-term benefit after circumferential ablation for paroxysmal atrial fibrillation. Circulation. 2004 Jan 27;109(3):327-34.

${ }^{68}$ Yao $\mathrm{Y}$, et al. Endocardial autonomic denervation of the left atrium to treat vasovagal syncope: an early experience in humans. Circ Arrhythm Electrophysiol. 2012 Apr;5(2):279-86.

69 Liang Z, et al. Selective atrial vagal denervation guided by evoked vagal reflex to treat refractory vasovagal syncope. Pacing Clin Electrophysiol. 2012 Jul;35(7): e214-8. doi: 10.1111/j.1540-8159.2011.03320.x. Epub 2012 Feb 3.

70 Stavrakis S, Scherlag BJ, Po SS. Autonomic modulation: an emerging paradigm for the treatment of cardiovascular diseases. Circ Arrhythm Electrophysiol. 2012 Apr;5(2):247-8.

71 Rivarola E, et al. Selective atrial vagal denervation guided by spectral mapping to treat advanced atrioventricular block. Europace. 2016 Mar;18(3):445-9. doi: 10.1093/europace/euv142. Epub 2015 Jun 11.

72 Lemola K, et al. Pulmonary vein region ablation in experimental vagal atrial fibrillation: role of pulmonary veins versus autonomic ganglia. Circulation. 2008 Jan 29;117(4):470-7.

73 Rosso R, et al. Vagal paroxysmal atrial fibrillation: prevalence and ablation outcome in patients without structural heart disease. J Cardiovasc Electrophysiol. 2010 May;21(5):489-93.

${ }^{74}$ Aksu T, et al. Catheter Ablation of Bradyarrhythmia: From the Beginning to the Future. Am J Med Sci. 2018 Mar;355(3):252-265. doi: 10.1016/j.amjms.2017.11.016. Epub 2017 Dec 1. 


\section{Anexos}

Anexo A - Patentes registradas e patentes pendentes relacionadas a esta Tese

\section{A.1 Patente nos EUA, referente aos Ninhos de Fibrilação Atrial}

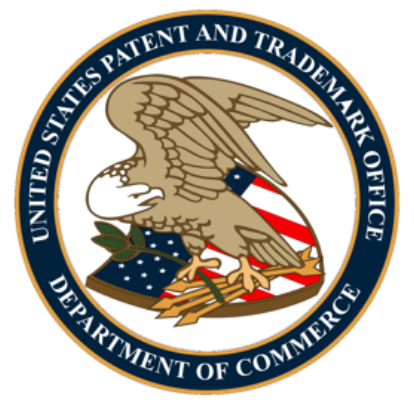

(19) United States

(12) Patent Application Publication Pachon Mateos et al.

(54) APPARATUS AND METHODS FOR ARRHYTHMIA TREATMENT BASED ON SPECTRAL MAPPING DURING SINUS RHYTHM

(76) Inventors: Jose Carlos Pachon Mateos, Moema-Sao Paulo (BR); Enrique Indalecio Pachon Mateo,

Moema-Sao Paulo (BR)

(21) Appl. No.: 13/008,644

(22) Filed: Jan. 18, 2011

\section{Related U.S. Application Data}

(63) Continuation of application No. 12/910,424, filed on Oct. 22, 2010, which is a continuation of application

\section{UNITED STATES \\ PATENT AND TRADEMARK OFFICE}

uspto

US 20110098699A1

(10) Pub. No.: US 2011/0098699 A1

(43) Pub. Date:

Apr. 28, 2011

No. 11/202,049, filed on Aug. 11, 2005, now Pat. No. $7,819,862$.

Publication Classification

(51) Int. Cl.
A61B 18/14
A61B $18 / 18$
(2006.01)
(2006.01)

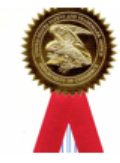

(52) U.S. Cl.

$606 / 33 ; 606 / 41$

\section{ABSTRACT}

Apparatus for curative ablation are provided to achieve the inactivation or destruction of fibrillar myocardium of the so-called AF nests. In addition, fibrillar myocardium may be identified and mapped by spectral analysis and phase study of the tissue during sinus rhythm. The procedure may be performed by transseptal puncture using only one catheter for ablation and mapping. The methods may be used to localize the application targets even during an arrhythmia.
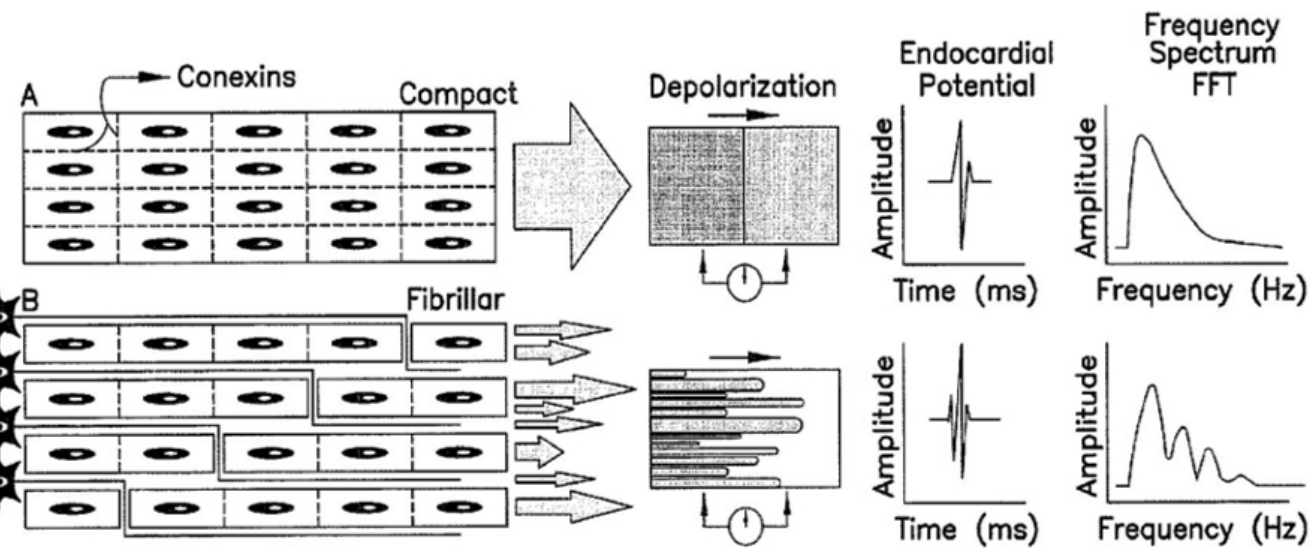


\section{A.2 Patente aplicada na Europa, referente ao Estimulador Neural Extracardíaco}

(19)

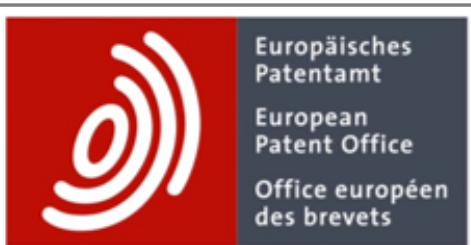

\section{EUROPEAN PATENT APPLICATION}

(43) Date of publication: 19.12.2018 Bulletin 2018/51

(21) Application number: $\mathbf{1 8 1 7 7 9 6 0 . 4}$

(22) Date of filing: 15.06.2018
(51) Int $\mathrm{Cl}$ :

$A 61 N 1 / 05^{(2006.01)} \quad A 61 N 1 / 36^{(2006.01)}$
(84) Designated Contracting States:

AL AT BE BG CH CY CZ DE DK EE ES FI FR GB GR HR HU IE IS IT LI LT LU LV MC MK MT NL NO PL PT RO RS SE SI SK SM TR

Designated Extension States:

BA ME

Designated Validation States:

KH MA MD TN

(30) Priority: 16.04.2017 US 201762485956 P 09.04 .2018 US 201815948298

(71) Applicants:

- Pachón Mateos, José Carlos

04081-010 São Paulo (BR)

- Pachón Mateos, Enrique Indalecio

04081-010 Săo Paulo (BR)

- Cunha Pachón, Carlos Thiene

04004-000 São Paulo (BR)
(72) Inventors:

- Pachón Mateos, José Carlos

04081-010 São Paulo (BR)

- Pachón Mateos, Enrique Indalecio

04081-010 São Paulo (BR)

- Cunha Pachón, Carlos Thiene

04004-000 São Paulo (BR)

(74) Representative: ABG Intellectual Property, S.L. Avenida de Burgos, 16D

Edificio Euromor

28036 Madrid (ES)

Remarks:

-A request for re-establishment of rights in respect of the twelve-month period from the date of filing of the first application has been granted (Art.87(1) and Art.122 EPC).

-Claims filed after the date of receipt of the application (Rule 68(4) EPC).

\section{(54) EXTRACARDIAC AUTONOMIC NERVE STIMULATION}

(57) The ExtraCardiac Nerve Stimulator and the ExtraCardiac Nerve Stimulation (ECANS) are, respectively, the apparatus and method to get remote nerve stimulation for medical applications. The system makes possible the stimulation without direct contact with the nerve based on special electrical wave. The remote nerve stimulation is extremely important for investigational and therapeutic proposals. The possibility of having this resource without surgical dissection, nerve exposure and tissue lesion with time-consuming process, is remarkable. This procedure relies on a settable stimulator with special features that releases a pulse wave with high frequency, very short pulse width, great amplitude, and precise current and time limitation connected to a special catheter, placed inside a vase or viscera. Frequency, pulse width, amplitude and time of application are operator adjustable to be effective against large patient variations, different anatomy, and areas of application. Special features prevent the application of the stimulus in the heart.

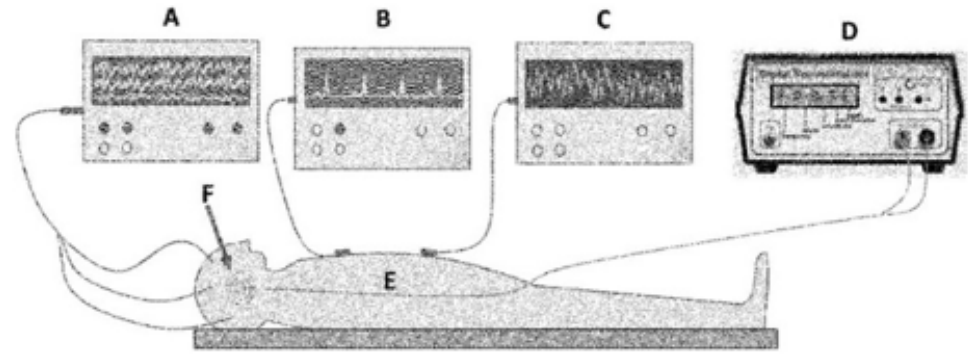

FIG. 2 


\section{A.3 Patente aplicada nos EUA, referente ao eletrodo para estimulação vagal por via endovascular}

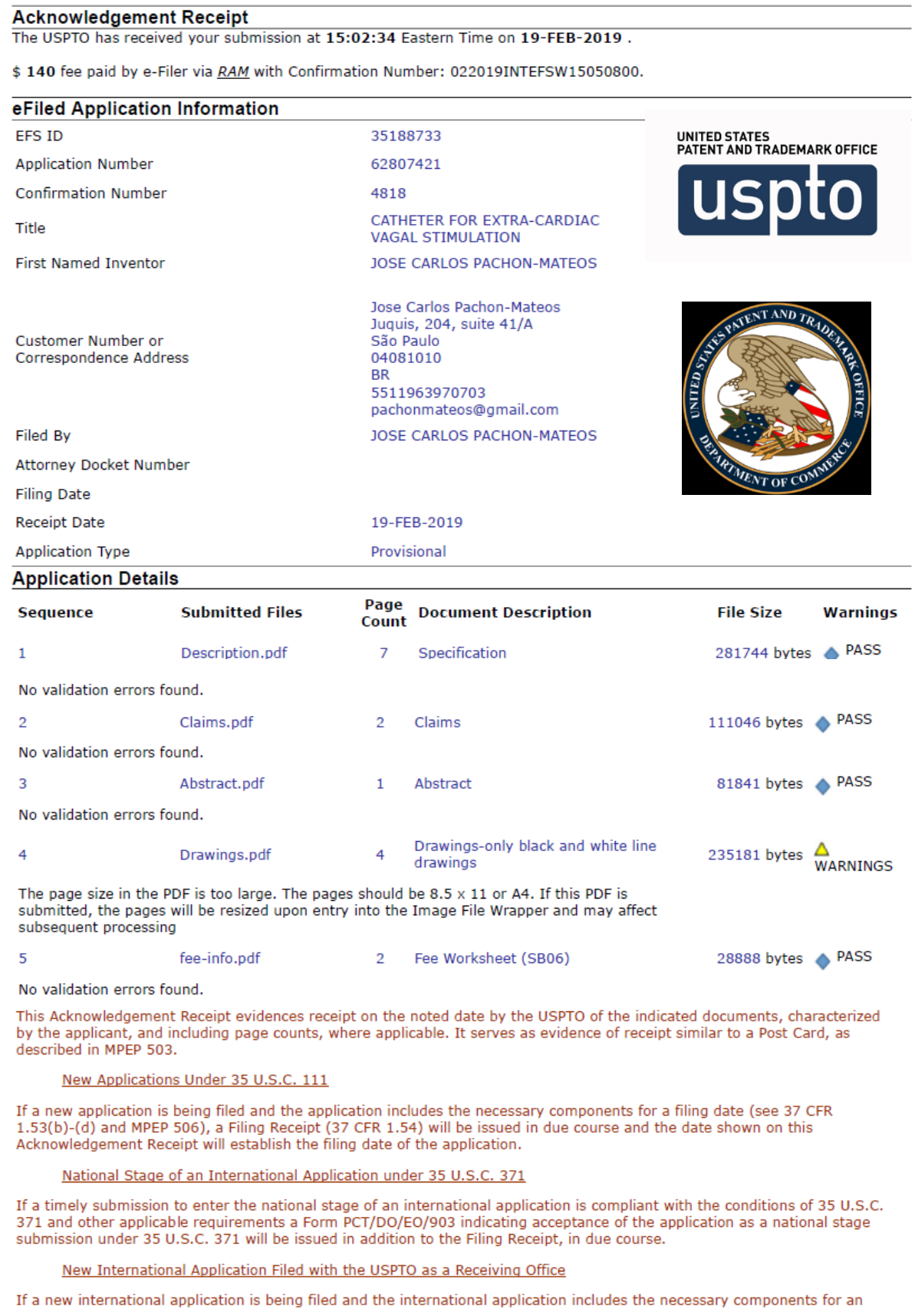




\section{A.4 Patente aplicada nos EUA, referente ao desviador mecânico do esôfago}

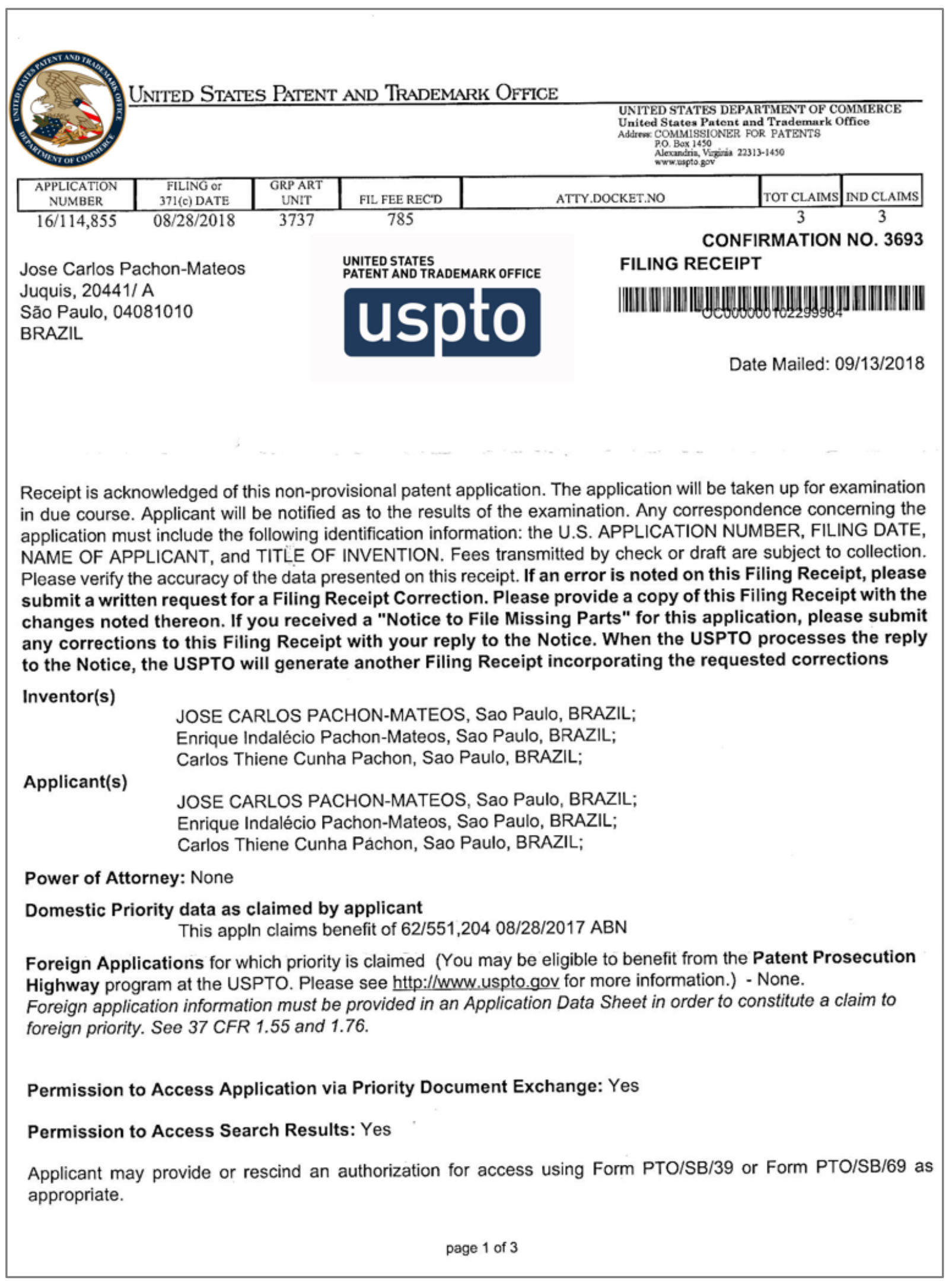




\section{Anexo B - Demonstração experimental dos efeitos da EVEC}

A estimulação vagal extracardíaca da forma como foi utilizada neste estudo é completamente inócua ao paciente. Para comprovar esta afirmação foi realizada uma demonstração experimental utilizando um bloco de peito de frango fresco submerso em uma solução de soro fisiológico a $37^{\circ} \mathrm{C}$, Figura 46.

Figura 46 - Preparação experimental de estimulação neural.

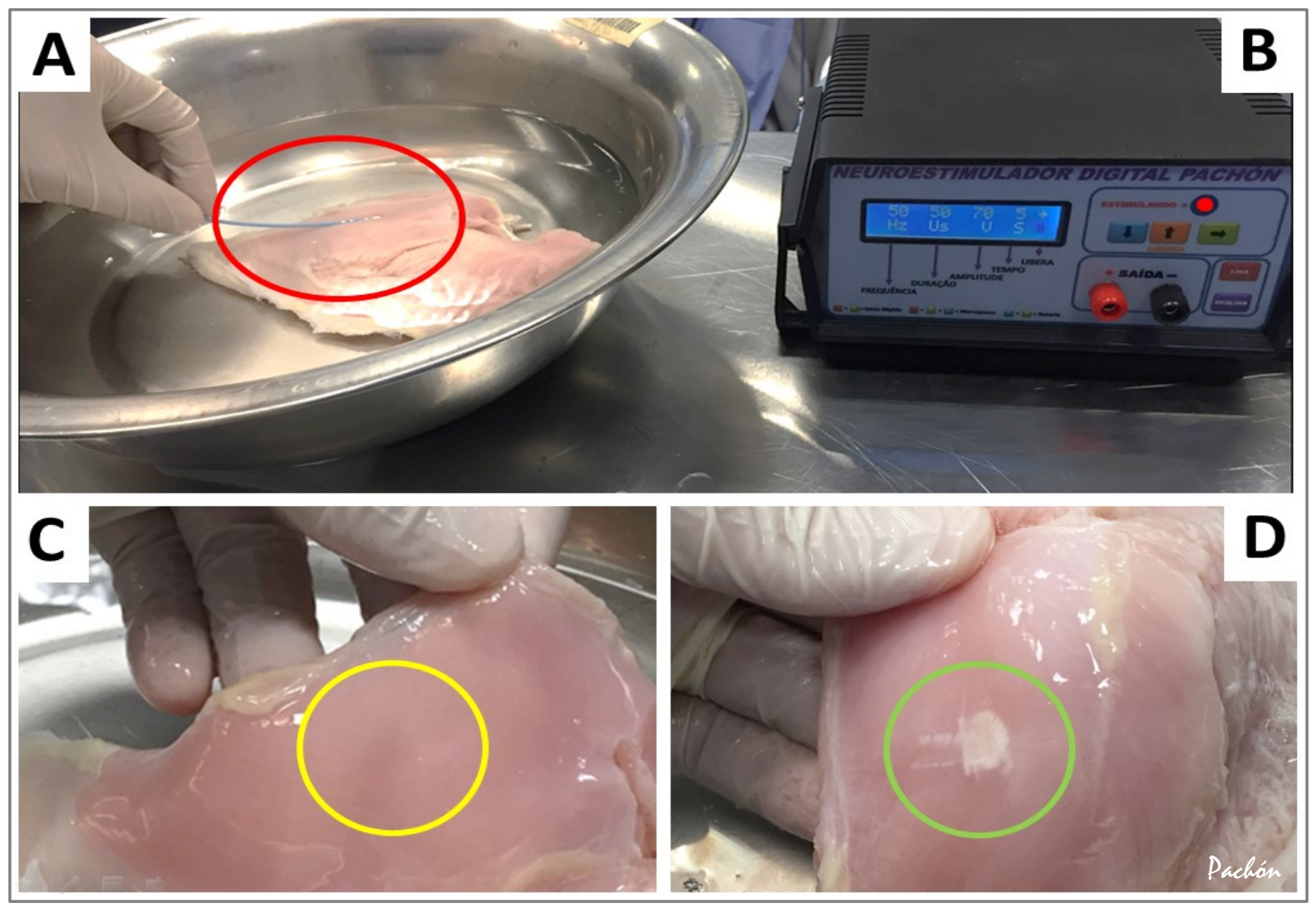

Estimulação neural realizada experimentalmente em um bloco de peito de frango imerso em solução fisiológica a $37^{\circ} \mathrm{C}(\mathrm{A})$. O mesmo cateter que foi utilizado na EVEC está apoiado sobre o tecido (círculo vermelho-A) e a estimulação habitual foi liberada pelo estimulador (B). Nota-se em C - círculo amarelo, que não ocorreu qualquer lesão visível por coagulação no tecido com a estimulação, enquanto que a aplicação de radiofrequência no mesmo tecido por $30 \mathrm{~s}$ (D-círculo verde) provoca uma lesão visível. Fonte: Arquivo SEMAP.

Sobre uma parte lisa e homogênea deste bloco foi posicionada a ponta de um cateter quadripolar, normalmente utilizado na EVEC, Figura 46-A, sendo aplicada discreta pressão para melhor contato. Em seguida, foi realizada a estimulação por $5 \mathrm{~s}$, com o estimulador vagal, Figura 46-B com os mesmos ajustes utilizados na EVEC 
(considerando um adulto de $70 \mathrm{~kg}$ ). Estas estimulações foram repetidas diversas vezes sobre o mesmo local. Após estas estimulações, o tecido foi cuidadosamente avaliado visualmente, e fotografado com ampliação, não sendo possível observar qualquer alteração macroscópica, Figura 46-C. Adicionalmente, e com fins de comparação, foi realizada uma aplicação unipolar de radiofrequência no mesmo bloco, com $30 \mathrm{~W}, 30 \mathrm{~s}, 45^{\circ} \mathrm{C}$, com cateter irrigado, observando-se claramente uma lesão por coagulação dos tecidos em contato com a ponta do cateter, Figura 46-D. Todo este experimento foi gravado em vídeo e disponibilizado na plataforma digital (vídeo: $\underline{\text { Teste }}$ Experimental da EVEC [https://youtu.be/fgmNxA1m0pU] e vídeo: Experimental EVEC XRF [https://youtu.be/Vep0sGnolJw]). 
Anexo C - Cronograma de Execução

\begin{tabular}{|c|c|c|c|c|c|c|c|c|}
\hline Itens & $\begin{array}{l}\text { Fev - } \\
\text { Jun } \\
2016\end{array}$ & $\begin{array}{l}\text { Jul - } \\
\text { Dez } \\
2016\end{array}$ & $\begin{array}{l}\text { Jan - } \\
\text { Jun } \\
2017\end{array}$ & $\begin{array}{l}\text { Jul - } \\
\text { Dez } \\
2017\end{array}$ & $\begin{array}{l}\text { Jan - } \\
\text { Jun } \\
2018\end{array}$ & $\begin{array}{l}\text { Jun - } \\
\text { Dez } \\
2018\end{array}$ & $\begin{array}{l}\text { Jan - } \\
\text { Jun } \\
2019\end{array}$ & $\begin{array}{l}\text { Jul - } \\
\text { Dez } \\
2019\end{array}$ \\
\hline $\begin{array}{l}\text { Curso das } \\
\text { Disciplinas }\end{array}$ & $x$ & $x$ & $x$ & & & & & \\
\hline $\begin{array}{l}\text { Levantamento } \\
\text { bibliográfico }\end{array}$ & $x$ & $x$ & $x$ & $x$ & $x$ & & & \\
\hline $\begin{array}{l}\text { Seleção dos } \\
\text { pacientes para } \\
\text { ablação }\end{array}$ & $x$ & $x$ & & & & & & \\
\hline $\begin{array}{l}\text { Avaliação dos } \\
\text { dados } \\
\text { coletados }\end{array}$ & $x$ & $x$ & $x$ & & & & & \\
\hline $\begin{array}{l}\text { Elaboração do } \\
\text { trabalho para } \\
\text { qualificação }\end{array}$ & $x$ & $x$ & $x$ & $x$ & & & & \\
\hline $\begin{array}{l}\text { Elaboração do } \\
\text { trabalho final }\end{array}$ & & & $x$ & $x$ & $x$ & $x$ & $x$ & \\
\hline
\end{tabular}




\title{
Anexo D - Termo de Consentimento Livre e Esclarecido
}

\author{
Hospital do Coração - Associação Beneficente Síria
}

Título do Estudo: "Estimulação Vagal Extracardíaca para Avaliar a Eficácia da Denervação Vagal Pós-Ablação dos Ninhos de Fibrilação Atrial”.

O(a) Sr(a) está sendo convidado a participar de um estudo. Antes de concordar em participar, é importante que o(a) Sr(a) entenda os objetivos deste estudo e esclareça todas as suas dúvidas. Caso o(a) Sr(a) aceite participar deste estudo, será necessário que o(a) Sr(a) e o pesquisador assinem duas vias deste documento, em todas as páginas. Nas primeiras páginas, a assinatura pode ser abreviada (rubrica). Uma via assinada deste termo será entregue a(o) Sr(a) e a outra ficará arquivada com o pesquisador.

\section{Introdução e justificativa:}

Este trabalho científico envolverá dois grupos de pacientes. Um grupo dos portadores de fibrilação atrial (Grupo NFA) e outro grupo de pacientes portadores de outras arritmias cardíacas como extrassístoles ventriculares, feixes anômalos ocultos, síndrome de WPW entre outras (Grupo Controle).

A fibrilação atrial é uma das arritmias supraventriculares mais frequentes na população em geral e ela tem sua incidência aumentada com a idade e com fatores adicionais tais como a hipertensão arterial, o uso de bebidas alcoólicas, isquemia cardíaca, cirurgias prévias no coração entre outras. Um tipo particular dessa arritmia, mais comum, mas não limitada a indivíduos jovens está relacionada à inervação autonômica do coração. $\mathrm{O}$ tratamento deste tipo de arritmia é mais difícil, pois não havia uma forma segura de se mapearem as regiões do coração por onde penetra a inervação vagal. Com o intuito de reduzir/eliminar esses pontos responsáveis pela fibrilação atrial vagal, nós vamos utilizar a 
metodologia desenvolvida por Pachón e colaboradores para identificar os ninhos de FA e trata-los através da ablação por radiofrequência termocontrolada. Adicionalmente será realizada uma neuroestimulação antes e após a ablação para comprovar que a resposta neural prévia foi reduzida ou eliminada pela aplicação efetiva de radiofrequência sobre os ninhos de FA. O grupo controle servirá exatamente para comprovar que, como não serão tratados os ninhos de FA, não haverá modificação da resposta vagal. Neste grupo, será realizada a neuroestimulação no início dos procedimentos e repetida de forma idêntica ao final, mostrando que não houve qualquer modificação. Este procedimento não irá alterar em nada a técnica de ablação da arritmia do paciente.

\section{Quais são os objetivos deste estudo?}

Através da técnica idealizada, publicada por Pachón e colaboradores e atualmente utilizada em várias partes do mundo, nos pacientes com fibrilação atrial, os pontos de penetração da inervação serão identificados pelo sistema de mapeamento endocárdico e tratados através da ablação por radiofrequência, da mesma forma que é realizada a ablação convencional da fibrilação atrial. Será avaliada a resposta vagal previamente ao procedimento através da estimulação neural sobre o nervo vago. Após a ablação, o paciente será submetido exatamente à mesma neuroestimulação para comprovar se a ablação foi capaz de reduzir e/ou eliminar a resposta vagal. Após esta etapa, a ablação será completada, utilizando-se a técnica convencional, permitindo assim que o paciente receba o tratamento integral.

Nos pacientes do grupo controle a ablação será realizada exatamente como seria independente do estudo, mas também será feita uma neuroestimulação no início do procedimento e ao final para comprovar que ablações fora dos ninhos de FA não produzem alterações da resposta vagal do coração. 


\section{Qual é o número de participantes no estudo e qual é a duração de minha participação?}

Esperamos 20 participantes neste estudo no Brasil, portadores de fibrilação atrial com características vagais. Outros 20 pacientes portadores de outras arritmias serão submetidos rotineiramente ao processo de ablação por radiofrequência das respectivas arritmias e também serão submetidos à estimulação neural antes e após a ablação de forma idêntica, para comprovar que neste grupo, não haverá qualquer alteração na resposta vagal. A duração prevista de sua participação é de até 3 meses à partir da sua ablação.

\section{Quais são os tratamentos do estudo?}

Todos os pacientes serão submetidos ao procedimento padrão realizado na SEMAP/HCor para ablação das respectivas arritmias. O grupo portador de fibrilação atrial, também será submetido à ablação de rotina, porém, em uma etapa inicial o mapeamento será direcionado para identificar as terminações nervosas do coração, onde será liberada a radiofrequência usual.

\section{Quais são os procedimentos do estudo?}

Os pacientes serão submetidos ao mesmo procedimento de rotina da SEMAP/HCor para ablação de fibrilação atrial e das outras arritmias (ablação de extrassístoles ventriculares, de feixes anômalos etc.) que consta da realização de hemograma, bioquímica, coagulograma, sorologias, exame de urina, radiografia de tórax, eletrocardiograma como exames préoperatórios. O procedimento de ablação consta de anestesia, colocação de placas adesivas no tórax para obtenção do sinal do coração, passagem de cateteres por punção (sem corte) para a realização do mapeamento dos focos das arritmias e tratamento (ablação), e passagem do transdutor (sonda) do ecocardiograma transesofágico para avaliação do coração (nos casos de fibrilação atrial). Desta forma, não há nenhum risco adicional para o procedimento em questão. O Dr. Enrique I. Pachón Mateo informará o(a) Sr(a) sobre os resultados dos exames feitos. 


\section{Quais são as minhas responsabilidades?}

O(a) Sr(a) precisará retornar em consulta com 30, 60 e 90 dias após o procedimento de ablação, na qual será realizada avaliação de rotina. É importante que o(a) Sr(a) venha em todas as consultas para que a equipe do estudo possa avaliar melhor o resultado do procedimento.

\section{Quais são os possíveis riscos de participar neste estudo?}

Os riscos do presente estudo estão relacionados ao procedimento em si, tais como alergias a medicações, arritmias cardíacas e complicações cardioembólicas (acidente vascular cerebral). Contudo, a participação neste estudo não submete o(a) senhor(a) a riscos adicionais ao procedimento, que está indicado independentemente da participação neste estudo. A estimulação neural que será utilizada em todos os pacientes é um procedimento comum utilizado em estudos neurológicos, não acrescentando qualquer risco adicional ao procedimento. É realizada utilizando a mesma via da ablação e não produz dor, até por que será feita após a anestesia para a ablação.

\section{Quais são os possíveis benefícios de participar neste estudo?}

No grupo NFA, a ablação dos focos arritmogênicos relacionados às terminações nervosas que penetram no coração se baseia na mesma técnica amplamente conhecida e utilizada para a ablação da fibrilação atrial, porém, o mapeamento será direcionado também para identificar essas terminações vagais, as quais serão também eliminadas pela ablação. A eliminação desses focos reduzirá a resposta vagal e consequentemente as arritmias provocadas pela sua participação, melhorando a resposta clínica ao tratamento desta arritmia. No grupo controle, a estimulação neural poderá ajudar no mapeamento e na indução das arritmias a serem tratadas facilitando o diagnóstico, e ao final, ajudar a comprovar a eliminação da arritmia. Adicionalmente, 
algumas drogas utilizadas para avaliar a arritmia (adenosina, isoprenalina) poderão não ser necessárias após a estimulação neural.

\section{E se eu não quiser participar do estudo, há outras opções?}

Sua participação neste estudo é voluntária e o(a) Sr(a) poderá recusar-se a participar ou retirar-se do estudo a qualquer momento sem punições ou prejuízo ao seu atendimento neste hospital. O seu cuidado neste hospital é de responsabilidade do seu médico assistente, independente da sua participação no estudo.

\section{Serei compensado por danos relacionados ao estudo?}

Será dado o tratamento médico necessário, caso ocorram eventuais danos, mencionados ou não neste termo, decorrentes do estudo, porém, não se espera que ocorram quaisquer problemas ou danos, já que são utilizadas técnicas amplamente difundidas e de grande conhecimento da equipe, que as utiliza para o tratamento rotineiro de outras arritmias.

10. Serei pago para participar deste estudo?

Não, o(a) Sr(a) não será pago(a) por sua participação neste estudo.

11. Serei reembolsado por algum custo decorrente de minha participação?

A participação no estudo não envolve nenhum custo para o(a) Sr(a). Desta forma, não há reembolso ou qualquer tipo de recompensa financeira.

\section{Quem está patrocinando este estudo?}

Não há patrocinador. 


\section{Quem terá acesso aos meus registros médicos? Minhas informações são confidenciais?}

Além dos procedimentos já descritos acima, também serão coletados alguns dados médicos do seu prontuário, como peso, altura, idade e histórico médico. Toda a informação médica será sigilosa e somente a equipe do estudo terá acesso. Em nenhum momento seu nome ou qualquer informação sobre a sua saúde será fornecida para qualquer pessoa que não seja da equipe do estudo. As informações serão confidenciais e utilizadas somente para fins desta pesquisa. Os resultados do estudo serão divulgados, para fins acadêmicos e científicos, sem a identificação de nenhum dado que revele a identidade dos participantes.

A Plataforma Brasil (site pelo qual os estudos são submetidos aos Comitês de Ética e CONEP) conta com um módulo público de interesse dos participantes de pesquisa. O site da Plataforma Brasil é http://www.saude.gov.br/plataformabrasil.

\section{Contato em caso de dúvidas ou emergência}

Este estudo foi aprovado pelo Comitê de Ética em Pesquisa do Hospital do Coração - Associação do Sanatório Sírio. O Comitê de Ética é um grupo que realiza a revisão ética inicial e contínua do estudo para manter sua segurança e proteger seus direitos. Se o(a) Sr(a) tiver qualquer dúvida em relação aos aspectos éticos do estudo, fique à vontade para entrar em contato com o Comitê de Ética em Pesquisa do Hospital do Coração - Hcor. Endereço: Rua Abrão Dib, 50 - térreo. Tel. (11) 3886-4688. Fax: 3886-4689. Ramal: 8458. Email: etica.pesquisa@hcor.com.br. Horário de funcionamento do CEP: 8h às 17h, ou comitê de ética do Instituto Dante Pazzanese de Cardiologia do Estado de São Paulo pelo telefone 5085 6040, av Dr. Dante Pazzanese, 500 - e-mail: cep@dantepazzanese.org.br.

A equipe do estudo está à disposição para prestar quaisquer esclarecimentos antes, durante e após o estudo:

Dr. Enrique I. Pachón Mateo. Endereço: HCor, Av. Bernardino de Campos, 186, $5^{\circ}$ andar, SEMAP, Paraíso, São Paulo, SP., Telefone para contato: (11) 3053-4500. Celular: (11) 985366046. 
Serão fornecidas ao(à) Sr(a) quaisquer informações que forem descobertas durante o estudo que possam influenciar sua decisão de continuar participando ou não deste estudo.

Se o (a) $\operatorname{Sr}(a)$ procurar por atendimento emergencial em outro hospital ou se for necessária internação, avise o médico deste outro hospital que o(a) Sr(a) faz parte de um estudo realizado pelo Dr. Enrique I. Pachón no Hospital do Coração - Associação do Sanatório Sírio.

\section{Declaração de consentimento:}

Fui informado(a) dos objetivos da pesquisa de forma clara e detalhada, e pude fazer perguntas. Também me foi garantido pelo pesquisador sigilo que assegure a privacidade dos dados obtidos na pesquisa. Estou ciente de todos os procedimentos que serão realizados e dos possíveis riscos e benefícios e, em caso de qualquer dúvida, poderei entrar em contato com a equipe do estudo. Ao assinar este termo de consentimento autorizo o acesso da equipe do estudo aos meus registros médicos e não estarei abrindo mão de meus direitos legais. Recebi uma via assinada deste documento.

Nome por extenso do Participante

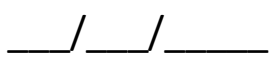

Data (registrada pelo participante)

\section{Assinatura}

$$
\text { pelo }
$$

Nome do Representante Legal do
Participante

Data
(registrada pelo
representante
legal)

Assinatura

Especificar a relação com o Participante

Nome por extenso da pessoa que obteve $o$ consentimento 


\section{Anexo E - Palavras de Escrita Imprecisa Utilizadas Nesta Tese:}

Algumas palavras são utilizadas com grafias diferentes na literatura médica e muitas vezes a forma trivial passa a ser consagrada pelo uso. Para uniformizá-las nesta tese, utilizamos os dicionários VOLP, Houaiss e Aurélio procurando o verbete mais adequado. A seguir, a lista dessas palavras utilizadas:

\begin{tabular}{ll|ll}
\hline GRAFIA CORRETA & GRAFIA TRIVIAL & GRAFIA CORRETA & GRAFIA TRIVIAL \\
\hline Denervação & Desnervação & Transeptal & Trans-septal \\
\hline Marca-passo & Marcapasso & Cateterizando & Verbete admitido \\
\hline Ablação & $\begin{array}{l}\text { Ablacionar }-(\text { não há a } \\
\text { forma verbal) }\end{array}$ & Cateterizar & Verbete admitido \\
\hline Cateter & Catéter & Interatrial & Inter-atrial \\
\hline Fibras Neurais & Fibras Neuronais & Femoral & Femural \\
\hline Atropinização & Verbete admitido & Intereletródica & Inter-eletródica \\
\hline Intraparietais & Intra-parietais & Transesofágico & Trans-esofágico \\
\hline Atrioventricular & Átrio-ventricular & Extracardíaca & Extra-cardíaca \\
\hline Extrassístole & Extra-sístole & Orotraqueal & Oro-Traqueal \\
\hline Verbete admitido & Ultrassom & Ultra-som \\
\hline
\end{tabular}

\section{Fontes:}

- Vocabulário Ortográfico da Língua Portuguesa - "VOLP" - Acesso online: http://www.academia.org.br/nossa-lingua/busca-no-vocabulario (atualizado em relação à versão impressa - $5^{a}$ edição);

- Grande Dicionário Houaiss: acesso online:

https://houaiss.uol.com.br/pub/apps/www/v3-3/html/index.php;

- Dicionário Aurélio: Acesso online: https://www.dicio.com.br/aurelio-2/

- Dicionário Médico: Acesso online: https://www.dicionáriomédico.com 
